\title{
Lightweight hydrides nanocomposites for hydrogen storage: Challenges, progress and prospects
}

\author{
$\mathrm{Li} \mathrm{Li}^{1,2 \dagger^{*}}$, Yike Huang ${ }^{2 \dagger}$, Cuihua $\mathrm{An}^{3}$ and Yijing Wang ${ }^{2 *}$
}

\begin{abstract}
As typical high-capacity complex hydrides, lightweight hydrides have attracted intensive attention due to their high gravimetric and volumetric energy densities of hydrogen storage. However, lightweight hydrides also have high thermodynamic stability and poor kinetics, so they ususally require high hydrogen desorption temperature and show inferior reversibility under mild conditions. This review summarizes recent progresses on the endeavor of overcoming thermodynamic and kinetic challenges for Mg based hydrides, lightweight metal borohydrides and alanates. First, the current state, advantages and challenges for Mg-based hydrides and lightweight metal hydrides are introduced. Then, alloying, nanoscaling and appropriate doping techniques are demonstrated to decrease the hydrogen desorption temperature and promote the reversibility behavior in lightweight hydrides. Selected scaffolds materials, approaches for synthesis of nanoconfined systems and hydriding-dehydriding properties are reviewed. In addition, the evolution of various dopants and their effects on the hydrogen storage properties of lightweight hydrides are investigated, and the relevant catalytic mechanisms are summarized. Finally, the remaining challenges and the sustainable research efforts are discussed.
\end{abstract}

Keywords: hydrogen storage, Mg-based materials, borohydrides, alanates, nanoscaling

\section{INTRODUCTION}

Hydrogen has been considered as an ideal alternative energy to replace fossil energy in the future because of high gravimetric energy density $\left(142 \mathrm{MJ} \mathrm{kg}^{-1}\right)$, non-toxicity and environmentally friendly properties [1]. However, the volumetric energy density of hydrogen gas is very low. At atmospheric pressure and $25^{\circ} \mathrm{C}$, the volumetric energy density is only $4.4 \mathrm{MJ} \mathrm{L}^{-1}$, which severely limits the on-board use of hydrogen [2]. The explosive nature and broad range of explosion limits are also the factors limiting its on-board applications [3]. Therefore, it is of vital importance to develop a safe and efficient way to store hydrogen.

Classically, hydrogen gas can be stored in a pressure container to reach a higher volumetric energy density, whereas the large-weight bulky tank decreases the gravimetric energy density [1]. Due to the gap between high storing pressure and accessible handling pressure, the extra devices for pressure controlling are also needed. Although the developed carbon fiber reinforced alloy can lessen the weight of container, the on-board use is still impractical. In addition, the high-pressure in container can be a safety risk, which is another disadvantage of this method.

Storing hydrogen in solid-state materials is a promising way to meet the requirements for on-board applications $[4,5]$. The hydrogen gas can be absorbed in solid-state materials in molecule form (physisorption) or atom form (chemisorption) [6]. Materials such as porous carbon, carbon nanotubes, zeolites and metal organic frameworks (MOFs) can absorb hydrogen rapidly, showing remarkable reversibility and cycle performance. However, satisfactory capacities of above materials can only be achieved at very low temperature [3]. Commonly, the room-temperature capacities of these materials are less than $1 \mathrm{wt} \%$. Fortunately, some metals and alloys can absorb hydrogen by bonding with the hydrogen to form metal hydride, which is a chemisorption approach. These

\footnotetext{
${ }^{1}$ School of Materials Science and Engineering, University of Jinan, Jinan 250022, China

${ }^{2}$ Key Laboratory of Advanced Energy Materials Chemistry (Ministry of Education), College of Chemistry, Nankai University, Tianjin 300071, China

${ }^{3}$ Tianjin Key Laboratory of Advanced Functional Porous Materials, Institute for New Energy Materials \& Low-Carbon Technologies, School of Materials Science and Engineering, Tianjin University of Technology, Tianjin 300384, China

$\uparrow$ These authors contributed equally to this paper.

*Corresponding authors (emails: mse_lil@ujn.edu.cn (Li L); wangyj@nankai.edu.cn (Wang Y))
} 
composites usually show high hydrogen capacities, but their practical applications are hindered due to low reaction rate, poor reversibility and requirement of high operation temperature [7]. Among the chemisorption materials, the lightweight hydrides, including metal hydrides and complex hydrides, have extraordinarily high gravimetric and volumetric density, which are expected to be the most promising candidates for on-board applications [8].

Because of the low atomic mass of metal elements, the lightweight hydrides have high gravimetric hydrogen content [9]. Especially, $\mathrm{LiBH}_{4}$ as a complex hydride can reach an outstanding capacity of $18.4 \mathrm{wt} \%$. Moreover, the reserves of lightweight metal elements such as $\mathrm{Na}, \mathrm{Mg}$ and $\mathrm{Al}$ are abundant in the earth, leading to the low cost of corresponding metal [10]. Therefore, the lightweight hydrides materials have been widely researched as a hot topic in the field of hydrogen storage.

Several lightweight metal hydrides are listed in Table 1 [11]. All of them are ionic compounds except $\mathrm{BeH}_{2}$ and $\mathrm{AlH}_{3}$. The strong ionic bond between metal element and hydrogen results in a large formation enthalpy and high decomposition temperature [12]. Also, the kinetic properties of them are sluggish [4]. Among these compounds, $\mathrm{MgH}_{2}$ has been considered as a promising candidate for on-board application because of its low decomposition temperature. However, both thermodynamic and kinetic performances of $\mathrm{MgH}_{2}$ still need to be adjusted.

Lightweight metal complex hydrides include borohydrides, amides and alanates. Several complex hydrides are listed in Table 2. These compounds have outstanding hydrogen contents and a complicated multi-step dehydrogenation reaction [13]. Multiple components are generated during the decomposition, leading to difficulties in rehydrogenation and poor cycle properties. In addition, complex hydrides also suffer from the problems of inappropriate thermodynamic and kinetic properties [4]. Encouragingly, methods such as nanoscaling and doping can enhance the regeneration processes and increase the kinetic properties [8]. However, even with the enhancement of these methods, these complex hydrides still hardly meet the requirement of on-board application.

Capacities, thermodynamic and kinetic performances are three critical factors for the practical application. It is very difficult to reach high capacity, moderate thermodynamic conditions and fast kinetic performance simultaneously. Numerous efforts have been made to regulate thermodynamic and kinetic performance while sacrificing capacity as low as possible.

In this review, we summarize the recent progresses in
Table 1 Thermodynamic properties and gravimetric hydrogen content of lightweight metal hydrides ${ }^{\text {a) }}$

\begin{tabular}{cccc}
\hline Compound & $\begin{array}{c}\Delta_{\mathrm{f}} \mathrm{H}_{298}{ }^{-1} \\
\left(\mathrm{~kJ} \mathrm{~mol}^{-1}\right)\end{array}$ & $\begin{array}{c}\text { Decomp. } \\
\text { Temp. }\left({ }^{\circ} \mathrm{C}\right)\end{array}$ & $\begin{array}{c}\mathrm{H}_{2} \text { content } \\
(\mathrm{wt} \%)\end{array}$ \\
\hline $\mathrm{LiH}$ & -90.5 & 820 & 12.7 \\
$\mathrm{NaH}$ & -56.3 & 480 & 4.2 \\
$\mathrm{BeH}_{2}$ & $/$ & 470 & 18.3 \\
$\mathrm{MgH}_{2}$ & -75.3 & 360 & 7.6 \\
$\mathrm{AlH}_{3}$ & -46.0 & $420-470$ & 10.1 \\
\hline
\end{tabular}

a) The enthalpy and decomposition temperature data are referenced from Ref. [11].

Table 2 Thermodynamic properties and gravimetric hydrogen content of lightweight metal complex hydrides ${ }^{\text {a) }}$

\begin{tabular}{ccc}
\hline Compound & $\Delta_{\mathrm{f}} \mathrm{H}_{298}{ }^{\ominus}\left(\mathrm{kJ} \mathrm{mol}^{-1}\right)$ & $\mathrm{H}_{2}$ content $(\mathrm{wt} \%)$ \\
\hline $\mathrm{LiBH}_{4}$ & -194 & 18.36 \\
$\mathrm{LiAlH}_{4}$ & -119 & 10.54 \\
$\mathrm{LiNH}_{2}$ & -179.6 & 8.78 \\
$\mathrm{NaBH}_{4}$ & -191 & 10.57 \\
$\mathrm{NaAlH}_{4}$ & -113 & 7.41 \\
$\mathrm{NaNH}_{2}$ & -123.8 & 5.15 \\
$\mathrm{Mg}\left(\mathrm{BH}_{4}\right)_{2}$ & $/$ & 14.82 \\
$\mathrm{Mg}\left(\mathrm{AlH}_{4}\right)_{2}$ & $/$ & 9.27 \\
$\mathrm{Mg}\left(\mathrm{NH}_{2}\right)_{2}$ & $/$ & 7.15 \\
\hline
\end{tabular}

a) The enthalpy data are referenced from Ref. [13].

the development of $\mathrm{MgH}_{2}$, lightweight metal borohydrides and alanates as the hydrogen storage materials. Especially, we focus on the modification and development for tuning hydrogen storage performance. The strategies will be classified and reviewed in detail.

\section{Mg-BASED HYDROGEN STORAGE MATERIALS}

$\mathrm{Mg}$ is an earth-abundant element with the $8^{\text {th }}$ crustal abundance order. Thus, Mg-based hydrogen storage materials are low-cost and have the potential for largescale production [14]. As clarified in the previous section, $\mathrm{MgH}_{2}$ is an ionic compound, so it has a high formation enthalpy which is a thermodynamic problem hindering its practical application [15]. To gain an insight into the mechanism of de/rehydrogenation processes, we analyzed a series of steps including $\mathrm{H}_{2}$ transport to the surface, $\mathrm{H}_{2}$ dissociation, $\mathrm{H}$ chemisorption, surface-bulk migration, $\mathrm{H}$ diffusion, nucleation and growth of hydride/metal phases [16]. The sluggish rate of these steps, such as hydrogen diffusion through $\mathrm{MgH}_{2}$ phase, is the kinetic problem. 
These thermodynamic and kinetic problems lead to a high operation temperature, impeding its practical application $[11,16]$. To overcome these defects, many strategies such as alloying, nanoscaling, and doping have been employed [2]. These techniques will be reviewed in detail in the section below.

\section{Alloying}

Alloying is one of the most effective ways to change the thermodynamic property of $\mathrm{MgH}_{2}$. Unlike adding catalysts, alloying method changes the reaction equation and reduces the formation enthalpy [17]. The drawback of this method is the significant decrease of capacity. Table 3 lists several reported Mg-based alloys for hydrogen storage. To decrease the stability of the hydride phase, the alloy elements selected should have a weak interaction with hydrogen, that is, the hydride formation enthalpy is low or the corresponding hydride does not exist. Also, elements should be selected according to the phase diagram, and not all the elements can form alloy with metal $\mathrm{Mg}$.

The Mg-based alloys for hydrogen storage include intermetallic compound alloys and solid solution alloys. The intermetallic compounds are homogeneous and atomic ordered with a fixed compound formula, such as $\mathrm{Mg}_{2} \mathrm{Ni}$ and $\mathrm{Mg}_{2} \mathrm{Cu}$. As a solid solution material, $\mathrm{Mg}$ metal bonds with other components in a solution form. The solid solution is also a homogeneous material, but in the atomic scale it could be either ordered or disordered. Depending on the solubility, the formula of solid solution could be variable with a continuous range, such as
$\mathrm{Mg}_{0.9} \mathrm{In}_{0.1}, \mathrm{Mg}_{0.95} \mathrm{In}_{0.05}$ and $\mathrm{Mg}_{0.98} \mathrm{In}_{0.02}$ [52].

Elements such as $\mathrm{Ni}$ and $\mathrm{Cu}$ are the ideal candidates to alloy with $\mathrm{Mg}$ [18-20]. In 1960s, $\mathrm{Mg}_{2} \mathrm{Ni}$ [18] and $\mathrm{Mg}_{2} \mathrm{Cu}$ [21] were reported as hydrogen storage alloys, and the two alloys involved different reaction pathways [22-26]. Tran et al. [27] focused on the decomposition process of $\mathrm{Mg}_{2} \mathrm{NiH}_{4}$, and examined the phase transformation detail by in-situ transmission electron microscopy (TEM) imaging. Due to the defect of low capacity, several scholars combined $\mathrm{Mg}_{2} \mathrm{NiH}_{4}$ with other high hydrogen capacity materials [28-30] or in-situ grew $\mathrm{Mg}_{2} \mathrm{NiH}_{4}$ on $\mathrm{MgH}_{2}$ in limited amount [31-36]. Besides $\mathrm{Mg}_{2} \mathrm{Ni}$ and $\mathrm{Mg}_{2} \mathrm{Cu}$, other intermetallic compounds such as $\mathrm{Mg}_{3} \mathrm{Cd}$ [37], $\mathrm{Mg}_{2} \mathrm{Si}$ [38-40], and $\mathrm{Mg}_{3} \mathrm{Ag}$ [41] were also reported to have a decreased decomposition temperature. However, the wide applications of these alloys are limited by various disadvantages, such as the high-toxic nature of $\mathrm{Cd}$, poor reversibility of $\mathrm{Mg}_{2} \mathrm{Si}$ and low capacity of $\mathrm{Mg}_{3} \mathrm{Ag}$.

Forming solid solution is another way to adjust the reaction path of $\mathrm{MgH}_{2}$ [42-46]. The homogeneous solid solution phase can be achieved with only a minor addition, and thus the capacity loss can be controlled under an acceptable scale. $\mathrm{Mg}$ - $\mathrm{Al}$ alloy is a typical solid-solution Mg-based hydrogen storage alloy, in which a certain proportion of several stable or metastable phases exist [47]. Bouaricha et al. [48] synthesized $\mathrm{Mg}$-Al alloys with the $\mathrm{Al}$ content ranging from 10 at.\% to 80 at.\% by ballmilling, and investigated the phase transformation and thermodynamic properties. The improved kinetic performances of $\mathrm{Mg}$-Al alloys were also widely reported $[49,50]$. However, the hydrogenation process leads to the

Table 3 Fundamental properties of several Mg-based alloys for hydrogen storage

\begin{tabular}{|c|c|c|c|c|c|}
\hline Name & $E_{\mathrm{a}}\left(\mathrm{kJ} \mathrm{mol}^{-1}\right)$ & $\Delta H\left(\mathrm{~kJ} \mathrm{~mol}^{-1}\right)$ & Dehy. Temp. $\left({ }^{\circ} \mathrm{C}\right)$ & $\mathrm{H}_{2}$ content $(\mathrm{wt} \%)$ & Ref. \\
\hline $\mathrm{Mg}$ & $160 \pm 10$ & 75.3 & 360 & 7.6 & {$[11],[16]$} \\
\hline $\mathrm{Mg}_{0.95} \mathrm{In}_{0.05}$ & I & $68.1 \pm 0.2$ & l & 5.3 & {$[42]$} \\
\hline $\mathrm{Mg}_{2} \mathrm{Ni}$ & I & 64.5 & 254 & 3.6 & [18] \\
\hline $\mathrm{Mg}_{80} \mathrm{Ce}_{18} \mathrm{Ni}_{2}$ & $63 \pm 3$ & $76.1 \pm 0.4$ & 232 & 4.03 & {$[43]$} \\
\hline $\mathrm{Mg}_{2} \mathrm{In}_{0.1} \mathrm{Ni}$ & 28.9 & 38.4 & 194 & 1 & {$[44]$} \\
\hline $\mathrm{Mg}_{80} \mathrm{Y}_{5} \mathrm{Ni}_{15}$ & 83.9 & I & 280 & 4.2 & {$[45]$} \\
\hline $\mathrm{Mg}_{2} \mathrm{Cu}$ & 1 & 77.1 & I & 2.3 & [19] \\
\hline $\mathrm{MgNi}_{10} \mathrm{Mm}_{3}$ & 88.6 & 56.75 & I & 5.79 & {$[20]$} \\
\hline $\mathrm{Mg}_{80} \mathrm{Y}_{5} \mathrm{Cu}_{15}$ & 132.3 & I & 300 & 3.7 & [45] \\
\hline $\mathrm{YMg}_{4} \mathrm{Cu}$ & $72.3 ; 76.8$ & I & 277 & 3.0 & {$[46]$} \\
\hline $\mathrm{Mg}_{3} \mathrm{Cd}$ & 69 & 65.5 & I & 2.8 & [37] \\
\hline $\mathrm{Mg}_{2} \mathrm{Si}$ & I & 36.4 & l & 5.0 & [39] \\
\hline $\mathrm{Mg}_{3} \mathrm{Ag}$ & l & 68.2 & I & 2.1 & {$[41]$} \\
\hline
\end{tabular}


phase separation of $\mathrm{MgH}_{2}$, which cannot be reversed in the dehydrogenation. Zhong et al. [42] reported Mg-In solid-solution alloy for hydrogen storage, which exhibited a complete reversibility after hydrogenation/dehydrogenation cycle. On this basis, Zhou et al. [51] added $\mathrm{TiMn}_{2}$ catalyst into Mg-In alloy and investigated the phase transformation (Fig. 1), finding that the dehydrogenation temperature decreased to $423 \mathrm{~K}$. Wang et al. [52] focused on the reversibility of solid-solution alloys, synthesized Mg-Al, Mg-In, and ternary Mg-Al-In alloys. They clarified that for sufficient reversibility, the atom contents of $\mathrm{Al}$ and In should be lower than $8 \%$ and $10 \%$, respectively.

It is extremely difficult to reach satisfactory thermodynamic property without sacrificing the capacity and cycle properties. And it is still a challenge to achieve highcapacity Mg-based alloys. Strategies to prepare homo- geneous alloys with a low cost need to be developed.

\section{Nanoscaling}

Nanoscaling is another way to modulate the thermodynamic and kinetic properties simultaneously [2]. Downsizing of $\mathrm{Mg} / \mathrm{MgH}_{2}$ can significantly improve the reaction rate, which is mainly due to the increase of reaction interface and the decrease of diffusion distance. Additionally, if the particle size decreases to nano-scale, the nanosizing effect will lead to a reduced enthalpy [53]. Wagemans et al. [54] used ab-initio Hartree-Fock and density functional theory (DFT) calculations, indicating that the 56-Mg-atom cluster showed an enthalpy that was roughly equal to bulk $\mathrm{MgH}_{2}$, while the 9-Mg-atom cluster $(0.9 \mathrm{~nm})$ could perform a decreased equilibrium desorption temperature of $200^{\circ} \mathrm{C}$. It can be concluded that for a significant desorption energy reduction, the crystallite
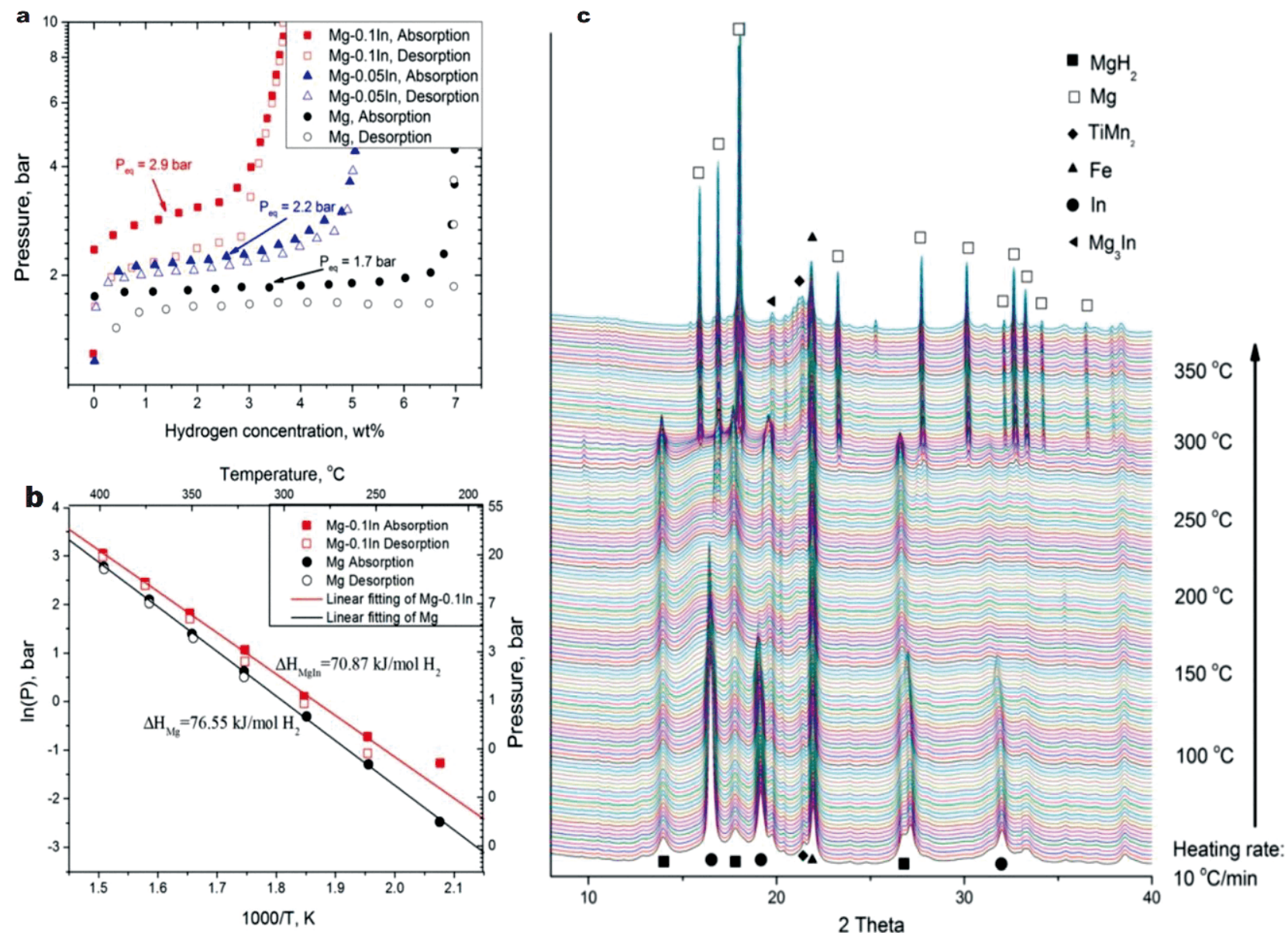

Figure 1 Pressure-composition-isotherm (PCI) curves of Mg-In-H system (a) comparing Mg-0.05In, Mg- $0.1 \mathrm{In}$ and $\mathrm{Mg}$ at temperature of $300^{\circ} \mathrm{C}$, and van't Hoff plot (b) comparing Mg-0.1In and Mg. (c) In-situ powder X-ray diffraction (XRD) spectra for dehydrogenation reaction of Mg-In-H system, the heating rate is $10^{\circ} \mathrm{C} \mathrm{min}^{-1}$ with experiment running from bottom to top of figure. Reproduced with permission from Ref. [51]. Copyright 2013, American Chemical Society. 
size should be smaller than $1.3 \mathrm{~nm}$. To reduce the particle size, many strategies such as ball-milling, physical/chemical vapor deposition (PVD and CVD), chemical reduction and nanoconfinement (NC) were employed.

Ball-milling is a typical method for reducing the particle size in a top-down mode, that is, physical downsizing of bulk $\mathrm{Mg}$ or $\mathrm{MgH}_{2}$. Since the as-prepared powder is sensitive to oxygen, the ball-milling should proceed under $\mathrm{Ar}$ or $\mathrm{H}_{2}$ condition [55]. These nanosized particles have a strong tendency to cold weld, forming aggregated particle, especially ductile Mg metal. The balance between cold welding and fracturing determined the final size of product [56]. Adding inert process control agent, such as benzene and cyclohexane [55], could reduce the effect of cold welding, but it still remained a challenge to reach a homogeneous crystallite size under $1.3 \mathrm{~nm}$. The dielectric barrier discharge plasma-assisted milling (P-milling) was a modified ball-milling method developed by Ouyang et al. [57]. With the assist of cold plasma, the milling process can be accelerated, and the morphology and reactivity of the product were quite different from that processed by traditional ball-milling [58,59]. Fig. 2a-d show the scanning electron microscopy (SEM) images of Mg-EG (expanded graphite) composites processed by Pmilling. The introduction of cold plasma created the rough surface and cracks, which enhanced the reaction activities. Some translucent few-layered graphene could also be observed in Fig. 2d, while the traditional ballmilling could not strip graphite in the same milling time. The kinetic curves shown in Fig. 2e further verified the improved performance of composites obtained by $\mathrm{P}$ milling method.

Besides the physical downsizing, sometimes ball-milling can also be employed as a chemical solid-state reaction method to prepare nanosized $\mathrm{MgH}_{2}$. Paskevicius et al. [60] synthesized $7 \mathrm{~nm} \mathrm{MgH}_{2}$ particles by ball-milled $\mathrm{MgCl}_{2}$ with LiH. Doppiu et al. [61] achieved nanosized $\mathrm{MgH}_{2}$ by ball-milling $\mathrm{Mg}$ or $\mathrm{Mg}_{99} \mathrm{Ni}_{1}$ under $\mathrm{H}_{2}$ condition. As the cold welding in top-down method limited the minimum particle size, the solid-state reaction method may be a new approach to achieve ultrafine $\mathrm{MgH}_{2}$.

PVD and CVD can achieve nanosized $\mathrm{Mg} / \mathrm{MgH}_{2}$ with various morphologies, such as wires [62-64], flakes [65], and films [66,67]. Matsumoto et al. [68] found that the morphology of $\mathrm{Mg} / \mathrm{MgH}_{2}$ could be controlled by altering the temperature and pressure. Zhu et al. [65] classified the deposition condition and the relationship with shape, size, and purity. Cui et al. [69] vaporized Mg metal and transported it into nanopores of anodic aluminium oxide (AAO) template, which improved the cycle property.
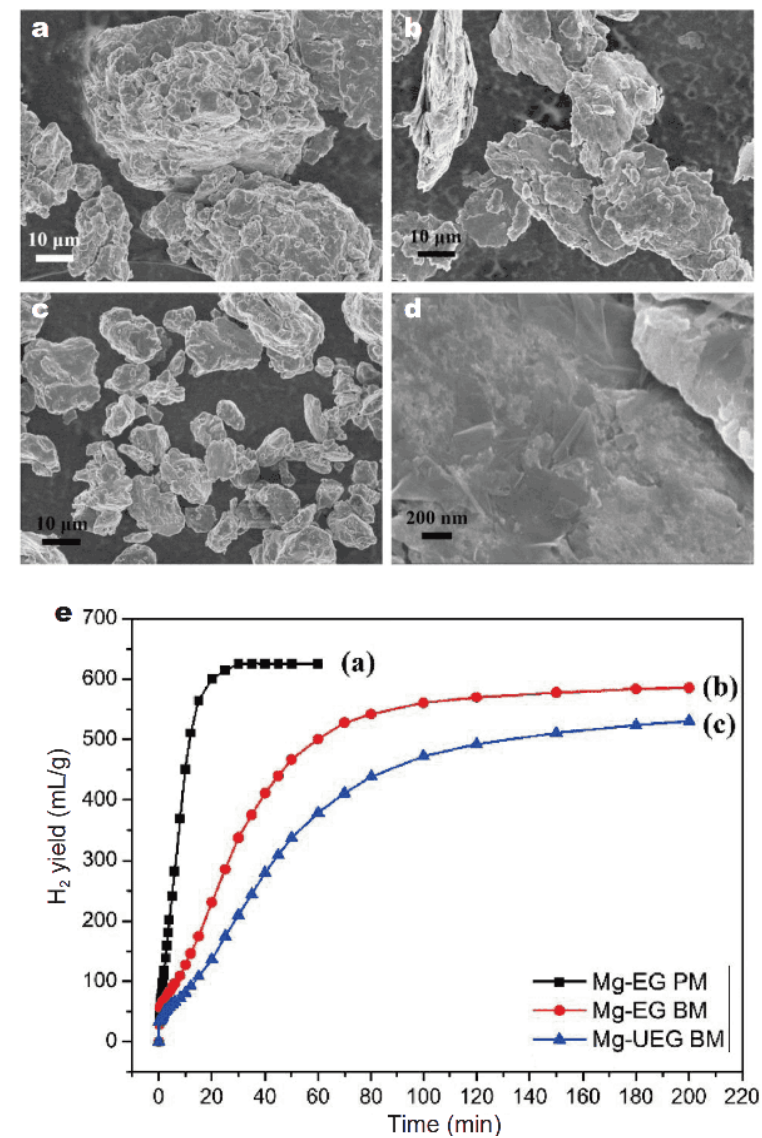

Figure 2 (a-d) SEM images of Mg-EG composites by P-milling for (a) $2 \mathrm{~h}$, (b) $5 \mathrm{~h}$, (c) $10 \mathrm{~h}$, and (d) enlarged version of $5 \mathrm{~h} \mathrm{Mg-EG} \mathrm{composite}$ with a typical area for Mg-few layer graphene and small graphite sheets. (e) Hydrolysis kinetic curves of the Mg-graphite composites at $318 \mathrm{~K}$ for (a) P-milling with EG, (b) planetary ball milling with EG, and (c) planetary ball milling with expandable graphite. Reproduced with permission from Ref. [59]. Copyright 2018, Elsevier.

Because of the explosive nature of $\mathrm{Mg}$ vapor, these deposition processes should be carefully handled. For practical production, there is a need to develop a deposition approach under moderate condition.

Chemical reduction is a technique to grow $\mathrm{Mg} / \mathrm{MgH}_{2}$ in a bottom-up approach. In 1972, Reike et al. [70] published a method to achieve highly reactive $\mathrm{Mg}$ powder by reduction reaction in anhydrous solvent. Nowadays, this Reike method has been derived into plenty of adaption to prepare nanosized $\mathrm{Mg} / \mathrm{MgH}_{2}$. The di- $n$-butylmagnesium $\left(\mathrm{MgBu}_{2}\right) \quad[71,72], \quad$ bis(cyclopentadienyl)magnesium $\left(\mathrm{Cp}_{2} \mathrm{Mg}\right)$ [73,74], and $\mathrm{MgCl}_{2}$ have been widely reported as the $\mathrm{Mg}$ source for chemical reduction. Norberg et al. [73] reduced $\mathrm{Cp}_{2} \mathrm{Mg}$ by different potassium organic reducing agents and obtained various crystal sizes of products. Liu et al. [75] reduced $\mathrm{MgCl}_{2}$ with other transition metal 
chlorides in a co-precipitation process, and the size of product ranged in $10-20 \mathrm{~nm}$.

$\mathrm{NC}$ is another approach to prepare nanoscale materials owing to its high economic efficiency and facile synthesis method. The surface functional groups and rigid framework of scaffold can also stabilize the nanoparticle. For the NC techniques such as melt infiltration $[76,77]$ and solvent infiltration $[31,71,72,78-85]$, an appropriate nanoscaffold is the prerequisite for a successful nanoscaling. The nanoscaffold material should be porous, chemically inert, and have high surface area and stabile structure. To insert $\mathrm{Mg}$ metal directly, de Jongh et al. [76] melt Mg, $\mathrm{MgH}_{2}$, and two-dimensional (2D) activated carbon (AC) scaffold at $666^{\circ} \mathrm{C}$. The crystallites size of product was less than $5 \mathrm{~nm}$ with a loading of $10.8 \mathrm{wt} \%$. They found that a smaller pore size could be beneficial to the infiltration process. However, this method required thermostable scaffold and involved a high infiltration temperature, causing the difficulty in operation. Zhang et al. [71] introduced solvent infiltration to embed $\mathrm{Mg}$ precursor $\left(\mathrm{MgBu}_{2}\right)$ into scaffold, followed by chemical reduction. In this model, infiltration was carried out at moderate conditions. Table 4 summarizes several reports of solvent infiltration applied in Mg-based hydrogen storage materials. Konarova et al. [80] selected SBA15 and CMK3 as scaffold and reduced the crystallite size of $\mathrm{MgH}_{2}$ to $4 \mathrm{~nm}$ with a lowered dehydrogenation peak temperature. Shinde et al. [83] reported that $\mathrm{MgH}_{2}$ was embedded in MOF derived carbon scaffold functionalized with transition metal, in which both NC and catalytic effect enhanced the hydrogen storage properties. However, it is a challenge to confine all the $\mathrm{MgH}_{2}$ inside the pores of scaffold with a high loading, because simply increasing the amount of $\mathrm{Mg}$ source will result in aggregation on the scaffold surface [80]. Confining $\mathrm{Mg}$ in 2D material surface could reach a larger loading than $3 \mathrm{D}$ scaffold pores $[31,84,86]$. Xia et al. [84] reduced $\mathrm{MgBu}_{2}$ on graphene and achieved dispersed $\mathrm{MgH}_{2}$ with an average particle diameter of $\sim 5.7 \mathrm{~nm}$. Cho et al. [31] confined transition metal doped $\mathrm{Mg}$ on graphene layers via co-reduction approach, which simultaneously realized high hydrogen storage capacity $(6.5 \mathrm{wt} \%)$ and excellent kinetics performance. Zhang et al. [87] confined $\mathrm{Mg}_{2} \mathrm{NiH}_{4}$ by exposing samples to Ar/air mixture, and achieved well-defined $\mathrm{MgO}$ coating on $\mathrm{Mg}_{2} \mathrm{NiH}_{4}$ with a thickness of $\sim 3 \mathrm{~nm}$ (Fig. 3). This coating could prevent aggregation during cycles and improve thermal and mechanical stability.

Nowadays, it remains a challenge to achieve homogeneous crystallite size under $1.3 \mathrm{~nm}$ due to the strong tendency to aggregate of particles with large surface energy. The poor loading and inhomogeneous dispersion are the main factors hindering the development of 3D scaffold NC. Therefore, efficient scaffold and infiltration technologies need to be developed. Confining $\mathrm{Mg} / \mathrm{MgH}_{2}$ in $2 \mathrm{D}$ scaffold can reach a high loading, and recent developed 2D materials such as graphene, $\mathrm{MoS}_{2}$ and MXene are potential scaffold candidates. Without rigid framework, the stabilization effect of $2 \mathrm{D}$ scaffold is relatively weak. In-situ generated coating [87] is a new type of NC and the stable ultrafine $\mathrm{MgH}_{2}$ may be accessible by quickly coating an inert layer on it.

\section{Adding dopants}

Doping is a method that mainly focuses on tuning kinetic properties [15]. Doping nonmetals [39,84,88,89], metals [90,91], metal compounds [35,92-99] or composites [32,100-105] could decrease the absorption/desorption temperatures of $\mathrm{Mg} / \mathrm{MgH}_{2}$. Several additives are listed in

Table 4 Scaffolds and loadings of several reported Mg-based NC materials

\begin{tabular}{|c|c|c|c|c|}
\hline Precursor & Scaffold & Dehy. $T_{\text {start }}\left({ }^{\circ} \mathrm{C}\right)$ & Loading ( $w \mathrm{t} \%)$ & Ref \\
\hline $\mathrm{MgBu}_{2}$ & Carbon aerogel & 1 & $15-17$ & {$[71]$} \\
\hline $\mathrm{MgBu}_{2}$ & Carbon aerogel & 175 & 18.2 and 10.0 & {$[72$} \\
\hline $\mathrm{MgBu}_{2}$ & Carbon aerogel & l & 10 & {$[78$} \\
\hline $\mathrm{MgBu}_{2}$ & Activated carbon fibre & 280 & 22 & {$[79]$} \\
\hline $\mathrm{MgBu}_{2}$ & SBA15 and CMK3 & 250 & $20,40,60,80$ & {$[80]$} \\
\hline $\mathrm{MgBu}_{2}$ & $\mathrm{Ni}-\mathrm{CMK} 3$ & 50 & 37.5 & {$[81]$} \\
\hline $\mathrm{MgBu}_{2}$ & Graphene oxide-based porous carbon & l & 53 & {$[82$} \\
\hline $\mathrm{MgBu}_{2}$ & MOFs derived carbon & 121 & $11-60$ & {$[83$} \\
\hline $\mathrm{MgBu}_{2}$ & Graphene & 150 & $20-75$ & {$[84]$} \\
\hline $\mathrm{Cp}_{2} \mathrm{Mg}$ & Graphene & I & 1 & {$[85$} \\
\hline $\mathrm{Cp}_{2} \mathrm{Mg}$ & $\mathrm{Ni}$-doped graphene & I & l & {$[31]$} \\
\hline
\end{tabular}



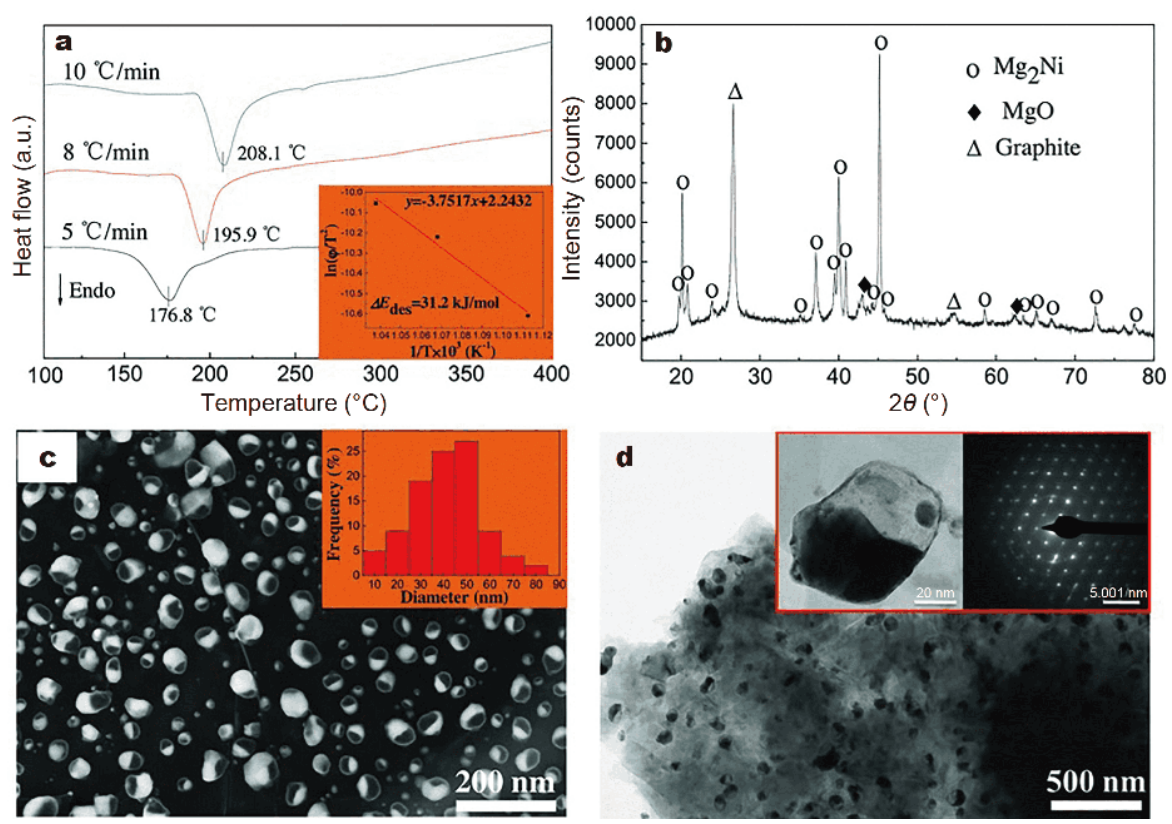

Figure 3 Dehydrogenation of $\mathrm{Mg}_{2} \mathrm{NiH}_{4}$ /graphene sheets (GS). (a) Differential scanning calorimetry (DSC) profiles for hydrogen desorption of $\mathrm{Mg}_{2} \mathrm{NiH}_{4} / \mathrm{GS}$ at different heating rates. Inset: Kissinger's plots derived from the DSC profiles. (b) XRD pattern after a typical DSC run. (c) Representative field emission SEM (FESEM) (the inset shows the particle size distribution) and (d) bright-field $\mathrm{TEM}$ images of $\mathrm{Mg}_{2} \mathrm{NiH}_{4} / \mathrm{GS}$ after hydrogen desorption. The inset in (d) is the TEM image of a single particle and the corresponding electron diffraction pattern. Reproduced with permission from Ref. [87]. Copyright 2017, John Wiley \& Sons, Inc.

Table 5. Kecik et al. [106] simulated the behavior of $\mathrm{H}_{2}$ at the surface of additive-doped $\mathrm{MgH}_{2}$ based on first-principles molecular dynamics method. They found that the introduction of transition elements from $\mathrm{Ti}$ to $\mathrm{Ni}$ in $3 \mathrm{~d}$ and from $\mathrm{Zr}$ to $\mathrm{Pd}$ in $4 \mathrm{~d}$ series could accelerate hydrogen dissociation and adsorption processes, especially $3 \mathrm{~d}$ series elements such as Co, Mn and Fe. Liang et al. [107] milled $\mathrm{MgH}_{2}$ with transition metal $\mathrm{Ti}, \mathrm{V}, \mathrm{Mn}, \mathrm{Fe}$ and $\mathrm{Ni}$, and found that all of them improved the kinetic properties. $\mathrm{MgH}_{2}-\mathrm{V}$ showed the most rapid desorption rate while $\mathrm{MgH}_{2}$-Ti exhibited most rapid absorption rate. Hanada et al. [108] introduced micro-particles and nano-particles of transition metals ( $\mathrm{Fe}, \mathrm{Co}, \mathrm{Ni}, \mathrm{Cu}$ ) to $\mathrm{MgH}_{2}$, the nanosized Ni-doped $\mathrm{MgH}_{2}$ showed the lowest activation energy of $94 \pm 3 \mathrm{~kJ} \mathrm{~mol}^{-1} \mathrm{H}_{2}$.

Metal oxides can also enhance the kinetic properties of $\mathrm{MgH}_{2}$. Oelerich et al. [109] investigated the absorption/ desorption properties of $\mathrm{MgH}_{2} / \mathrm{Mg}_{2} \mathrm{NiH}_{4}$ with oxides, including $\mathrm{Sc}_{2} \mathrm{O}_{3}, \mathrm{TiO}_{2}, \mathrm{~V}_{2} \mathrm{O}_{5}, \mathrm{Cr}_{2} \mathrm{O}_{3}, \mathrm{Mn}_{2} \mathrm{O}_{3}, \mathrm{Fe}_{3} \mathrm{O}_{4}, \mathrm{CuO}$, $\mathrm{Al}_{2} \mathrm{O}_{3}$, and $\mathrm{SiO}_{2}$. $\mathrm{MgH}_{2} / \mathrm{Cr}_{2} \mathrm{O}_{3}$ performed the fastest hydrogen absorption whereas $\mathrm{V}_{2} \mathrm{O}_{5}$ and $\mathrm{Fe}_{3} \mathrm{O}_{4}$ exhibited the fastest desorption of hydrogen. Dehouche et al. [97] synthesized $0.2 \mathrm{~mol} \% \mathrm{Cr}_{2} \mathrm{O}_{3}$-containing $\mathrm{MgH}_{2}$ and found that it revealed enhanced kinetic properties and remarkable cycle stability even after 1000 absorption/desorption cycles. Aguey-Zinsou et al. [110] prepared $\mathrm{MgH}_{2}-\mathrm{Nb}_{2} \mathrm{O}_{5}$ by ball-milling, indicating that $\mathrm{Nb}_{2} \mathrm{O}_{5}$ not only acted as a catalyst but also a process control agent to prevent the cold welding during ball-milling. Recently, Zhang et al. [100] synthesized $\mathrm{TiO}_{2}$ nanosheets (NS) with exposed $\{001\}$ facets, and introduced it into $\mathrm{MgH}_{2}$ by ball-milling. Compared with the mixture with commercial $\mathrm{TiO}_{2}$ nanoparticles $(5-10 \mathrm{~nm})$, the $\mathrm{TiO}_{2}$ (NS)-containing $\mathrm{MgH}_{2}$ composite displayed a $36^{\circ} \mathrm{C}$ lower dehydrogenation peak temperature.

Metal halides are also potential additives for enhancing kinetic properties, especially metal fluorides and metal chlorides. Malka et al. [111] studied the influences of nineteen different halide additives on the $\mathrm{MgH}_{2}$ desorption/absorption processes. They found that halides from group IV and V of the periodic table with a highest oxidation state were better catalysts in comparison with the other halides, and fluorides demonstrated a better catalytic performance than chlorides. Jin et al. [112] investigated the enhancement effect by adding seven different transition metal fluorides. They found that $\mathrm{MgH}_{2}$ could react with fluorides rapidly, forming $\mathrm{MgF}_{2}$ and corresponding hydrides or metal-hydrogen solid solutions. These products acted as the catalysts to improve the kinetic properties. Ma et al. [93] revealed that besides 
Table 5 Several additives for Mg-based hydrogen storage materials

\begin{tabular}{|c|c|c|c|c|}
\hline Additive & Amount & Dehy. $T_{\text {start }}\left({ }^{\circ} \mathrm{C}\right)$ & Capacity (wt\%) & Ref. \\
\hline Graphite & $5 \mathrm{wt} \%$ & 1 & 5.0 & [88] \\
\hline Single-walled carbon nanotube (SWCNT) & $5 \mathrm{wt} \%$ & l & 6.0 & [89] \\
\hline Graphene & $25 \mathrm{wt} \%$ & 150 & 5.4 & [84] \\
\hline $\mathrm{Si}$ & $33.3 \mathrm{~mol} \%$ & 295 & 5.0 & [39] \\
\hline $\mathrm{Ti}$ & $9 \mathrm{wt} \%$ & ca. 300 & 4.8 & {$[90]$} \\
\hline $\mathrm{TiCl}_{3}$ & $15 \mathrm{wt} \%$ & I & 6.7 & {$[92]$} \\
\hline $\mathrm{TiF}_{3}$ & $4 \mathrm{~mol} \%$ & I & $5.0-5.5$ & {$[93]$} \\
\hline $\mathrm{TiO}_{2}$ & $20 \mathrm{wt} \%$ & l & 4.7 & [94] \\
\hline $\mathrm{TiO}_{2} \mathrm{NS}$ & $5 \mathrm{wt} \%$ & 180.5 & 6.0 & {$[100]$} \\
\hline $\mathrm{Na}_{2} \mathrm{Ti}_{3} \mathrm{O}_{7}$ & $5 \mathrm{wt} \%$ & 308.4 & 6.5 & [95] \\
\hline $\mathrm{Ti}_{3} \mathrm{C}_{2}$ & $5 \mathrm{wt} \%$ & 185 & 6.2 & {$[96]$} \\
\hline TiN@reduced graphene oxide (rGO) & $10 \mathrm{wt} \%$ & 167 & 6.0 & [101] \\
\hline $\mathrm{V}$ & $25 \mathrm{wt} \%$ & l & 4.0 & {$[91]$} \\
\hline $\mathrm{V}_{2} \mathrm{O}_{3} @ \mathrm{C}$ & $9 \mathrm{wt} \%$ & 215 & 6.4 & {$[102]$} \\
\hline $\mathrm{Cr}_{2} \mathrm{O}_{3}$ & $0.2 \mathrm{~mol} \%$ & I & 6.4 & [97] \\
\hline $\mathrm{Fe}_{3} \mathrm{O}_{4} @$ graphene & $5 \mathrm{wt} \%$ & 262 & 6.5 & [103] \\
\hline $\mathrm{FeS}_{2}$ & $16.7 \mathrm{wt} \%$ & I & 6.06 & {$[98]$} \\
\hline $\mathrm{Co} / \mathrm{C}$ & $6 \mathrm{wt} \%$ & I & 6.5 & [32] \\
\hline $\mathrm{Ni} / \mathrm{C}$ & $6 \mathrm{wt} \%$ & l & 6.5 & [32] \\
\hline $\mathrm{Ni@rGO}$ & $5 \mathrm{wt} \%$ & 160 & 6.0 & [104] \\
\hline $\mathrm{Ni}_{3} \mathrm{C}$ & $5 \mathrm{wt} \%$ & 160 & 6.2 & {$[35]$} \\
\hline $\mathrm{Ni}_{3} \mathrm{~N} @ \mathrm{~N}$-doped carbon (NC) & $5 \mathrm{wt} \%$ & 175 & 6.0 & [105] \\
\hline $\mathrm{CeO}_{2}$ & $5 \mathrm{wt} \%$ & l & 3.6 & [99] \\
\hline
\end{tabular}

$\mathrm{MgF}_{2}$, Ti-F-Mg bonding was formed in the $\mathrm{TiF}_{3}$-doped $\mathrm{MgH}_{2}$ whereas only one stable binding state of $\mathrm{MgCl}_{2}$ was found in the $\mathrm{TiCl}_{3}$-doped $\mathrm{MgH}_{2}$. This may be responsible for the advantage of fluorides over chlorides in improving kinetics properties.

Recently, building multiphase nanostructured hybrids have emerged as a new strategy to design efficient additives. Commonly, these hybrids contained dispersed transition metals or metal compounds and 2D/3D scaffold materials. The scaffold material can stabilize the reactive phases and introduce $\mathrm{NC}$ effect to $\mathrm{MgH}_{2}$. Graphene is an ideal scaffold material due to its low-density, high chemical stability and large surface area. There are plenty of studies reporting the enhanced kinetics by adding metal-graphene composites, such as Ni@rGO [104,113,114], NiCo@rGO [115], Ni Ni $_{2} @$ rGO [36], TiN@rGO [101], and $\mathrm{CeF}_{4} @ G r$ [116]. Adding graphene not only enhances the dispersion of metal compounds, but also prevents the aggregation of $\mathrm{MgH}_{2}$, thereby further enhancing cycle properties. In recent years, MOFs derived metal-carbon composites as promising additives have been widely studied. Zhang et al. [117] achieved carbon-supported $\mathrm{TiO}_{2}$ by calcining furfuryl alcohol-filled MIL-125(Ti); Wang et al. [102] obtained cubic carbon nanoboxes supported $\mathrm{V}_{2} \mathrm{O}_{3}$ by calcining MIL-47(V) (Fig. 4); Huang et al. [32] synthesized carbon wrapped $\mathrm{Ni}$ /Co by calcining MOFs-74-Co and MOFs-74-Ni under dynamic vacuum. The ligands derived carbon structure limited the particle size of metal/metal compound and enhanced the catalytic activities. All of these researches reported significant improvement of kinetic properties.

Because of the strong reducibility of $\mathrm{Mg}$ and $\mathrm{MgH}_{2}$, most of the dopants with high chemical states are thermodynamically feasible to react with $\mathrm{MgH}_{2}$. On the other hand, for most situations these reactions are conducted in solid-state with a kinetic obstacle. Whether the dopants reduce or not depends on the experimental conditions such as milling rate and milling time, adding of liquid agents, and the surface functional group of dopants. In the case that dopants are reduced by $\mathrm{MgH}_{2}$, the production can often enhance the kinetic performance, but may also lead to loss of capacity. Chen et al. [34] reported 

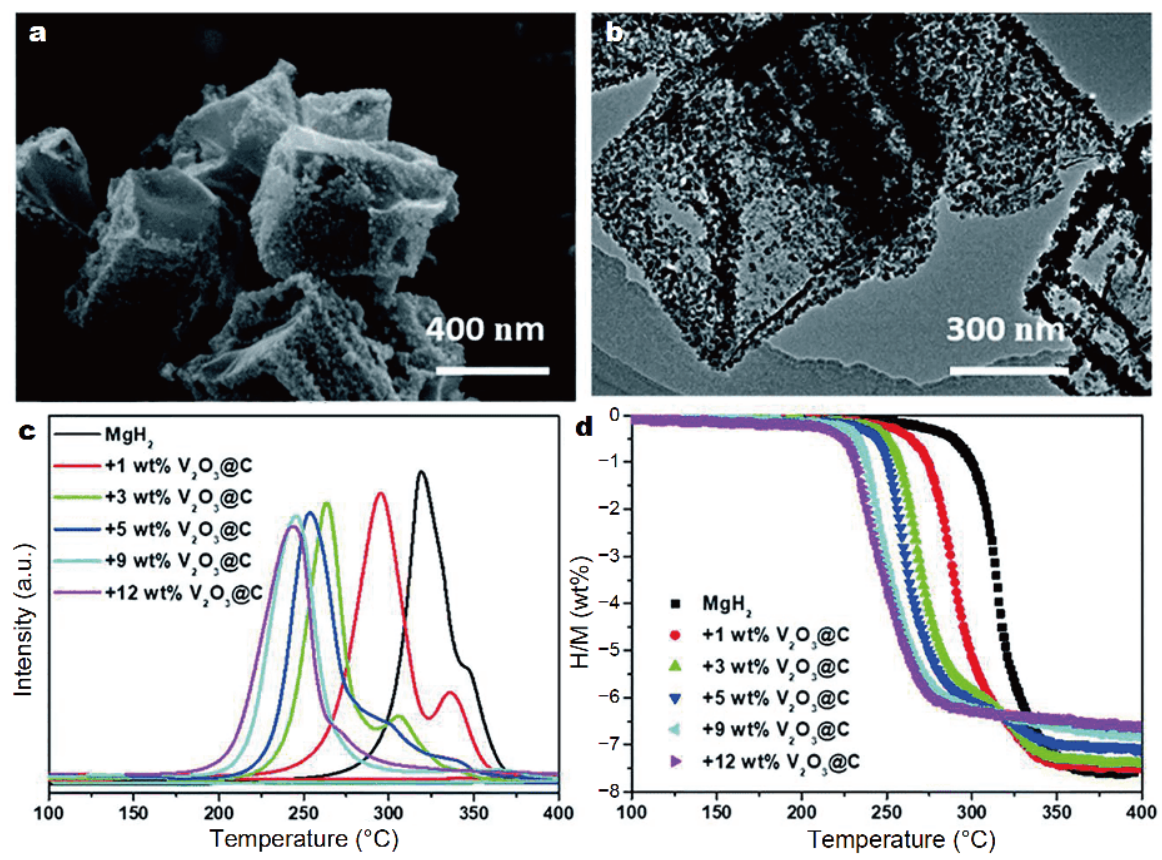

Figure 4 (a) SEM and (b) TEM image of the prepared nano- $\mathrm{V}_{2} \mathrm{O}_{3} @ \mathrm{C}$ composite. (c) Temperature programmed desorption (TPD) and (d) volumetric release curves of $\mathrm{MgH}_{2}-x \mathrm{wt} \% \mathrm{~V}_{2} \mathrm{O}_{3} @ \mathrm{C}$ samples $(x=0,1,3,5,9,12)$. Reproduced with permission from Ref. [102]. Copyright 2018, the Royal Society of Chemistry.

that the $\mathrm{TiO}_{2}$ could be reduced by $\mathrm{MgH}_{2}$, resulting in the formation of multiple valence titanium composites (II, III, and IV). They found these products enhanced the electron transfer and improved the performance. Bhatnagar et al. [103] milled $\mathrm{MgH}_{2}$ with $\mathrm{Fe}_{3} \mathrm{O}_{4}$ for $25 \mathrm{~h}$, the formation of $\mathrm{Fe}_{2} \mathrm{O}_{3}$ and the $\mathrm{Fe}$ metal were verified after cycle de/re-hydrogenation process. The generation of $\mathrm{Mg}_{1-x} \mathrm{Fe}_{x} \mathrm{O}$ can puncture the layer of $\mathrm{MgO}$ to form the diffusion path, and the Fe metal can enhance the electron transfer. Cui et al. [92] combined $\mathrm{Mg}$ and $\mathrm{TiCl}_{3}$ in THF solution, and observed the generation of multi-valence Ti-based materials coating on $\mathrm{Mg}$ surface. This layer showed a positive influence on the dehydrogenation of $\mathrm{MgH}_{2}$. Our previous work [36] also reported the reaction between $\mathrm{MgH}_{2}$ and $\mathrm{Ni}_{2} \mathrm{P}$-based additives. During the dehydrogenation, $\mathrm{Ni}_{2} \mathrm{P}$ were partially reduced to $\mathrm{Mg}_{2} \mathrm{Ni}$, which prevented the aggregation and improved the cycle performance. In conclusion, it should be mentioned that adding dopants always accompany the phase transformation. The resulting multiple phase structure, highly reactive products, cracks and defects on $\mathrm{MgH}_{2}$ can further improve the kinetic performance, but the loss of capacity should also be considered.

Considerable researches prove that the doping is an effective strategy to tune kinetic properties of $\mathrm{Mg} / \mathrm{MgH}_{2}$. However, this strategy can hardly influence the thermo- dynamic property significantly. Moreover, the high cost in synthesis of some additives offsets the price advantage of $\mathrm{Mg}$ metal. Combining with alloying or nanostructuring strategies is crucial for practical application of the doping approach. Moreover, it is of great importance to develop a low cost synthesis route to obtain highly effective additives.

\section{LIGHTWEIGHT METAL BOROHYDRIDES}

For lightweight complex hydrides, four hydrogen atoms can be covalently bonded with a metal atom in the center, such as aluminum and boron, forming anion tetrahedron, i.e., $\left[\mathrm{AlH}_{4}\right]^{-}$or $\left[\mathrm{BH}_{4}\right]^{-}$. The alkali and alkaline earth metals, including $\mathrm{Li}, \mathrm{Na}, \mathrm{K}, \mathrm{Mg}, \mathrm{Ca}$, can form lightweight complex hydrides with anion tetrahedron. More importantly, the reserves of $\mathrm{Li}, \mathrm{Na}, \mathrm{K}, \mathrm{Mg}, \mathrm{Ca}$ and $\mathrm{Al}$ elements are abundant, which makes large-scale application of lightweight complex hydrides possible. Lightweight metal borates and alanates, as the important types of lightweight hydrides, have been widely investigated owing to the high gravimetric and volumetric densities.

As discussed previously, lightweight borohydrides are promising candidates as hydrogen storage materials due to their outstanding hydrogen content. Like $\mathrm{MgH}_{2}$, the wide application of these compounds is also limited by sluggish kinetics and poor thermodynamic properties. 
Moreover, their reversibility is also a critical factor for onboard application [4,118]. Nakamori et al. [119] investigated the thermodynamic stabilities of nine metal borohydrides using first-principles calculations and experimental data. The decomposition peak temperatures of $\mathrm{LiBH}_{4}, \mathrm{NaBH}_{4}$, and $\mathrm{Mg}\left(\mathrm{BH}_{4}\right)_{2}$ are all above $500 \mathrm{~K}$. They also found that $\mathrm{LiBH}_{4}, \mathrm{NaBH}_{4}$, and $\mathrm{KBH}_{4}$ decomposed to hydride phases, whereas $\mathrm{Mg}\left(\mathrm{BH}_{4}\right)_{2}$ was subjected to a multistep decomposition process to form borides. Due to several irreversible decomposition steps, phase aggregation and separation in multiphase product, stable intermediate compounds and many other factors, it is difficult for lightweight borohydrides to reach a sustainable rehydrogenation rate with cycling [120]. Therefore, considerable efforts have been made to adjust their kinetic and thermodynamic properties and improve reversibility.

\section{Nanoscaling}

Nanoscaling can adjust thermodynamic and kinetic properties simultaneously. Mechanical milling is a facile physical approach to reduce both the particle and crystallite size. Varin et al. [121] used controlled mechanical milling (CMM) method to prepare $\mathrm{NaBH}_{4}$ with a few tens of nanometers crystallite size under various milling modes. Due to the solubility of lightweight borohydrides in ether solvent, evaporating borohydrides solution is another way to achieve nanoscale morphology. Wan et al. [122] prepared $\mathrm{LiBH}_{4}$ powder with particle sizes ranging from 20 to $50 \mathrm{~nm}$ via evaporation of $\mathrm{LiBH}_{4}$-THF solution, without the aid of any additives or scaffolds. Pang et al. [123] prepared $\mathrm{LiBH}_{4}$ nanobelts with width of $10-40 \mathrm{~nm}$ using methyl tert-butyl ether as the ligand. The onset decomposition temperature was reduced to $60^{\circ} \mathrm{C}$, and they also found that physical vapour deposition approach can be used to prepare other soluble hydrides. Because of the high surface energy, downsizing borohydrides without introducing additives or supports can hardly achieve the size lower than ten nanometers. Therefore, besides the downsizing technique, stabilizing ultrafine borohydrides is also a challenge.

$\mathrm{NC}$ is another common strategy for borohydrides to reduce particle and crystallite size. Moreover, the introduction of scaffold can also mitigate sintering and improve the cycle capacity [124]. Due to the low melt temperature $\left(\mathrm{LiBH}_{4} 268^{\circ} \mathrm{C}\right.$ [13]) and solubility in ether solvent, both melt [124-129] and solvent [129-141] infiltration techniques have been widely investigated, as shown in Table 6. Gross et al. [124] melted $\mathrm{LiBH}_{4}$ at $300^{\circ} \mathrm{C}$ and infiltrated it into nanoporous carbon scaffolds. The rate of hydrogen exchange was significantly enhanced, and the capacity loss over three cycles was reduced from $72 \%$ to $\sim 40 \%$. Ngene et al. [129] confined

Table 6 Hydrogen storage properties of several reported nanoconfined borohydrides composites

\begin{tabular}{|c|c|c|c|c|c|c|}
\hline Borohydride & Scaffold & Infiltration method & Dehy. $T_{\text {start }}\left({ }^{\circ} \mathrm{C}\right)$ & Loading ( $w t \%)$ & Capacity (wt\%)/Cycles & Ref. \\
\hline $\mathrm{LiBH}_{4}$ & Carbon aerogels & Melt & l & $\begin{array}{l}25-30 \\
45-50\end{array}$ & l & {$[124]$} \\
\hline $\mathrm{LiBH}_{4}$ & Porous carbons & Melt & l & $10-30$ & $5.5 / 6$ & {$[125]$} \\
\hline $\mathrm{LiBH}_{4}$ & Porous carbons & Melt & 300 & $5-25$ & l & {$[126]$} \\
\hline $\mathrm{LiBH}_{4}$ & SBA15 & Melt & 150 & $10-65$ & l & {$[127]$} \\
\hline $\mathrm{LiBH}_{4}$ & Zeolite-templated carbon & Melt & 194 & 41.5 & l & {$[128]$} \\
\hline $\mathrm{LiBH}_{4}$ & Activated carbon & Solvent & 220 & 30 & $6.6 / 2$ & {$[130]$} \\
\hline $\mathrm{LiBH}_{4}$ & $\mathrm{Cu}-\mathrm{MOFs}$ & Solvent & 60 & l & l & {$[131]$} \\
\hline $\mathrm{LiBH}_{4}$ & Porous $\mathrm{TiO}_{2}$ micro-tubes & Solvent & 183 & 22.97 & l & {$[132]$} \\
\hline $\mathrm{LiBH}_{4}$ & Porous $\mathrm{ZnO} / \mathrm{ZnCo}_{2} \mathrm{O}_{4}$ & Solvent & 169 & 50 & l & {$[133]$} \\
\hline $\mathrm{LiBH}_{4}$ & $\mathrm{Ti}_{3} \mathrm{C}_{2}$ & Solvent & 172.6 & 33.3 & $5.5 / 3$ & {$[134]$} \\
\hline $\mathrm{NaBH}_{4}$ & Nanoporous carbon & Melt/Solvent & 250 & 25 & 1 & {$[129]$} \\
\hline $\mathrm{NaBH}_{4}$ & Mesoporous carbon & Solvent & l & 20 & l & {$[135]$} \\
\hline $\mathrm{NaBH}_{4}$ & SBA15/CMK3 & Solvent & l & 20 & I & {$[136]$} \\
\hline $\mathrm{NaBH}_{4}$ & Graphene & Solvent & 40 & & $7.1 / 6$ & {$[137]$} \\
\hline $\mathrm{Mg}\left(\mathrm{BH}_{4}\right)_{2}$ & Activated carbon & Solvent & 150 & 41 & 1 & {$[138]$} \\
\hline $\mathrm{Mg}\left(\mathrm{BH}_{4}\right)_{2}$ & Activated carbon & Solvent & 40 & l & I & {$[139]$} \\
\hline $\mathrm{Mg}\left(\mathrm{BH}_{4}\right)_{2}$ & CMK3-Ni & Solvent & 75 & 45 & l & {$[140]$} \\
\hline $\mathrm{Mg}\left(\mathrm{BH}_{4}\right)_{2}$ & Ni-Pt@C & Solvent & 250 & 30 & 1 & {$[141]$} \\
\hline
\end{tabular}


$\mathrm{NaBH}_{4}$ in nanoporous carbon via both melt and solvent infiltration methods. The onset dehydrogenation temperature decreased to $250^{\circ} \mathrm{C}, 220^{\circ} \mathrm{C}$ lower than bulk $\mathrm{NaBH}_{4}$. Besides, this material showed a $43 \%$ reversible hydrogen capacity, which is a considerable reverse hydrogen uptake in $\mathrm{NaBH}_{4}$. Chong et al. [137] encapsulated $\mathrm{NaBH}_{4}$ into graphene, which effectively prevented the aggregation and phase separation during the dehydrogenation process (Fig. 5). The composite could maintain $93 \%$ retention of the initial capacity even at end of the $6^{\text {th }}$ cycle.

Besides the physical confinement effect, the chemical nature of scaffolds can also influence hydrogen storage performance. Recently, Suwarno et al. [142] used quasielastic neutron scattering and calorimetric measurements to study the chemical influence of scaffolds. Comparing $\mathrm{LiBH}_{4}$ infiltrated into silica and carbon scaffolds with similar pore size, they found that thickness of $\mathrm{LiBH}_{4}$ layer near the pore walls was quite different. Also, the discrepancy in the fraction of $\mathrm{LiBH}_{4}$ with high hydrogen mobility was confirmed by quasi-elastic neutron scattering. These results indicated that the chemical nature of scaffold could affect the morphology and chemical activity of borohydrides in addition to the pore size. The nanostructured transtion metal compounds [132,133] such as MOFs [131] and MXene [134] are potential scaffolds with strong chemical influence. Liu et al. [132] confined $\mathrm{LiBH}_{4}$ into $\mathrm{TiO}_{2}$ nanotube by solvent infiltration approach. Besides the decreased activation energy, they detected the formation of $\mathrm{LiTiO}_{2}, \mathrm{Li}_{0.5} \mathrm{TiO}_{2}, \mathrm{TiB}_{2}$ and $\mathrm{TiO}$ during the dehydrogenation, which implied the change of reaction pathway. Sun et al. [131] investigated the interaction between $\mathrm{LiBH}_{4}$ and $\mathrm{Cu}-\mathrm{MOF}$, which were introduced as a scaffold. They found that the $\mathrm{LiBH}_{4}$ molecules were trapped by $\mathrm{Cu}^{2+}$ inside the scaffolds, which enhanced the decomposition of $\mathrm{LiBH}_{4}$ and reduced the dehydrogenation temperature. The recently developed MXene composites were also promising candidates as the NC scaffolds, owing to its unique multilayer morphology and the transition element contained. Our group reported the $\mathrm{Ti}_{3} \mathrm{C}_{2}$ as a $2 \mathrm{D}$ scaffold to confine $\mathrm{LiBH}_{4}$ with homogeneous dispersion [134] (Fig. 6). The onset dehydrogenation temperature of $\mathrm{LiBH}_{4} @ 2 \mathrm{Ti}_{3} \mathrm{C}_{2}$ hybrid decreased to $172.6^{\circ} \mathrm{C}$ with an initial capacity of $9.6 \mathrm{wt} \%$. And the dehydrogenated products could rehydrogenate at $300^{\circ} \mathrm{C}$ and 95 bar of hydrogen pressure with 5.5 wt $\%$ capacity after 3 cycles.

Besides these methods, other reported approaches such as self-printing [143] and solid-gas reaction [144] could also achieve nanostructure borohydrides. Zhang et al.
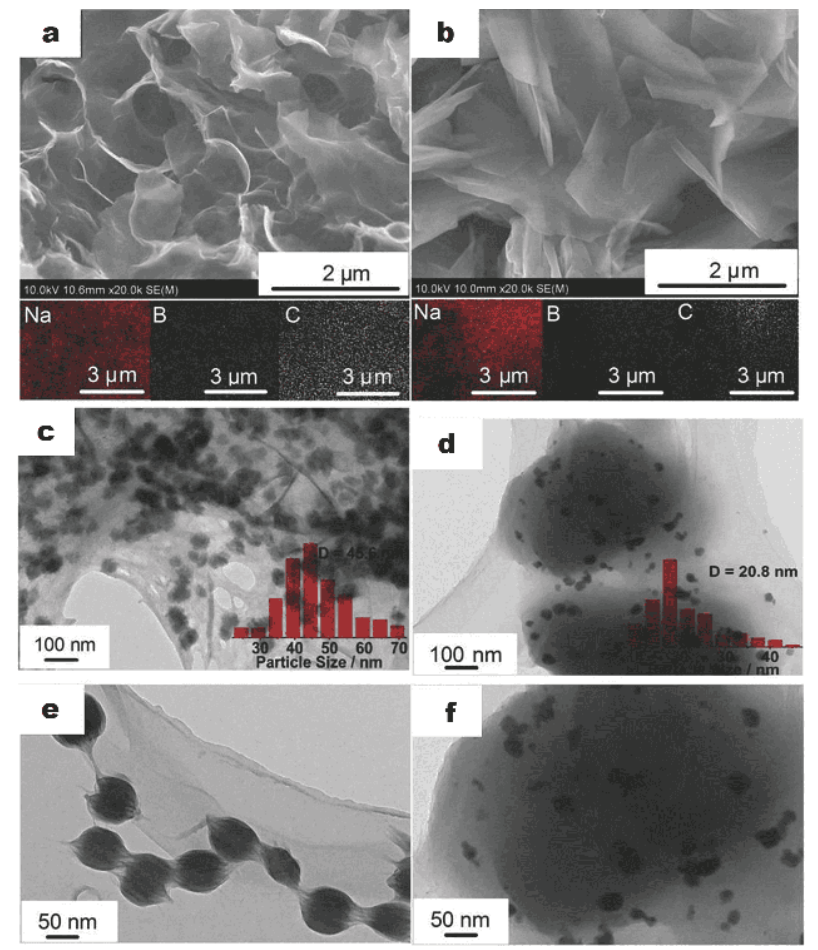

Figure 5 SEM images of (a) rehydrogenated $\mathrm{NaBH}_{4} @$ graphene and (b) rehydrogenated $\mathrm{NaBH}_{4}+$ graphene, and their associated energy dispersive spectrometer (EDS) maps of Na, B, and C. (c, e) TEM images of $\mathrm{NaBH}_{4} @$ graphene and diameter distribution (inset of (c)). (d, f) TEM images of $\mathrm{NaBH}_{4}+$ graphene and diameter distribution (inset of (d)). Reproduced with permission from Ref. [137]. Copyright 2015, John Wiley \& Sons, Inc.

[144] obtained dispersed $\mathrm{Mg}\left(\mathrm{BH}_{4}\right)_{2}$ by a space-confined solid-gas reaction using graphene support $\mathrm{MgH}_{2}$ as the precursor. DFT calculation verified that graphene scaffold could promote the reaction of $\mathrm{MgH}_{2}$ and $\mathrm{B}_{2} \mathrm{H}_{6}$, and stabilize $\mathrm{Mg}\left(\mathrm{BH}_{4}\right)_{2}$ particles. The graphene supported $\mathrm{Mg}\left(\mathrm{BH}_{4}\right)_{2}$ with an average particle size of $\sim 10 \mathrm{~nm}$ showed a decreased onset dehydrogenation temperature at $154^{\circ} \mathrm{C}$, and $9.04 \mathrm{wt} \% \mathrm{H}_{2}$ was released at $225^{\circ} \mathrm{C}$.

Nowadays, various approaches can downsize borohydrdies to nanoscale under a significantly decreased dehydrogenation temperature. However, mechanical and thermal approaches require high hydrogen pressure to avoid the decomposition, which hinders their practical production, and the solvent approaches face the problem of ether residues. It is still a challenge to achieve ultrafine particles with a significant enthalpy decrease. Thus, it is of great importance to develop safe, efficient and low-cost techniques for nanostructuring.

\section{Adding dopants}

Adding dopants is another valid way to enhance hydro- 

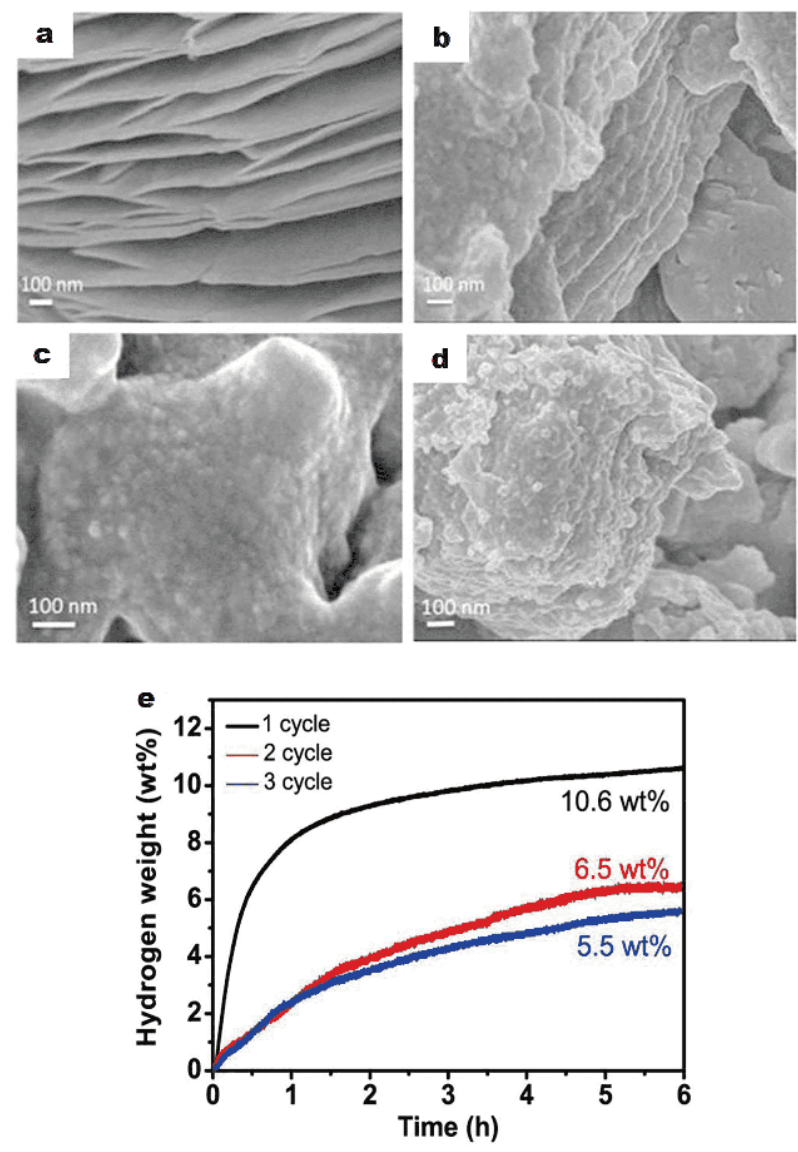

Figure 6 (a-d) SEM images of (a) $\mathrm{Ti}_{3} \mathrm{C}_{2}$, (b, c) LBH@2 $\mathrm{Ti}_{3} \mathrm{C}_{2}$ hybrid before dehydrogenation and (d) after dehydrogenation. (e) Dehydrogenation cycle profiles of the LBH@2 $\mathrm{Ti}_{3} \mathrm{C}_{2}$ hybrid. Reproduced with permission from Ref. [134]. Copyright 2018, American Chemical Society.

gen storage performances. Due to the high-reactive nature of borohydrides, a wide range of dopants can react with them and change the de-/re-hydrogenation pathway. Thus, the enhanced performances always result from thermodynamic and kinetics improvement. Table 7 lists several reported additives for borohydrides hydrogen storage system. The inert scaffold such as Si and C could perform a chemical interaction with borohydrides, so the nonmetal materials are also candidates for tuning thermodynamic and kinetic properties [145-149]. Yu et al. [145] synthesized carbon nanotubes-doped $\mathrm{LiBH}_{4}$, and found that $\mathrm{Li}_{2} \mathrm{C}_{2}$ phase was generated during the dehydrogenation process. The $\mathrm{Li}_{2} \mathrm{C}_{2}$ could be transformed into $\mathrm{LiH}$ during rehydrogenation process, which contributed to the cycle capacity to a certain extent. Cai et al. [146] investigated the destabilization effect of $\mathrm{H}_{3} \mathrm{BO}_{3}, \mathrm{HBO}_{2}$, and $\mathrm{B}_{2} \mathrm{O}_{3}$ on $\mathrm{LiBH}_{4}$ and observed $5.8 \mathrm{wt} \%$ hydrogen releasing of $\mathrm{H}_{3} \mathrm{BO}_{3}$-doped composite at $110^{\circ} \mathrm{C}$. This im- provement was ascribed to the $\mathrm{H}^{+}-\mathrm{H}^{-}$coupling mechanism, with the evidence of limited enhancement in $\mathrm{B}_{2} \mathrm{O}_{3}-\mathrm{LiBH}_{4}$ composite. Recently, Dolotko et al. [147] investigated $\mathrm{Li} / \mathrm{NaBH}_{4}-\mathrm{Si}_{2} \mathrm{~S}_{2}$ systems and found that $\mathrm{Li}_{x} \mathrm{SiS}_{2}\left(\mathrm{BH}_{4}\right)_{x}$ phase was formed due to readily reaction between $\mathrm{Si}_{2} \mathrm{~S}_{2}$ and borohydrides. The $\mathrm{S}^{-}$ion coordinated with $\mathrm{BH}_{4}^{-}$and terminated by $\mathrm{Li}^{+}$. The $6 \mathrm{LiBH}_{4}-\mathrm{SiS}_{2}$ system exhibited onset desorption temperature of $92^{\circ} \mathrm{C}$, with an initial capacity of $8.2 \mathrm{wt} \%$.

Like Mg-based materials, metal and metal compounds are also promising candidates as the additives [150-172]. Yang et al. [154] milled $\mathrm{LiBH}_{4}$ with a serious of metal/ metal hydrides, and the $\mathrm{Mg}, \mathrm{MgH}_{2}, \mathrm{Al}$ and $\mathrm{CaH}_{2}$-doped composites displayed changed reaction pathways in de-/ re-hydrogenation processes. The $\mathrm{MgH}_{2}-\left(\mathrm{LiBH}_{4}\right)_{2}$ and $\mathrm{Al}-$ $\left(\mathrm{LiBH}_{4}\right)_{2}$ composites exhibited reversible capacities of 10.2 and $6.7 \mathrm{wt} \%$, respectively. Garroni et al. [164] investigated the phase transformation in dehydrogenation of $\mathrm{NaBH}_{4}-\mathrm{MgH}_{2}$ system by in-situ synchrotron XRD method. They found that the $\mathrm{MgH}_{2}$ decomposed to $\mathrm{Mg}$ metal, which was then reacted with the $\mathrm{NaBH}_{4}$ derived intermediate compounds to produce $\mathrm{MgB}_{2}$. Li et al. [155] further investigated $\mathrm{LiBH}_{4}-\mathrm{CaH}_{2}$ composite, the measured enthalpy was almost $60 \mathrm{~kJ} \mathrm{~mol}^{-1} \mathrm{H}_{2}, 14 \mathrm{~kJ} \mathrm{~mol}^{-1} \mathrm{H}_{2}$ lower than pure $\mathrm{LiBH}_{4}$. With the addition of $\mathrm{TiCl}_{3}$, the capacity could reach $7.1 \mathrm{wt} \%$ after 10 cycles. Xia et al. [152] wrapped $\mathrm{MgH}_{2}-\left(\mathrm{LiBH}_{4}\right)_{2}$ composites in graphene, in which the confinement effect further improved the reversibility and cycle properties. The LBMH80@G composite could remain $8.9 \mathrm{wt} \%$ capacity even after 25 cycles (Fig. 7). Yu et al. [157] investigated the destabilization of $\mathrm{LiBH}_{4}$ by various oxides. It was found that the $\mathrm{Fe}_{2} \mathrm{O}_{3}$-doped composite demonstrated the best performance and desorbed $6 \mathrm{wt} \% \mathrm{H}_{2}$ at $200^{\circ} \mathrm{C}$. Moreover, they speculated the decomposition of $\mathrm{LiBH}_{4} /$ oxide system should follow the formula of $x \mathrm{LiBH}_{4}+\mathrm{M}_{y} \mathrm{O}_{z} \rightarrow \mathrm{Li}_{x} \mathrm{M}_{y} \mathrm{O}_{z}$ $+x \mathrm{~B}+2 x \mathrm{H}_{2}$. Liu et al. [173] revealed that addition of $\mathrm{Fe}_{2} \mathrm{O}_{3}$ could form $\mathrm{Fe}_{2} \mathrm{O}_{3}-2 \mathrm{LiBH}_{4}$ complex on the interface via the first-principles DFT calculations, which would act as the nucleation site to improve the kinetic properties. Besides single-metal oxides, multi-metal oxides could also improve the hydrogen storage performances, for instance, $\mathrm{NiFe}_{2} \mathrm{O}_{4}$ [174], $\mathrm{NiCo}_{2} \mathrm{O}_{4}$, [158] and $\mathrm{MgFe}_{2} \mathrm{O}_{4}$ [175]. Our group [158] reported $\mathrm{NiCo}_{2} \mathrm{O}_{4}$ nanorods as the additives for improving dehydrogenation performance of $\mathrm{LiBH}_{4}$. The $\mathrm{NiCo}_{2} \mathrm{O}_{4}$ doped composites showed better performance than $\mathrm{NiO}$ or $\mathrm{Co}_{3} \mathrm{O}_{4}$. The mechanism analysis revealed that in-situ formed $\mathrm{Co}(\mathrm{Ni})$ and $\mathrm{Co}-\mathrm{B}(\mathrm{Ni}-\mathrm{B})$ were the actual active catalysts improving the kinetic performance. 
Table 7 Several additives for lightweight borohydride-based hydrogen storage materials

\begin{tabular}{|c|c|c|c|c|c|c|}
\hline Borohydride & Additive & Amount & Dehy. $T_{\text {start }}\left({ }^{\circ} \mathrm{C}\right)$ & Capacity (wt\%) & Capacity (wt\%)/Cycles & Ref. \\
\hline $\mathrm{LiBH}_{4}$ & $\mathrm{LiNH}_{2}$ & $66.7 \mathrm{~mol} \%$ & 250 & $\geq 10$ & / & {$[150]$} \\
\hline $\mathrm{LiBH}_{4}$ & $\mathrm{MgH}_{2}, \mathrm{TiCl}_{3}$ & $\begin{array}{c}50 \mathrm{~mol} \% \\
2-3 \mathrm{~mol} \%\end{array}$ & l & $8-10$ & $8 / 3$ & [151] \\
\hline $\mathrm{LiBH}_{4}$ & $\mathrm{MgH}_{2}$, graphene & l & / & 9.1 & $8.9 / 25$ & {$[152]$} \\
\hline $\mathrm{LiBH}_{4}$ & $\begin{array}{c}\mathrm{MgH}_{2} \\
\mathrm{Ni} / \mathrm{C}\end{array}$ & $\begin{array}{c}33.3 \mathrm{~mol} \% \\
10 \mathrm{wt} \%\end{array}$ & I & 9.3 & $9.27 / 2$ & {$[153]$} \\
\hline $\mathrm{LiBH}_{4}$ & $\mathrm{Al}$ & $33.3 \mathrm{~mol} \%$ & 320 & 6.3 & $3.8 / 3$ & {$[154]$} \\
\hline $\mathrm{LiBH}_{4}$ & $\begin{array}{l}\mathrm{CaH}_{2} \\
\mathrm{TiCl}_{3}\end{array}$ & $\begin{array}{c}14.3 \mathrm{~mol} \% \\
1 \mathrm{~mol} \%\end{array}$ & l & 11.7 & $7.1 / 10$ & {$[155]$} \\
\hline $\mathrm{LiBH}_{4}$ & $\begin{array}{l}\mathrm{CeH}_{2}, \\
\mathrm{TiCl}_{3}\end{array}$ & $\begin{array}{l}13.9 \mathrm{~mol} \% \\
2.78 \mathrm{~mol} \%\end{array}$ & / & 6.1 & / & [156] \\
\hline $\mathrm{LiBH}_{4}$ & Carbon nanotubes & $33.3-66.7 \mathrm{wt} \%$ & 250 & 8.3 & $3.8 / 2$ & {$[145]$} \\
\hline $\mathrm{LiBH}_{4}$ & $\mathrm{SiS}_{2}$ & $14.3 \mathrm{~mol} \%$ & 92 & 8.2 & $2.4 / 2$ & {$[147]$} \\
\hline $\mathrm{LiBH}_{4}$ & $\begin{array}{l}\text { Ionic liquid } \\
\text { bmimNTf }_{2}\end{array}$ & I & 160 & I & l & {$[148]$} \\
\hline $\mathrm{LiBH}_{4}$ & $\mathrm{H}_{3} \mathrm{BO}_{3}$ & $33.3 \mathrm{~mol} \%$ & 110 & 5.8 & l & {$[146]$} \\
\hline $\mathrm{LiBH}_{4}$ & $\mathrm{Fe}_{2} \mathrm{O}_{3}$ & $66.7 \mathrm{wt} \%$ & $<100$ & $\sim 6$ & I & {$[157]$} \\
\hline $\mathrm{LiBH}_{4}$ & $\mathrm{NiCo}_{2} \mathrm{O}_{4}$ & $50 \mathrm{wt} \%$ & 80 & 12 & I & {$[158]$} \\
\hline $\mathrm{LiBH}_{4}$ & $\mathrm{TiCl}_{3}$ & $25 \mathrm{~mol} \%$ & 100 & 6.4 & $4.0 / 2$ & [159] \\
\hline $\mathrm{LiBH}_{4}$ & $\mathrm{TiF}_{3}$ & $0.1 \mathrm{~mol} \%$ & l & 12 & $6.0 / 2$ & [160] \\
\hline $\mathrm{LiBH}_{4}$ & $\mathrm{GdF}_{3}$ & $25 \mathrm{~mol} \%$ & 112 & 3.50 & $1.96 / 50$ & {$[161]$} \\
\hline $\mathrm{LiBH}_{4}$ & Fluorinated graphene & $20 \mathrm{wt} \%$ & 204 & 10.01 & $3.2 / 4$ & [149] \\
\hline $\mathrm{LiBH}_{4}$ & $\mathrm{MoS}_{2}$ & $50 \mathrm{wt} \%$ & 171 & 5.6 & I & {$[162]$} \\
\hline $\mathrm{NaBH}_{4}$ & $\mathrm{NaNH}_{2}$ & $50 \mathrm{~mol} \%$ & 227 & $6-7.7$ & l & {$[163]$} \\
\hline $\mathrm{NaBH}_{4}$ & $\mathrm{MgH}_{2}$ & $33.3 \mathrm{wt} \%$ & 320 & 7.9 & / & {$[164]$} \\
\hline $\mathrm{NaBH}_{4}$ & $\mathrm{Ni}$ & I & 50 & 5 & $5 / 5$ & [165] \\
\hline $\mathrm{NaBH}_{4}$ & $\mathrm{TiF}_{3}$ & $5 \mathrm{~mol} \%$ & 380 & 8.4 & $4.0 / 2$ & {$[166]$} \\
\hline $\mathrm{NaBH}_{4}$ & $\mathrm{NbF}_{3}$ & $25 \mathrm{~mol} \%$ & 80 & 3.40 & $3.3 / 2$ & {$[167]$} \\
\hline $\begin{array}{c}\mathrm{NaBH}_{4}^{-} \\
\mathrm{Mg}\left(\mathrm{BH}_{4}\right)_{2}\end{array}$ & $\begin{array}{l}\text { fluoro- } \\
\text { graphene }\end{array}$ & $40 \mathrm{wt} \%$ & 114.9 & 6.9 & l & {$[178]$} \\
\hline $\mathrm{Mg}\left(\mathrm{BH}_{4}\right)_{2}$ & $\mathrm{LiNH}_{2}$ & $50 \mathrm{~mol} \%$ & 160 & 7.2 & I & {$[168]$} \\
\hline $\operatorname{Mg}\left(\mathrm{BH}_{4}\right)_{2}$ & $\mathrm{TiCl}_{3}$ & 25 wt $\%$ & 88 & 13.3 & l & {$[169]$} \\
\hline $\operatorname{Mg}\left(\mathrm{BH}_{4}\right)_{2}$ & $\mathrm{ScCl}_{3}, \mathrm{TiF}_{3}$ & $5 \mathrm{~mol} \%$ & I & 13 & l & {$[170]$} \\
\hline $\mathrm{Mg}\left(\mathrm{BH}_{4}\right)_{2}$ & Co-based compounds & $2 \mathrm{~mol} \%$ & 100 & 4 & $2.0 / 2$ & {$[171]$} \\
\hline $\mathrm{Mg}\left(\mathrm{BH}_{4}\right)_{2}$ & $\mathrm{LiBF}_{4}$ & l & $<90$ & 9.21 & l & {$[172]$} \\
\hline
\end{tabular}

Metal halides are also potential additives for borohydrides. Both metal cation and halide anion can influence the de/rehydrogenation. Christian et al. [165] doped $\mathrm{NiCl}_{2}$ to $\mathrm{NaBH}_{4}$, where the $\mathrm{Ni}^{2+}$ was reduced by $\mathrm{BH}_{4}^{-}$and Ni metal coating formed on $\mathrm{NaBH}_{4}$ particle surface. This core-shell strategy improved the kinetic performance and reversibility. Au et al. [160] ball-milled $\mathrm{LiBH}_{4}$ with eight different halides, and they found that $\mathrm{TiCl}_{3}, \mathrm{TiF}_{3}$, and $\mathrm{ZnF}_{2}$ significantly reduced the dehydrogenation tem- perature and enhanced the reversibility. They found that the improved performance was ascribed to the cation exchange reaction with $\mathrm{LiBH}_{4}$ as well as the formation of unstable transition metal borohydrides. Yin et al. [176] investigated the influence of doping $\mathrm{LiBH}_{4}$ with $\mathrm{F}$ anion by first principles calculations, and found that $\mathrm{F}$ anion could substitute both hydrogenated $\left(\mathrm{LiBH}_{4}\right)$ and dehydrogenated $(\mathrm{LiH})$ states, which resulted in the enhanced thermodynamic properties. Guo et al. [159] investigated 

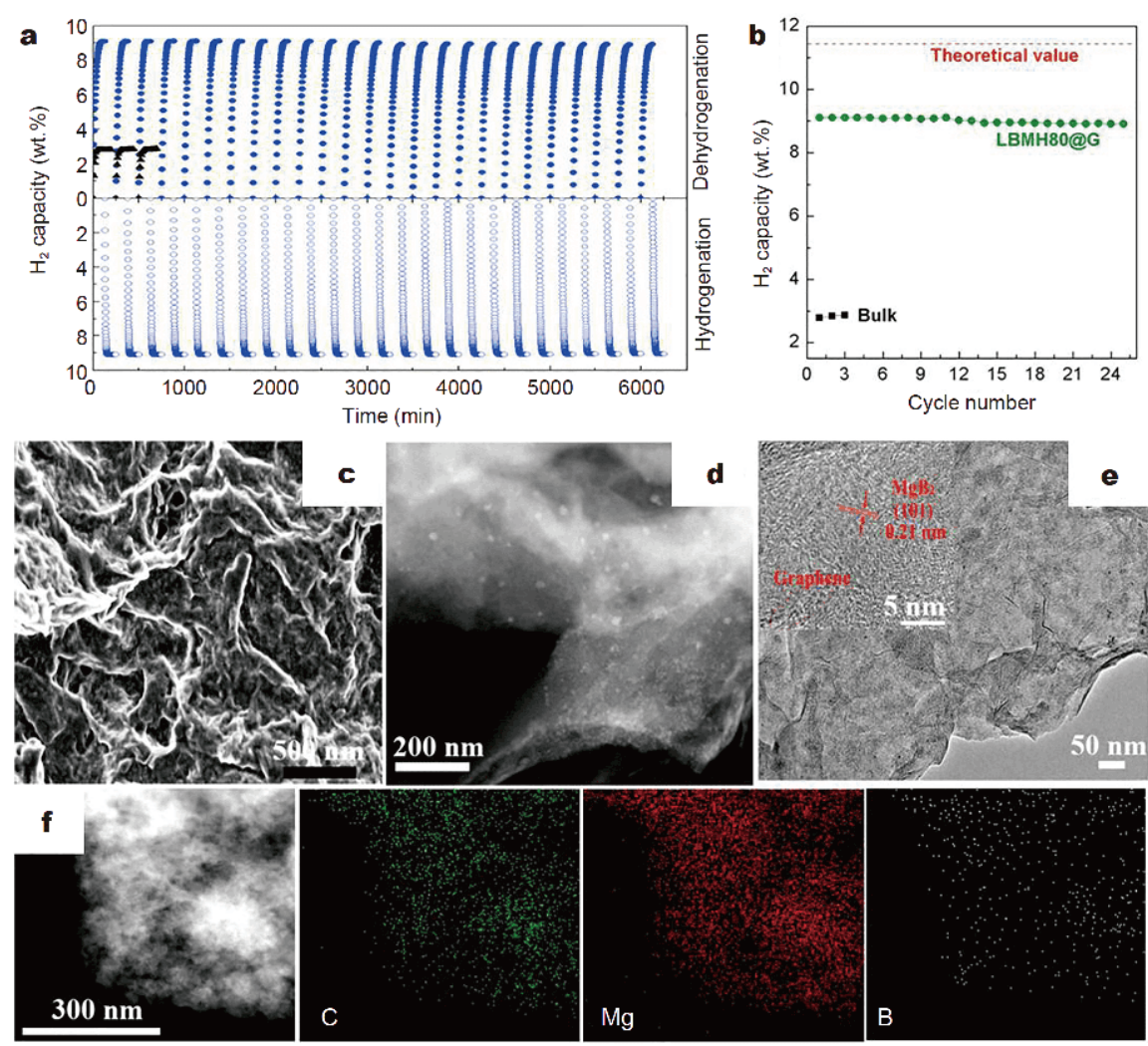

Figure 7 (a) Long-term cycling performance of the dehydrogenation (under a back pressure of $0.3 \mathrm{MPa}$ ) and hydrogenation for LBMH80@G and bulk $2 \mathrm{LiBH}_{4}-\mathrm{MgH}_{2}$ composite at $350^{\circ} \mathrm{C}$; (b) normalized $\mathrm{H}_{2}$ capacity as a function of cycle number, where the hydrogen capacities are normalized to the theoretical value of $2 \mathrm{LiBH}_{4}-\mathrm{MgH}_{2}$ composite; (c) SEM, (d) scanning TEM (STEM), and (e) TEM images, with the inset containing a high resolution TEM (HRTEM) image LBMH80@G after 15 cycles of dehydrogenation; and (f) elemental mapping of LBMH80@G after 15 cycles of hydrogenation. The $\mathrm{H}_{2}$ capacity is expressed here per mass of the whole composite. Reproduced with permission from Ref. [152]. Copyright 2016, Elsevier Ltd.

the $\mathrm{LiBH}_{4}-\mathrm{TiF}_{3}$ system and confirmed that the $\mathrm{TiB}_{2}$ and $\mathrm{LiF}$ formed during dehydrogenation, which affected the reaction enthalpy. Chong et al. [161] introduced several lanthanide elements fluorides into $\mathrm{NaBH}_{4}$, and observed that the $3 \mathrm{NaBH}_{4}-\mathrm{GaF}_{3}$ composites displayed a fast kinetics and remained high cycling stability even after 51 cycles. Richter et al. [177] reported that milling with $\mathrm{LiBF}_{4}$ could significantly decrease the decomposition temperature of $\mathrm{LiBH}_{4}$, but only diborane gas was released during this process. Zheng et al. [178] ball-milled $\mathrm{NaBH}_{4}$ and $\mathrm{Mg}\left(\mathrm{BH}_{4}\right)_{2}$ with fluorographene. The composite could release $6.9 \mathrm{wt} \%$ hydrogen at $114.9^{\circ} \mathrm{C}$ in seconds (Fig. 8), but the dehydrogenated product $\mathrm{NaMgF}_{3}$ could hardly reverse into borohydrides.

Compared to metal hydrides, the interaction between borohydrides and additives is more complicated. The additives can act as catalysts or in-situ generated catalytic products to enhance the kinetic properties; they can also change the reaction pathway, affect the thermodynamic and cycle properties. However, this strategy is limited by drawbacks such as high cost, the loss of capacity and phase separation during cycles. Further theoretical and experimental studies on both additives and assembly method are needed to realize practical application.

\section{LIGHTWEIGHT METAL ALANATES}

Lightweight metal alanates with general formula of $\mathrm{M}\left(\mathrm{AlH}_{4}\right)_{n}$ have been widely investigated, since Bogdanović et al. [179] discovered that Ti-doped $\mathrm{NaAlH}_{4}$ could reversibly absorb and release hydrogen. However, it is difficult to release and absorb hydrogen due to the strong covalent bonds of $\mathrm{Al}-\mathrm{H}$. The inferior reversibility, high desorption temperature and sluggish de-/rehydrogenation kinetics hinder the application for rechargeable hydrogen devices. Considerable efforts have been made to explore the hydrogenation and dehydrogenation performances of lightweight metal alanates [180-185]. Many effective approaches have been proposed to enhance hy- 


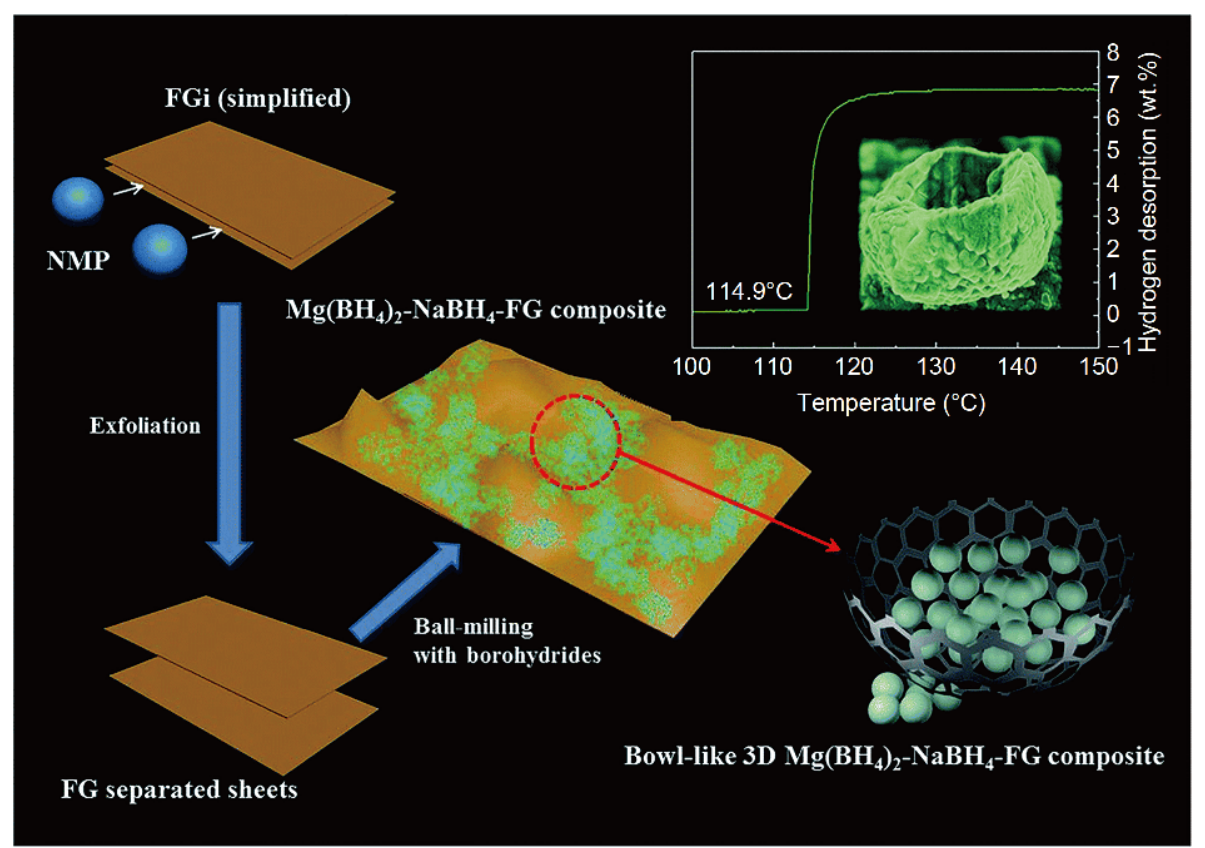

Figure 8 Illustration of the formation mechanism of the 3D bowl-like $\mathrm{Mg}\left(\mathrm{BH}_{4}\right)_{2}-\mathrm{NaBH}_{4}$-FG composite. Reproduced with permission from Ref. [178]. Copyright 2017, the Royal Society of Chemistry.

drogen storage performances by nanoscaling [186,187], wet chemistry infiltration [188-190], adding dopants [191-195], and mixing in the lightweight metal hydride [189,196-198]. In this part, we will summarize the challenges and progresses of lightweight metal alanates and focus on the effects of nanoscaling and multifarious dopants.

\section{Nanoscaling}

Nanoscaling appears to be an effective strategy for improving the hydrogen storage properties of lightweight metal alanates, such as $\mathrm{NaAlH}_{4}$ and $\mathrm{LiAlH}_{4}$ [199-201]. Gutowska et al. [202] reported that hydrogen desorption properties of ammonia borane could be dramatically promoted through confining it into high-surface-area mesoporous silica SBA15. The enhanced hydrogenation and dehydrogenation properties were influenced by the size of lightweight metal alanates [203]. Nanoscaling strategy can lead to the reduction in particle size and hydrogen diffusion path length, increasing the hydrogen diffusion rate and nucleation sites for dehydrogenation and hydrogenation. Table 8 summarizes the nanoscaling strategies, scaffolds, and the hydrogen storage performances of lightweight metal alanates.

In general, effective nanoscaling strategies can be achieved using high energy ball milling (HEBM) [204,205] and NC [206-208] techniques. In HEBM technique, the collision and fracture effects can result in the reduction of particle size. However, porous materials can also be destructed due to drastic collision among balls, tank and powder during ball milling, and coldwelding effect may lead to an increase of particle size. Varin et al. [204] reported that average equivalent circle diameter particle size of $\mathrm{LiAlH}_{4}$ ball-milled for $2 \mathrm{~h}$ reduced to $2.8 \pm 2.3 \mu \mathrm{m}$, which was much smaller than the original particle size $(9.9 \pm 5.2 \mu \mathrm{m})$ of commercial $\mathrm{LiAlH}_{4}$. Ball milled $\mathrm{LiAlH}_{4}$ could release $7.1 \mathrm{wt} \% \mathrm{H}_{2}$ at $120^{\circ} \mathrm{C}$ under $0.1 \mathrm{MPa} \mathrm{H}_{2}$. In $\mathrm{NC}$ techniques, including melt infiltration and solvent infiltration, many kinds of porous nanoscaffolds, such as $\mathrm{CeO}_{2}$ hollow nanotubes, mesoporous silica, porous carbon and MOFs have been intensively applied [190,200,208-210].

Melt infiltration can be applied as a conventional NC technique when melting point of lightweight metal hydrides is lower than the decomposition temperature of porous scaffolds. This means porous nanoscaffolds should be stable hosts and capable of providing high reactivity of alanates in molten state during de-/hydrogenation processes. Stephens et al. [211] loaded $\mathrm{NaAlH}_{4}$ into nanoporous carbon aerogel (NCA) with pore diameter of $13 \mathrm{~nm}$ by melt infusion method. The uncatalyzed $\quad \mathrm{NaAlH}_{4} @$ aerogel exhibited lower dehydrogenation temperature $\left(150^{\circ} \mathrm{C}\right)$ and faster dehydrogenation kinetics than bulk uncatalyzed $\mathrm{NaAlH}_{4}$, and 
Table 8 Hydrogen storage properties of nanoconfined lightweight metal alanates in porous materials

\begin{tabular}{|c|c|c|c|c|c|c|c|}
\hline Alanate & Scaffold & $\begin{array}{c}\text { Nanoscaling } \\
\text { strategy }\end{array}$ & $\begin{array}{c}\text { Loading } \\
\text { (wt } \%)\end{array}$ & $\begin{array}{l}\text { Dehy. } \\
T\left({ }^{\circ} \mathrm{C}\right)\end{array}$ & $\begin{array}{c}\text { Rehy. T }\left({ }^{\circ} \mathrm{C}\right) / \\
P\left(\mathrm{MPa} \mathrm{H}_{2}\right)\end{array}$ & $\begin{array}{l}\text { Dehy. content: } \\
(\mathrm{wt} \%)\end{array}$ & Ref. \\
\hline $\mathrm{LiAlH}_{4}$ & I & Ball-milling & I & 120 & I & 7.1 & [204] \\
\hline $\mathrm{NaAlH}_{4}$ & $\mathrm{NC}$ & Melt & $5-80$ & 170 & $150 / 55$ bar & 3.3 & {$[199]$} \\
\hline $\mathrm{NaAlH}_{4}$ & $\mathrm{NCA}$ & Melt & 48.6 & 150 & $160 / 100 \mathrm{bar}$ & 4.76 & {$[211]$} \\
\hline $\mathrm{NaAlH}_{4}$ & $\mathrm{MC}$ & Melt & 26 & 180 & $150 / 7$ & 5.0 & {$[209]$} \\
\hline $\mathrm{NaAlH}_{4}$ & Ti-OMCs & Melt & 33.3 & 160 & 120/101 bar & 2.15 & {$[206]$} \\
\hline $\mathrm{NaAlH}_{4}$ & Ti-MOF74 & Melt & 21 & 200 & $160 / 10.5$ & 4.1 & [187] \\
\hline $\mathrm{NaAlH}_{4}$ & $\mathrm{CeO}_{2}$ & Melt & 50 & 180 & I & 5.10 & {$[190]$} \\
\hline $\mathrm{LiAlH}_{4}$ & Ni-MCS & Melt & 45 & 225 & I & 6.19 & [182] \\
\hline $\mathrm{NaAlH}_{4}$ & $\begin{array}{l}\text { Ordered meso- } \\
\text { porous silica } \\
\text { (OMS) }\end{array}$ & Solvent & 20 & 180 & $150 / 5.5$ & 5 & {$[208]$} \\
\hline $\mathrm{NaAlH}_{4}$ & MOFs & Solvent & 4 & 155 & I & 4.48 & {$[213]$} \\
\hline $\mathrm{LiAlH}_{4}$ & $\begin{array}{l}\text { High surface area } \\
\text { graphite (HSAG) }\end{array}$ & Solvent & 22 & I & $300 / 7$ & 0.6 & {$[200]$} \\
\hline
\end{tabular}

was readily rehydrogenated to $4.76 \mathrm{wt} \%$ hydrogen at approximately $160^{\circ} \mathrm{C}$ under 100 bar $\mathrm{H}_{2}$. Above results indicated that confining the $\mathrm{NaAlH}_{4}$ into nanoscale within aerogel pores by melt infusion was responsible for the enhanced dehydrogenation and rehydrogenation performances. A typical procedure of melt infiltration is illustrated in Fig. 9 [209]. $\mathrm{NaAlH}_{4}$ loaded in ordered mesoporous carbon (MC) was prepared by melt infusion and de-/rehydrogenation. For the space-confined $\mathrm{NaAlH}_{4} / \mathrm{MC}$, the activation energy $\left(E_{a}\right)$ for dehydrogenation was decreased to $46 \pm 5 \mathrm{~kJ} \mathrm{~mol}^{-1}$ and the capacity remained more than $80 \%$ after 15 cycles.

Xiong et al. [206] reported the hydrogen storage properties of $\mathrm{NaAlH}_{4}$ with Ti-loaded high-ordered me- a

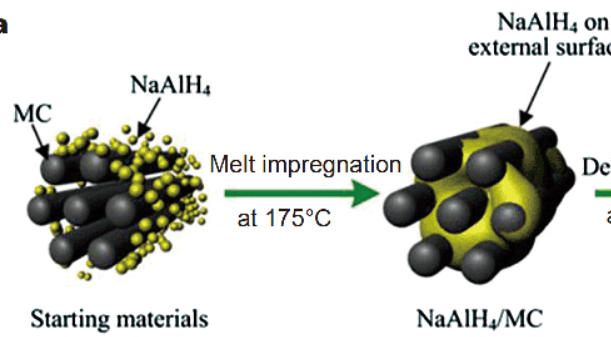

Starting materials

b

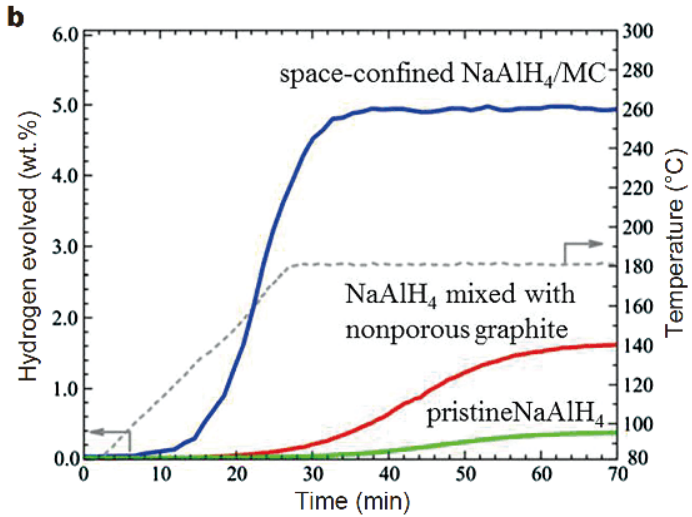

Al aggregates plus $\mathrm{NaH} \quad$ Unreacted $\mathrm{Al}$ aggregates plus on external surfaces $\quad \mathrm{NaH}$ on external surfaces

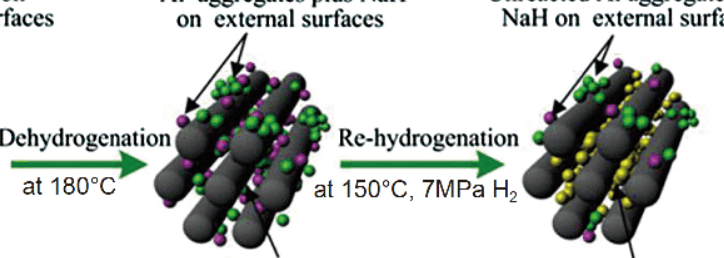

$\mathrm{NaH}$ plus $\mathrm{Al}$ on internal surfaces

Regenerated $\mathrm{NaAlH}_{4}$ on internal surfaces

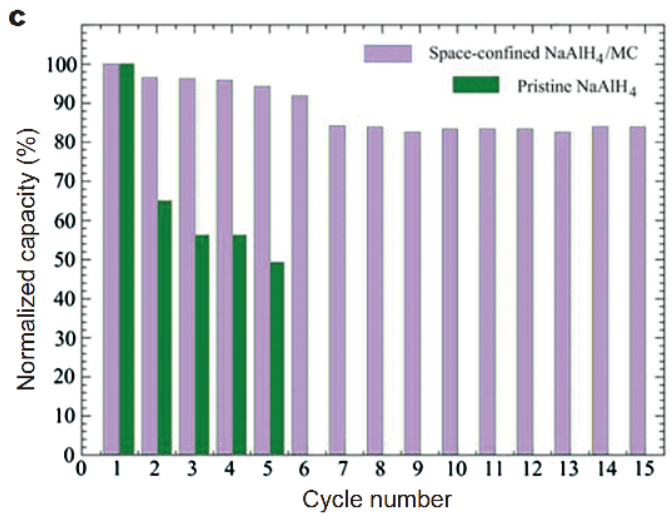

Figure 9 (a) Schematic illustrations of preparation process of $\mathrm{NaAlH}_{4}$ exclusively confined in $\mathrm{MC}$, (b) initial dehydrogenation curves of the samples and (c) the normalized hydrogen capacity pattern upon multiple cycling. Reproduced with permission from Ref. [209]. Copyright 2011, Elsevier. 
soporous carbons (Ti-OMCs). The dehydrogenation temperature was reduced to about $60^{\circ} \mathrm{C}$, and approximately $80 \% \mathrm{H}_{2}$ was released after 11 de-/rehydrogenation cycles within $20 \mathrm{~min}$. In addition, the dehydrogenated sample could be rehydrogenated at $120^{\circ} \mathrm{C}$ under 101 bar hydrogen pressure, demonstrating excellent reversibility and stability. Recently, Carr et al. [212] reported that $\mathrm{NaAlH}_{4}$ melt infiltrated into nitrogen-doped nanoporous carbon frameworks exhibited a lowered $E_{a}$ value for dehydrogenation by $70 \mathrm{~kJ} \mathrm{~mol}^{-1}$, larger than the decrease in nonfunctionalized carbons. However, an anomalous and unexpected hydrogen desorption rate appeared with a remarkably lowered $E_{a}$ value in the $\mathrm{N}$-doped nanoporous carbon frameworks. This indicated that existence of nitrogen may prevent the formation of $\mathrm{H}_{2}$ at the interface between hydride and nanoporous carbon frameworks, meanwhile a rate-limiting step for desorption may be related to the nitrogen doping in the nanoporous carbon frameworks. More interestingly, $\mathrm{NaAlH}_{4}$ confined into $\mathrm{CeO}_{2}$ hollow nanotubes (HNTs) showed dramatically enhanced dehydrogenation properties [190]. Approaximately $5.51 \mathrm{wt} \% \mathrm{H}_{2}$ could be rapidly released at $180^{\circ} \mathrm{C}$ within $30 \mathrm{~min}$. The significant reduction in the $E_{a}$ $\left(76.32 \mathrm{~kJ} \mathrm{~mol}^{-1}\right)$ immediately testified the enhancement of the hydrogen release kinetics owing to the synergistic effects contributed by the $\mathrm{CeO}_{2}$ HNTs, which served as a hollow scaffold material to confine the hydride and as an additive to improve the dehydrogenation properties.

Solvent infiltration is usually carried out under mild conditions compared with melt infiltration. The solvents such as tetrahydrofuran (THF) or methyl tert-butyl ether (MTBE) are required to be able to dissolve alanates so as to form a homogeneous solution. Next, porous nanoscaffold is impregnated in the homogeneous solution and all the pores should be entirely infiltrated by the solution. After that, the solvent can be removed by evaporation and alanates solidify to generate nano-sized particles in the pores.

In 2008, THF solvent mediated infiltration was carried out by loading $\mathrm{NaAlH}_{4}$ into the as-synthesized OMS [208] with $10 \mathrm{~nm}$ in diameter. The de-/re-hydrogenation temperatures were reduced and hydrogen absorption/ desorption kinetics was remarkably promoted. As shown in Fig. 10, the pristine $\mathrm{NaAlH}_{4}$ desorbed negligible hydrogen at $150 / 180^{\circ} \mathrm{C}$, only $0.3 \mathrm{wt} \% \mathrm{H}_{2}$ could be released at $180^{\circ} \mathrm{C}$. For OMS confined $\mathrm{NaAlH}_{4}$, the capacity could reach $3.0 \mathrm{wt} \%$. Besides, the rehydrogenation in a dehydrogenated $\mathrm{NaAlH}_{4} / \mathrm{OMS}$ could be achieved even under milder conditions $\left(125-150^{\circ} \mathrm{C}, 3.5-5.5 \mathrm{MPa}\right.$ hydrogen), $0.9 \mathrm{wt} \% \mathrm{H}_{2}$ capacity could be achieved at the second cycle, while the pristine $\mathrm{NaAlH}_{4}$ could hardly be rehydrogenated under the same situation (less than $0.1 \mathrm{wt} \%$
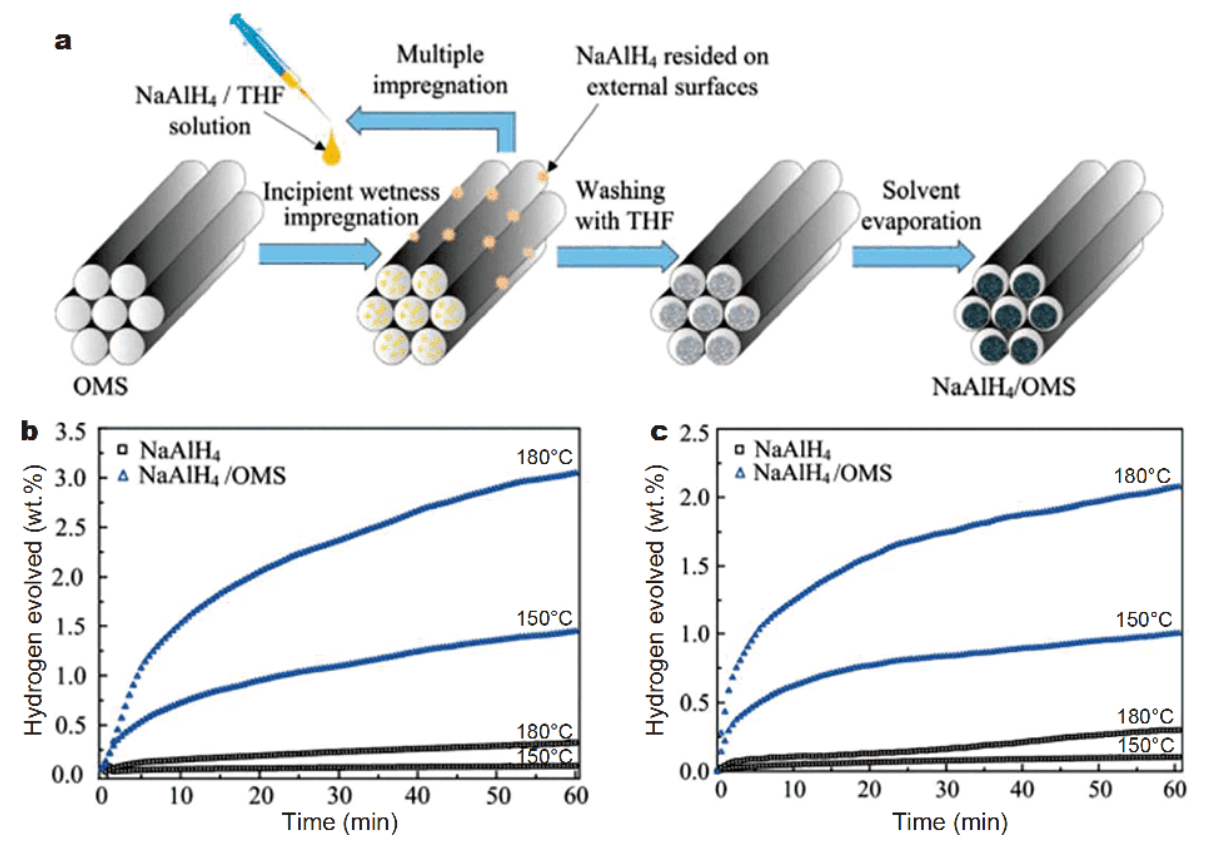

Figure 10 (a) Schematic illustrations of $\mathrm{NaAlH}_{4}$ confined in OMS by solvent mediated infiltration. Dehydrogenation curves for (b) the pristine $\mathrm{NaAlH}_{4}, \mathrm{NaAlH}_{4} / \mathrm{OMS}$ and (c) the rehydrogenated $\left(150^{\circ} \mathrm{C}\right.$ and $5.5 \mathrm{MPa} \mathrm{H}_{2}$ pressure) samples at 150 and $180^{\circ} \mathrm{C}$. Reproduced with permission from Ref. [208]. Copyright 2008, American Chemical Society. 
$\mathrm{H}_{2}$ ). These excellent properties were ascribed to that the $\mathrm{NaAlH}_{4}$ particles and the dehydrogenated products of $\mathrm{Al}$ and $\mathrm{NaH}$ were controlled to be nanoscale under the confined effect of the OMS pores. Bhakta et al. [213] successfully encapsulated $\mathrm{NaAlH}_{4}$ in MOF (HKUST-1) by a wet chemical approach. The onset dehydrogenation temperature of $\mathrm{NaAlH}_{4} / \mathrm{MOF}$ reduced about $70^{\circ} \mathrm{C}$. About $80 \%$ of the total $\mathrm{H}_{2}$ was released at $155^{\circ} \mathrm{C}$; however, pristine $\mathrm{NaAlH}_{4}$ released $70 \%$ of the total hydrogen at $250^{\circ} \mathrm{C}$

Christian et al. [214] infiltrated the $\mathrm{NaAlH}_{4}$ and $\mathrm{LiAlH}_{4}$ into carbon nanotubes (CNT) with a diameter of $10 \mathrm{~nm}$. The loading amount of lightweight metal alanates was less than $6 \mathrm{wt} \%$. For $\mathrm{LiAlH}_{4}$ encapsulated in CNT, dehydrogenation started at the sub-ambient condition. In addition, dehydrogenation peak was observed at $120^{\circ} \mathrm{C}$ and hydrogen release was absolutely completed by $250^{\circ} \mathrm{C}$. The activation energy of dehydrogenation process from $\mathrm{LiAlH}_{4}-\mathrm{CNT}$ was remarkably reduced $64 \pm 5 \mathrm{~kJ} \mathrm{~mol}^{-1}$, a decrease of $18 \mathrm{~kJ} \mathrm{~mol}^{-1}$ from $82 \mathrm{~kJ} \mathrm{~mol}^{-1}$ of bulk $\mathrm{LiAlH}_{4}$. In addition, ordered mesoporous carbon CMK-3 was also applied as a scaffold for $\mathrm{LiAlH}_{4}$. Unfortunately, nanoscale aluminum oxide was generated inside the CMK-3 of reaction products rather than a metal or alloy [188]. Recently, HSAG was applied to confine $\mathrm{LiAlH}_{4}$ with a saturated THF solution [200]. Upon nanoconfinement in HSAG, the particle size of $\mathrm{LiAlH}_{4}$ was reduced to 3-15 $\mathrm{nm}$. In addition, there were some residual solvent in the $\mathrm{LiAlH}_{4}$ nanoconfined in HSAG, which led to the formation of the $\mathrm{LiAlH}_{4} \cdot n$ THF with the strong bonding between $\mathrm{LiAlH}_{4}$ and THF. The initial hydrogen release temperature was $100^{\circ} \mathrm{C}$. A reversibly capacity of $0.6 \mathrm{wt} \%$ was obtained at $300^{\circ} \mathrm{C}$ under $7 \mathrm{MPa}$, which was about $30 \%$ of the capacity of $\mathrm{LiAlH}_{4}$ nanoconfined in HSAG. However, low capacity and inferior dynamics hinder the development of nanoscaling strategies. Therefore, effective strategies should be proposed to enhance the hydrogen storage properties of lightweight metal alanates systems.

\section{Adding dopants}

Introduction of suitable dopants is also an effective approach to improve the hydrogen storage properties of lightweight metal alanates systems. An extensive variety of dopants, such as transition metals, rare-earth metals, carbon materials and co-dopants additives, have been surveyed during the last two decades [183,215-217]. Several doping strategies, such as wet doping and highenergy ball milling have been presented for the preparation of additive-doped lightweight metal alanates. How- ever, introducing Ti-based species into $\mathrm{NaAlH}_{4}$ in diethyl ether solutions by the wet-doping approach is considerably complicated [179]. In contrast, ball milling is the most common approach for the introduction of dopants as it can achieve homogeneous distribution of dopant in lightweight metal alanates and realize close contact between dopant and hydrides. Table 9 summarizes the hydrogen storage performances of additivedoped lightweight metal alanates.

At present, Ti-based compounds are the mostly used and highly active dopants for increasing the hydrogen storage properties of lightweight metal alanates. Bogdanović et al. [179] firstly synthesized the $\mathrm{Ti}(\mathrm{OBu})_{4}$ and $\mathrm{TiCl}_{3}$-doped $\mathrm{NaAlH}_{4}$ which could be rehydrogenated at $170^{\circ} \mathrm{C}$ under $15.2 \mathrm{MPa}$ and a reversible $\mathrm{H}_{2}$ capacity of $4.2 \mathrm{wt} \%$ was obtained. Through mechanically mixing $\mathrm{Ti}(\mathrm{OBu})_{4}$ with $\mathrm{NaAlH}_{4}$, the dehydrogenation temperature reduced and capacity of rehydrogenation increased [218]. However, the heavy weight of the additive and gas impurities contamination restricts further application of hydrides.

Up to now, Ti-based halides have been extensively studied as dopants for enhancing de-/rehydrogenation properties [219-226]. Sandrock et al. [219] reported that $\mathrm{NaAlH}_{4}$ ball-milled with $\mathrm{TiCl}_{3}$ dopant could release $3 \mathrm{wt} \% \mathrm{H}_{2}$ and absorb $4.2 \mathrm{wt} \% \mathrm{H}_{2}$ in $60 \mathrm{~min}$ at $125^{\circ} \mathrm{C}$ under 91 bar hydrogen pressure. Wang et al. [220] demonstrated the catalytic property of $\mathrm{TiF}_{3}$ additive was superior to $\mathrm{TiCl}_{3}$ in the reversible hydrogen storage of $\mathrm{NaAlH}_{4} \cdot \mathrm{TiF}_{3}$-containing composite displayed a more significant kinetics improvement and a higher reversible hydrogen capacity than the $\mathrm{TiCl}_{3}$-containing composite. $\mathrm{TiF}_{3}$-doped $\mathrm{NaAlH}_{4}$ was able to absorb approximately $3.4 \mathrm{wt} \% \mathrm{H}_{2}$ in $10 \mathrm{~h}$ at $60^{\circ} \mathrm{C}$ under 110 bar hydrogen pressure. However, $\mathrm{TiCl}_{3}$-containing sample absorbed only $3.2 \mathrm{wt} \% \mathrm{H}_{2}$ even in more than $10 \mathrm{~h}$ at $80^{\circ} \mathrm{C}$. In 2010 , Langmi et al. [221] revealed that the decomposition temperature of $\mathrm{TiCl}_{3}$-doped $\mathrm{LiAlH}_{4}$ was reduced approximately $60-75^{\circ} \mathrm{C}$ lower than that of undoped $\mathrm{LiAlH}_{4}$. The enthalpy of the first hydrogen release of $\mathrm{TiCl}_{3}$-doped $\mathrm{LiAlH}_{4}$ was estimated to be $0.86 \mathrm{~kJ} \mathrm{~mol}^{-1}$. For $10 \mathrm{~mol} \%$ $\mathrm{TiF}_{3}$-doped $\mathrm{Li}_{3} \mathrm{AlH}_{6}$ sample prepared by mechanical ball milling, the onset dehydrogenation temperature was evidently reduced by $60^{\circ} \mathrm{C}$ as compared with that of pristine $\mathrm{Li}_{3} \mathrm{AlH}_{6}$ (around $190^{\circ} \mathrm{C}$ ), and approximately $3.0 \mathrm{wt} \% \mathrm{H}_{2}$ could be released at $120^{\circ} \mathrm{C}$. The apparent $E_{a}$ of $\mathrm{Li}_{3} \mathrm{AlH}_{6}$ dehydrogenation was remarkably reduced by $29 \mathrm{~kJ} \mathrm{~mol}^{-1}$, which was ascribed to in-situ formed highly active $\mathrm{Al}_{3} \mathrm{Ti}$ and $\mathrm{TiH}_{2}$ [222].

Other Ti-based additives, such as $\mathrm{TiO}_{2}, \mathrm{TiH}_{2}, \mathrm{TiC}, \mathrm{TiN}$, 
Table 9 Hydrogen storage properties of additive-doped lightweight metal alanates

\begin{tabular}{|c|c|c|c|c|c|c|c|c|}
\hline \multirow{2}{*}{ Alanate } & \multirow[t]{2}{*}{ Additive } & \multicolumn{2}{|c|}{$\begin{array}{c}\text { Dehy. } \\
\text { non-isothermal }\end{array}$} & \multicolumn{2}{|c|}{ Isothermal } & \multicolumn{2}{|c|}{$\begin{array}{l}\text { Rehy. } \\
\text { isothermal }\end{array}$} & \multirow{2}{*}{ Ref. } \\
\hline & & $T_{\text {start }}\left({ }^{\circ} \mathrm{C}\right)$ & Capacity (wt\%) & $T\left({ }^{\circ} \mathrm{C}\right)$ & Capacity (wt\%) & $T\left({ }^{\circ} \mathrm{C}\right) / P($ bar $)$ & $\begin{array}{c}\text { Capacity } \\
\text { (wt\%)/Cycles }\end{array}$ & \\
\hline $\mathrm{NaAlH}_{4}$ & $\mathrm{Ti}(\mathrm{OBu})_{4}$ & 100 & 5.3 & l & l & $200 / 1600$ psi & $2.12 / 1$ & {$[218]$} \\
\hline $\mathrm{NaAlH}_{4}$ & $\mathrm{TiCl}_{4}$ & I & 1 & 125 & 3 & $125 / 91$ & $4.2 / 5$ & [219] \\
\hline $\mathrm{NaAlH}_{4}$ & $\mathrm{TiF}_{3}$ & / & l & 150 & 4 & $120 / 110$ & $3.7 / 10$ & {$[220]$} \\
\hline $\mathrm{Li}_{3} \mathrm{AlH}_{6}$ & $\mathrm{TiF}_{3}$ & 130 & 3.8 & 120 & 3 & I & I & [222] \\
\hline $\mathrm{KAlH}_{4}$ & $\mathrm{TiF}_{3}$ & 100 & 4.25 & 1 & l & I & I & [226] \\
\hline $\mathrm{LiAlH}_{4}$ & $\begin{array}{c}\mathrm{TiCl}_{3-} \\
\text { MWCNTs }\end{array}$ & 75 & 4.68 & 110 & 3.6 & 1 & / & [223] \\
\hline $\mathrm{NaAlH}_{4}$ & $\mathrm{TiC}$ & I & I & 155 & 3.8 & $120 / 11.5 \mathrm{MPa}$ & $4.77 / 1$ & {$[230]$} \\
\hline $\mathrm{LiAlH}_{4}$ & TiN & 90 & 7.1 & 130 & 7.1 & I & I & {$[234]$} \\
\hline $\mathrm{NaAlH}_{4}$ & $\mathrm{TiB}_{2}$ & 70 & 5.0 & 90 & 3 & $90 / 4 \mathrm{MPa}$ & $2.85 / 2$ & [192] \\
\hline $\mathrm{NaAlH}_{4}$ & $\begin{array}{l}\text { MXene/ } \\
\text { A-TiO }_{2}\end{array}$ & 90 & 5.2 & 140 & 4.8 & $120 / 12 \mathrm{MPa}$ & $4.7 / 5$ & [229] \\
\hline $\mathrm{LiAlH}_{4}$ & $\mathrm{ScCl}_{3}$ & 90 & 5.7 & 150 & 3.6 & I & I & [237] \\
\hline $\mathrm{NaAlH}_{4}$ & $\mathrm{CeAl}_{2}$ & I & I & 160 & 4.7 & $120 / 12 \mathrm{MPa}$ & $4.9 / 1$ & [239] \\
\hline $\mathrm{LiAlH}_{4}$ & $\mathrm{SrFe}_{12} \mathrm{O}_{19}$ & 80 & 6.75 & 130 & 5.54 & I & I & [249] \\
\hline $\mathrm{NaAlH}_{4}$ & $\mathrm{ZrCl}_{4}$ & 145 & 5.6 & 140 & 4.34 & l & I & [250] \\
\hline $\mathrm{NaAlH}_{4}$ & NCNT/NG & I & I & I & l & $180 / 65$ & $1.8 / 5$ & [253] \\
\hline $\mathrm{LiAlH}_{4}$ & MWCNTs & 150 & 6.1 & 120 & 4.0 & I & I & [254] \\
\hline $\mathrm{NaAlH}_{4}$ & $\mathrm{TiCl}_{4}+\mathrm{Zr}$ & l & I & 125 & 4.3 & $125 / 110$ & $4.0 / 1$ & [257] \\
\hline $\mathrm{NaAlH}_{4}$ & $\mathrm{Ti}+\mathrm{KH}$ & l & I & 150 & 4.7 & $120 / 100$ & $4.7 / 10$ & [258] \\
\hline $\mathrm{NaAlH}_{4}$ & $\mathrm{TiO}_{2} @ \mathrm{C}$ & 90 & 4.6 & I & I & $115 / 100$ & $4.5 / 5$ & [228] \\
\hline
\end{tabular}

and $\mathrm{TiB}_{2}$, have also been extensively researched because of their capacity of enhancing de-/rehydrogenation in lightweight metal alanates. $\mathrm{TiO}_{2}$-based additives apparently improved the cycling stability and increased the available hydrogen capacity for $\mathrm{LiAlH}_{4}$ and $\mathrm{NaAlH}_{4}$ [227229]. Zhang et al. [228] reported that $\mathrm{TiO}_{2} @ \mathrm{C}$-doped $\mathrm{NaAlH}_{4}$ started to release hydrogen at around $90^{\circ} \mathrm{C}$ and was entirely reloaded $4.5 \mathrm{wt} \% \mathrm{H}_{2}$ at $115^{\circ} \mathrm{C}$ under $100 \mathrm{bar}$ hydrogen pressure. Interestingly, this study result demonstrated that catalytic activities can be ranked in the order $\mathrm{Al}-\mathrm{Ti}>\mathrm{TiH}_{0.71}>\mathrm{TiH}_{2}>\mathrm{TiO}_{2}$. In 2009, Xiao et al. [230] synthesized $\mathrm{NaAlH}_{4}$ by ball milling the mixture of $\mathrm{NaH}$ and $\mathrm{Al}$ with $\mathrm{TiC}$ additive under $0.6 \mathrm{MPa}$ hydrogen pressure. The TiC-containing NaH/Al composite could absorb $4.77 \mathrm{wt} \% \mathrm{H}_{2}$ in $10 \mathrm{~h}$ at $120^{\circ} \mathrm{C}$ under $11.5 \mathrm{MPa}$ hydriding pressure, and hydrided $\mathrm{TiC}$-containing $\mathrm{NaH} /$ $\mathrm{Al}$ sample released $3.85 \mathrm{wt} \% \mathrm{H}_{2}$ at $155^{\circ} \mathrm{C}$. The catalytic mechanism (Fig. 11) was that $\mathrm{TiC}$ additive acted not only as the catalytic active sites for hydrogen spillover, but also suppressed the particles' agglomeration. TiN and $\mathrm{TiB}_{2}$ dopants [191,192,231-234] were also used to promote de-/rehydrogenation of $\mathrm{LiAlH}_{4}$ and $\mathrm{NaAlH}_{4}$.

Our group [231] reported that $\mathrm{TiN}$-doped $\mathrm{NaH} / \mathrm{Al}$ composite released $5.44 \mathrm{wt} \% \mathrm{H}_{2}$ at $190^{\circ} \mathrm{C}$ and the onset hydrogen desorption temperature was decreased to around $100^{\circ} \mathrm{C}$. Recently, co-doping $\mathrm{TiO}_{2}$ and $2 \mathrm{D}$ MXene synthesized by chemical exfoliation has been added into $\mathrm{NaAlH}_{4}$ [229]. For $10 \mathrm{wt} \% \mathrm{MXene} / \mathrm{A}-\mathrm{TiO}_{2}-\mathrm{NaAlH}_{4}$ sample, approximately $4.8 \mathrm{wt} \% \mathrm{H}_{2}$ was liberated within $200 \mathrm{~min}$ at $140^{\circ} \mathrm{C}$, and the hydrogen desorption amount still maintained $4.7 \mathrm{wt} \%$ after five cycles at $120^{\circ} \mathrm{C}$ under $12 \mathrm{MPa}$ hydrogen pressure.

Apart from Ti-containing compounds, other transitionmetal, MOFs, rare-earth-metal-based compounds have also been explored and investigated as dopants, which were proved to be able to enhance hydrogen storage properties of alanates [193,235-244]. Bogdanović et al. [235-237] revealed that $\mathrm{CeCl}_{3}$ and $\mathrm{ScCl}_{3}$ additives could remarkably promote the hydrogen desorption kinetics of $\mathrm{NaAlH}_{4}$ and $\mathrm{LiAlH}_{4}$. More importantly, the hydrogenation rate of $\mathrm{ScCl}_{3}$-doped $\mathrm{NaAlH}_{4}$ at 50 bar hydrogen pressure was 10 times faster than that of Ti-doped 

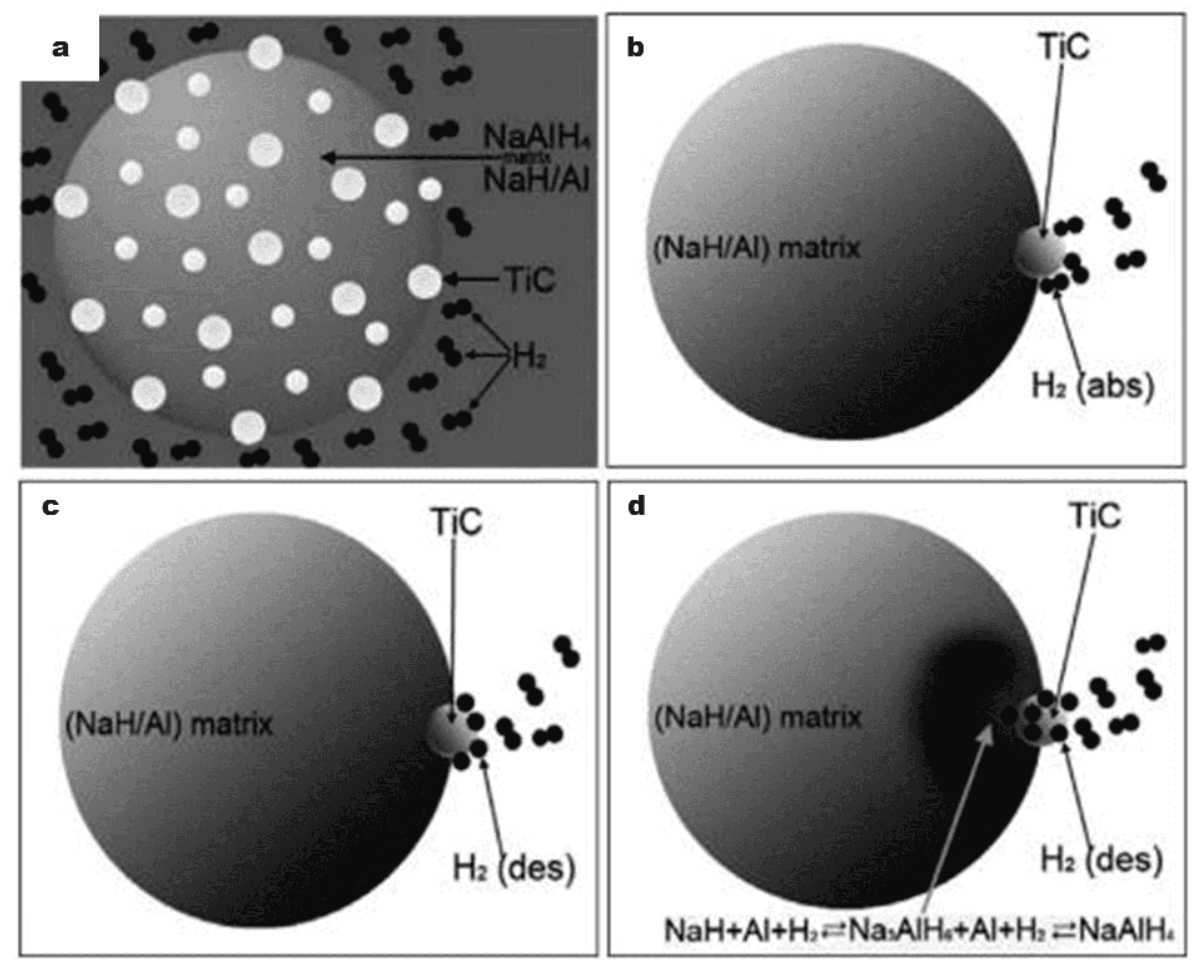

Figure 11 Scheme of TiC-doped $\mathrm{NaH} / \mathrm{Al}$ composite in different states of hydrogenation. (a) Ball-milled NaH/Al, (b) adsorbed, (c) dissociated, and (d) diffused state of hydrogenation. Reproduced with permission from Ref. [230]. Copyright 2009, American Chemistry Society.

$\mathrm{NaAlH}_{4}$. Transition metal oxides were also highly efficient in decreasing the hydrogen desorption temperature and improving the hydriding-dehydriding kinetics of alanates [193,245-249]. Sulaiman et al. [249] demonstrated that $10 \mathrm{wt} \% \mathrm{SrFe}_{12} \mathrm{O}_{19}$-containing $\mathrm{LiAlH}_{4}$ composite released around $5.54 \mathrm{wt} \% \mathrm{H}_{2}$ at $130^{\circ} \mathrm{C}$ in $20 \mathrm{~min}$. In-situ dehydrogenated products of $\mathrm{Fe}$ and $\mathrm{LiFeO}_{2}$ species and Sr-containing species may play a synergistic role in improving the desorption properties of $\mathrm{LiAlH}_{4}$. In 2012, Pitt et al. [250] studied transition-metal chlorides enhanced $\mathrm{NaAlH}_{4}$ system. They elucidated that $\mathrm{ZrCl}_{4}$-containing composite displayed the highest hydrogen capacity of $4.34 \mathrm{wt} \%$ at $140^{\circ} \mathrm{C}$ under 150 bar pressure. This study proposed a dual catalytic mechanism resulting from the surface-embedded $\mathrm{Al}_{1-x} \mathrm{Ti}_{x}$ specie. Fan et al. $[238,239]$ investigated the enhanced hydriding-dehydriding properties of Ce-Al species-doped $\mathrm{NaAlH}_{4}$. Assynthesized $\mathrm{CeAl}_{2}$-doped $\mathrm{NaAlH}_{4}$ released around $70 \%$ of the hydrogen capacity in the first hydrogen evolution step at $160^{\circ} \mathrm{C}$ within $6 \mathrm{~min}$, and could be hydrogenated under $12 \mathrm{MPa}$ hydrogen pressure at $120^{\circ} \mathrm{C}$ in $20 \mathrm{~min}$, with a hydrogen capacity of $4.9 \mathrm{wt} \%$. Compared with the second cycle, hydrogenated capacity slightly decreased after 40 cycles. Stabilized $\mathrm{CeAl}_{4}$ phase could be generated due to the reaction between $\mathrm{CeAl}_{2}$ additive and $\mathrm{Al}$ after prolonged cycling, which played a crucial role for hydridingdehydriding properties of $\mathrm{CeAl}_{2}$-doped $\mathrm{NaAlH}_{4}$.

Carbon materials, as the typical nonmetal dopants, have been also widely investigated owing to the low density and high activity [251-254]. Kumar et al. [253] revealed that nitrogen-doped carbon materials, including carbon nanotubes (NCNT) and graphene (NG), showed excellent catalytic activity compared with pristine carbon materials. NCNT-doped $\mathrm{NaAlH}_{4}$ could reversibly take $1.8 \mathrm{wt} \%$ hydrogen in $2.5 \mathrm{~h}$. The onset hydrogen desorption temperature of multi-walled carbon nanotubes (MWCNTs) modified- $\mathrm{LiAlH}_{4}$ was reduced by around $60^{\circ} \mathrm{C}$; and $10 \mathrm{wt} \%$ MWCNTs-modified $\mathrm{LiAlH}_{4}$ released

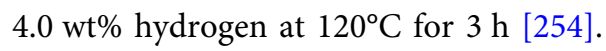

Recently, it has become a hot issue to construct highly efficient multicomplex dopants or co-dopants with synergetic effects [241,247,255-263]. Bimetallic additives have been explored to promote the hydriding-dehydriding properties of hydrides [256,257]. Schmidt et al. [257] found that hydrogen desorption and reabsorption kinetics of the Ti-Zr-co-doped $\mathrm{NaAlH}_{4}$ was superior to that of $\mathrm{NaAlH}_{4}$, meanwhile about $4 \mathrm{wt} \%$ hydrogen could be reversibly stored at $125^{\circ} \mathrm{C}$ in $5 \mathrm{~h}$. Co-doping $\mathrm{TiCl}_{3}$ and 
MWCNTs formed a synergetic effect, which greatly reduced the hydrogen desorption temperature of $\mathrm{LiAlH}_{4}$. For $\mathrm{LiAlH}_{4}$ with the addition of $20 \mathrm{wt} \% \mathrm{TiCl}_{3}$-MWCNTs, the first stage dehydrogenation temperature could be lowered to $80^{\circ} \mathrm{C}$ and $3.6 \mathrm{wt} \% \mathrm{H}_{2}$ could be released at $110^{\circ} \mathrm{C}$ in $2 \mathrm{~h} \mathrm{[223].} \mathrm{In} \mathrm{contrast,} 20 \mathrm{wt} \%$ MWCNTs-containing $\mathrm{NaAlH}_{4}$ started to release hydrogen at $140^{\circ} \mathrm{C}$, and only $4.6 \mathrm{wt} \%$ of $\mathrm{H}_{2}$ was released when it was heated to $300^{\circ} \mathrm{C}$. Recent research revealed that potassium hydride $(\mathrm{KH})$ could improve the catalytic effect of $\mathrm{Ti}-$ and Cebased catalysts. Wang et al. [258] reported that introducing $\mathrm{KH}$ into Ti-containing alanates resulted in a significant enhancement in the hydrogen desorption kinetics of the second decomposition step. For the $\mathrm{KH}+\mathrm{Ti}$ cocontaining sample, dehydriding capacity increased to around $4.7 \mathrm{wt} \%$. The second decomposition rate was approximately 5 times faster than that of the Ti-doped sample.

An illustration of the character of the active species and the explanation of reaction mechanisms are essentially important for the evolution of additive-containing alanates with pronouncedly enhanced hydriding-dehydriding performances [230,231]. However, it is difficult to explain the reaction mechanisms on the hydriding-dehydriding properties of alanates due to high complicacy of active species. Numerous researches showed that insitu dehydrogenated products of Sr-containing species, $\mathrm{Al}_{3} \mathrm{Ti}, \mathrm{Ce}_{7} \mathrm{O}_{12}, \mathrm{CeAl}_{4}$ or $\mathrm{Al}_{85} \mathrm{Ti}_{15}$ composites played an important role in improving the desorption properties of hydrides $[239,249,250,264-267]$. Up to now, several catalytic mechanisms have been developed: (1) providing an active site for the dissociation and recombination of $\mathrm{H}-\mathrm{H}$ bonds [268]; (2) alloy formation at or near the surface of bulk aluminum [269]; (3) weakening the $\mathrm{Al}-\mathrm{H}$ bonding [270]; (4) promoting the nucleation of dehydrogenation products [271]; (5) promoting the $\mathrm{AlH}_{3}$-vacancy mediation [272]. Hence, exploring and synthesizing active dopants with excellent catalytic properties, instead of dopant precursors, is crucial for the development of additivesdoped lightweight metal alanates with a high available hydrogen capacity.

\section{SUMMARY AND OUTLOOK}

Lightweight hydrides are the most promising candidates to promote the practical application of solid-state hydrogen storage materials owing to their high gravimetric hydrogen contents. However, their on-board applications were still limited due to some drawbacks. Although many efforts have been devoted to tuning kinetics, thermodynamics, reversible capacity and cycle performance of existing lightweight hydrides, it is still a challenge to meet the requirements of practical use.

Alloying, nanoscaling and doping techniques have been demonstrated to decrease the hydrogen desorption temperature and to promote the reversibility behavior of lightweight hydrides. Nanoscaling is a promising strategy to tune both kinetic and thermodynamic properties. However, for a significant thermodynamic improvement, the crystallites size should be less than $1.3 \mathrm{~nm}$, which is still a challenge for homogeneously preparation. These ultrafine particles with high surface energy have a strong tendency to aggregate, thus a suitable scaffold is necessary. Both strategies for "Achieving" and "Stabilizing" the ultrafine lightweight hydrides need to be further researched. Alloying and doping have been widely studied for several decades. The changed reaction pathway can adjust thermodynamic properties while the catalytic effect can improve the kinetics. Sometimes the interaction of additives and hydrides is complicated, which makes it difficult to distinguish the mechanism of the improvement. The analysis techniques need to be further developed to reveal mechanism in detail, thus providing theoretical basis for additives design and synthesis.

Employing multiple strategies to improve hydrogen storage properties is the recent researching tendency, for instance, combining nanocofinement with catalytic strategy. These complex multiphase nanocomposites require homogeneous dispersion, which sets a high demand on synthesis technique. Moreover, it remains a challenge on both composites design and cost-effective synthesis route. Although there is a long way to go before on-board application of lightweight hydrides as hydrogen storage materials, we believe that continuous efforts will eventually realize the practical applications and bring hydrogen energy to our real life.

Received 30 April 2019; accepted 4 August 2019;

published online 6 September 2019

1 Züttel A. Materials for hydrogen storage. Mater Today, 2003, 6: 24-33

2 Li J, Li B, Shao H, et al. Catalysis and downsizing in Mg-based hydrogen storage materials. Catalysts, 2018, 8: 89

3 Sreedhar I, Kamani KM, Kamani BM, et al. A Bird's eye view on process and engineering aspects of hydrogen storage. Renew Sustain Energy Rev, 2018, 91: 838-860

4 Lai Q, Paskevicius M, Sheppard DA, et al. Hydrogen storage materials for mobile and stationary applications: Current state of the art. ChemSusChem, 2015, 8: 2789-2825

5 Milanese C, Garroni S, Gennari F, et al. Solid state hydrogen storage in alanates and alanate-based compounds: A review. Metals, 2018, 8: 567

6 Schneemann A, White JL, Kang SY, et al. Nanostructured metal 
hydrides for hydrogen storage. Chem Rev, 2018, 118: 1077510839

7 Jain A, Agarwal S, Ichikawa T. Catalytic tuning of sorption kinetics of lightweight hydrides: A review of the materials and mechanism. Catalysts, 2018, 8: 651

8 Møller K, Sheppard D, Ravnsbæk D, et al. Complex metal hydrides for hydrogen, thermal and electrochemical energy storage. Energies, 2017, 10: 1645

9 Mohtadi R, Orimo SI. The renaissance of hydrides as energy materials. Nat Rev Mater, 2016, 2: 16091

10 Kim KC. A review on design strategies for metal hydrides with enhanced reaction thermodynamics for hydrogen storage applications. Int J Energy Res, 2018, 42: 1455-1468

11 Aldridge S, Downs AJ. Hydrides of the main-group metals: New variations on an old theme. Chem Rev, 2001, 101: 3305-3366

12 Sakintuna B, Lamaridarkrim F, Hirscher M. Metal hydride materials for solid hydrogen storage: A review. Int J Hydrogen Energy, 2007, 32: 1121-1140

13 Orimo SI, Nakamori Y, Eliseo JR, et al. Complex hydrides for hydrogen storage. Chem Rev, 2007, 107: 4111-4132

14 Zhang J, Li Z, Wu Y, et al. Recent advances on the thermal destabilization of $\mathrm{Mg}$-based hydrogen storage materials. RSC Adv, 2019, 9: 408-428

15 Wang Y, Wang Y. Recent advances in additive-enhanced magnesium hydride for hydrogen storage. Prog Nat Sci-Mater Int, 2017, 27: 41-49

16 Fernández JF, Sánchez CR. Rate determining step in the absorption and desorption of hydrogen by magnesium. J Alloys Compd, 2002, 340: 189-198

17 Zhu M, Lu Y, Ouyang L, et al. Thermodynamic tuning of Mgbased hydrogen storage alloys: A review. Materials, 2013, 6: 46544674

18 Reilly Jr. JJ, Wiswall Jr. RH. Reaction of hydrogen with alloys of magnesium and nickel and the formation of $\mathrm{Mg}_{2} \mathrm{NiH}_{4}$. Inorg Chem, 1968, 7: 2254-2256

19 Shao H, Wang $\mathrm{Y}, \mathrm{Xu} \mathrm{H}$, et al. Preparation and hydrogen storage properties of nanostructured $\mathrm{Mg}_{2} \mathrm{Cu}$ alloy. J Solid State Chem, 2005, 178: 2211-2217

20 Yuan JG, Xing N, Wu Y. The effect of Mm content on microstructure and hydrogen storage properties of the as-cast $\mathrm{Mg}$ $10 \mathrm{Ni}-x \mathrm{Mm}(x=1,2,3$ at.\%) alloys. Int J Hydrogen Energy, 2017, 42: $6118-6126$

21 Reilly Jr. JJ, Wiswall Jr. RH. Reaction of hydrogen with alloys of magnesium and copper. Inorg Chem, 1967, 6: 2220-2223

22 Zhao X, Han S, Zhu X, et al. Effect of $\mathrm{LaH}_{3}-\mathrm{TiH}_{2}$ composite additive on the hydrogen storage properties of $\mathrm{Mg}_{2} \mathrm{Ni}$ alloys. J Alloys Compd, 2013, 581: 270-274

23 Song J, Han S, Fu R. Effect of $\mathrm{La}_{2} \mathrm{O}_{3}-\mathrm{CaO}$ composite additive on the hydrogen storage properties of $\mathrm{Mg}_{2} \mathrm{Ni}$ alloy. Mater Sci Eng-B, 2014, 188: 114-118

24 Hou X, Hu R, Zhang T, et al. Hydrogen desorption performance of high-energy ball milled $\mathrm{Mg}_{2} \mathrm{NiH}_{4}$ catalyzed by multi-walled carbon nanotubes coupling with $\mathrm{TiF}_{3}$. Int $\mathrm{J}$ Hydrogen Energy, 2014, 39: 19672-19681

25 Au YS, Ponthieu M, van Zwienen $\mathrm{R}$, et al. Synthesis of $\mathrm{Mg}_{2} \mathrm{Cu}$ nanoparticles on carbon supports with enhanced hydrogen sorption kinetics. J Mater Chem A, 2013, 1: 9983-9991

26 Khan D, Zou J, Zeng X, et al. Hydrogen storage properties of nanocrystalline $\mathrm{Mg}_{2} \mathrm{Ni}$ prepared from compressed $2 \mathrm{MgH}_{2} \mathrm{Ni}$ powder. Int J Hydrogen Energy, 2018, 43: 22391-22400
27 Tran XQ, McDonald SD, Gu Q, et al. In-situ investigation of the hydrogen release mechanism in bulk $\mathrm{Mg}_{2} \mathrm{NiH}_{4}$. J Power Sources, 2017, 341: 130-138

28 Javadian P, Zlotea C, Ghimbeu CM, et al. Hydrogen storage properties of nanoconfined $\mathrm{LiBH}_{4}-\mathrm{Mg}_{2} \mathrm{NiH}_{4}$ reactive hydride composites. J Phys Chem C, 2015, 119: 5819-5826

29 Bergemann $\mathrm{N}$, Pistidda $\mathrm{C}$, Milanese $\mathrm{C}$, et al. $\mathrm{Ca}\left(\mathrm{BH}_{4}\right)_{2}-\mathrm{Mg}_{2} \mathrm{NiH}_{4}$ : on the pathway to a $\mathrm{Ca}\left(\mathrm{BH}_{4}\right)_{2}$ system with a reversible hydrogen cycle. Chem Commun, 2016, 52: 4836-4839

30 Li S, Zhu Y, Liu Y, et al. Synergistic hydrogen desorption properties of the $4 \mathrm{LiAlH}_{4}+\mathrm{Mg}_{2} \mathrm{NiH}_{4}$ composite. J Alloys Compd, 2017, 697: 80-85

31 Cho ES, Ruminski AM, Liu YS, et al. Hierarchically controlled inside-out doping of $\mathrm{Mg}$ nanocomposites for moderate temperature hydrogen storage. Adv Funct Mater, 2017, 27: 1704316

32 Huang X, Xiao X, Zhang W, et al. Transition metal (Co, Ni) nanoparticles wrapped with carbon and their superior catalytic activities for the reversible hydrogen storage of magnesium hydride. Phys Chem Chem Phys, 2017, 19: 4019-4029

33 House SD, Vajo JJ, Ren C, et al. Effect of ball-milling duration and dehydrogenation on the morphology, microstructure and catalyst dispersion in $\mathrm{Ni}$-catalyzed $\mathrm{MgH}_{2}$ hydrogen storage materials. Acta Mater, 2015, 86: 55-68

34 Chen M, Xiao X, Zhang M, et al. Excellent synergistic catalytic mechanism of in-situ formed nanosized $\mathrm{Mg}_{2} \mathrm{Ni}$ and multiple valence titanium for improved hydrogen desorption properties of magnesium hydride. Int J Hydrogen Energy, 2019, 44: 1750-1759

35 Zhang Q, Zang L, Huang Y, et al. Improved hydrogen storage properties of $\mathrm{MgH}_{2}$ with Ni-based compounds. Int J Hydrogen Energy, 2017, 42: 24247-24255

36 Zhang Q, Xu Y, Wang Y, et al. Enhanced hydrogen storage performance of $\mathrm{MgH}_{2} \mathrm{Ni}_{2} \mathrm{P} /$ graphene nanosheets. Int J Hydrogen Energy, 2016, 41: 17000-17007

37 Skripnyuk VM, Rabkin E. $\mathrm{Mg}_{3} \mathrm{Cd}$ : A model alloy for studying the destabilization of magnesium hydride. Int J Hydrogen Energy, 2012, 37: 10724-10732

38 Wang Y, Zhou Z, Zhou W, et al. Effects of in-situ formed $\mathrm{Mg}_{2} \mathrm{Si}$ phase on the hydrogen storage properties of $\mathrm{Mg}$ - $\mathrm{Li}$ solid solution alloys. Mater Des, 2016, 111: 248-252

39 Vajo JJ, Mertens F, Ahn CC, et al. Altering hydrogen storage properties by hydride destabilization through alloy formation: $\mathrm{LiH}$ and $\mathrm{MgH}_{2}$ destabilized with Si. J Phys Chem B, 2004, 108: 13977-13983

40 Kelly ST, Van Atta SL, Vajo JJ, et al. Kinetic limitations of the $\mathrm{Mg}_{2} \mathrm{Si}$ system for reversible hydrogen storage. Nanotechnology, 2009, 20: 204017

41 Si TZ, Zhang JB, Liu DM, et al. A new reversible $\mathrm{Mg}_{3} \mathrm{Ag}-\mathrm{H}_{2}$ system for hydrogen storage. J Alloys Compd, 2013, 581: 246-249

42 Zhong HC, Wang H, Liu JW, et al. Altered desorption enthalpy of $\mathrm{MgH}_{2}$ by the reversible formation of $\mathrm{Mg}$ (In) solid solution. Scripta Mater, 2011, 65: 285-287

43 Ouyang LZ, Yang XS, Zhu M, et al. Enhanced hydrogen storage kinetics and stability by synergistic effects of in situ formed $\mathrm{CeH}_{2.73}$ and $\mathrm{Ni}$ in $\mathrm{CeH}_{2.73}-\mathrm{MgH}_{2}-\mathrm{Ni}$ nanocomposites. J Phys Chem C, 2014, 118: 7808-7820

44 Ouyang LZ, Cao ZJ, Wang H, et al. Dual-tuning effect of In on the thermodynamic and kinetic properties of $\mathrm{Mg}_{2} \mathrm{Ni}$ dehydrogenation. Int J Hydrogen Energy, 2013, 38: 8881-8887

$45 \mathrm{Xu} \mathrm{C}$, Lin HJ, Wang Y, et al. Catalytic effect of in situ formed nano- $\mathrm{Mg}_{2} \mathrm{Ni}$ and $\mathrm{Mg}_{2} \mathrm{Cu}$ on the hydrogen storage properties of 
Mg-Y hydride composites. J Alloys Compd, 2019, 782: 242-250

46 Jiang $\mathrm{X}, \mathrm{Fu} \mathrm{K}$, Xiao R, et al. Hydrogen storage properties of $\mathrm{Y}$ $\mathrm{Mg}-\mathrm{Cu}-\mathrm{H}$ nanocomposite obtained by hydrogen-induced decomposition of $\mathrm{YMg}_{4} \mathrm{Cu}$ intermetallic. J Alloys Compd, 2018, 751: $176-182$

47 Andreasen $\mathrm{A}$. Hydrogenation properties of $\mathrm{Mg}-\mathrm{Al}$ alloys. Int J Hydrogen Energy, 2008, 33: 7489-7497

48 Bouaricha S, Dodelet JP, Guay D, et al. Hydriding behavior of $\mathrm{Mg}-\mathrm{Al}$ and leached $\mathrm{Mg}-\mathrm{Al}$ compounds prepared by high-energy ball-milling. J Alloys Compd, 2000, 297: 282-293

49 Li Y, Zhang Y, Shang H, et al. Investigation on structure and hydrogen storage performance of as-milled and cast $\mathrm{Mg}_{90} \mathrm{Al}_{10}$ alloys. Int J Hydrogen Energy, 2018, 43: 6642-6653

$50 \mathrm{Li} \mathrm{Y}$, Shang $\mathrm{H}$, Zhang $\mathrm{Y}$, et al. Effects of adding nano- $-\mathrm{CeO}_{2}$ powder on microstructure and hydrogen storage performances of mechanical alloyed $\mathrm{Mg}_{90} \mathrm{Al}_{10}$ alloy. Int J Hydrogen Energy, 2019, 44: 1735-1749

51 Zhou C, Fang ZZ, Lu J, et al. Thermodynamic and kinetic destabilization of magnesium hydride using $\mathrm{Mg}$-In solid solution alloys. J Am Chem Soc, 2013, 135: 10982-10985

52 Wang H, Zhong H, Ouyang L, et al. Fully reversible de/hydriding of $\mathrm{Mg}$ base solid solutions with reduced reaction enthalpy and enhanced kinetics. J Phys Chem C, 2014, 118: 12087-12096

53 Gleiter H. Nanostructured materials: basic concepts and microstructure. Acta Mater, 2000, 48: 1-29

54 Wagemans RWP, van Lenthe JH, de Jongh PE, et al. Hydrogen storage in magnesium clusters: Quantum chemical study. J Am Chem Soc, 2005, 127: 16675-16680

55 Imamura $\mathrm{H}$, Masanari $\mathrm{K}$, Kusuhara $\mathrm{M}$, et al. High hydrogen storage capacity of nanosized magnesium synthesized by high energy ball-milling. J Alloys Compd, 2005, 386: 211-216

56 Suryanarayana C. Mechanical alloying and milling. Prog Mater Sci, 2001, 46: 1-184

57 Ouyang L, Cao Z, Wang H, et al. Application of dielectric barrier discharge plasma-assisted milling in energy storage materials-A review. J Alloys Compd, 2017, 691: 422-435

58 Ouyang LZ, Cao ZJ, Wang $\mathrm{H}$, et al. Enhanced dehydriding thermodynamics and kinetics in $\mathrm{Mg}(\mathrm{In})-\mathrm{MgF}_{2}$ composite directly synthesized by plasma milling. J Alloys Compd, 2014, 586: 113117

59 Ma M, Yang L, Ouyang L, et al. Promoting hydrogen generation from the hydrolysis of Mg-graphite composites by plasma-assisted milling. Energy, 2019, 167: 1205-1211

60 Paskevicius M, Sheppard DA, Buckley CE. Thermodynamic changes in mechanochemically synthesized magnesium hydride nanoparticles. J Am Chem Soc, 2010, 132: 5077-5083

61 Doppiu S, Schultz L, Gutfleisch O. In situ pressure and temperature monitoring during the conversion of $\mathrm{Mg}$ into $\mathrm{MgH}_{2}$ by high-pressure reactive ball milling. J Alloys Compd, 2007, 427: 204-208

$62 \mathrm{Li} \mathrm{W}, \mathrm{Li} \mathrm{C}, \mathrm{Ma} \mathrm{H}$, et al. Magnesium nanowires: Enhanced kinetics for hydrogen absorption and desorption. J Am Chem Soc, 2007, 129: 6710-6711

63 Zhu C, Sakaguchi N, Hosokai S, et al. In situ transmission electron microscopy observation of the decomposition of $\mathrm{MgH}_{2}$ nanofiber. Int J Hydrogen Energy, 2011, 36: 3600-3605

64 Zhu C, Hosokai S, Akiyama T. Direct synthesis of $\mathrm{MgH}_{2}$ nanofibers from waste Mg. Int J Hydrogen Energy, 2012, 37: 83798387

65 Zhu C, Hosokai S, Matsumoto I, et al. Shape-controlled growth of
$\mathrm{MgH}_{2} / \mathrm{Mg}$ nano/microstructures via hydriding chemical vapor deposition. Cryst Growth Des, 2010, 10: 5123-5128

66 Zhang H, Zheng X, Wang T, et al. Significantly improved hydrogen desorption property of $\mathrm{La}_{2} \mathrm{Mg}_{17}$ alloy modified with $\mathrm{Ni}-\mathrm{Al}$ nanocrystalline. Intermetallics, 2016, 70: 29-32

67 Fry CMP, Grant DM, Walker GS. Catalysis and evolution on cycling of nano-structured magnesium multilayer thin films. Int J Hydrogen Energy, 2014, 39: 1173-1184

68 Matsumoto I, Akiyama T, Nakamura Y, et al. Controlled shape of magnesium hydride synthesized by chemical vapor deposition. J Alloys Compd, 2010, 507: 502-507

69 Cui J, Wang H, Sun DL, et al. Realizing nano-confinement of magnesium for hydrogen storage using vapour transport deposition. Rare Met, 2016, 35: 401-407

70 Rieke RD, Hudnall PM. Activated metals. I. Preparation of highly reactive magnesium metal. J Am Chem Soc, 1972, 94: 7178-7179

71 Zhang S, Gross AF, Van Atta SL, et al. The synthesis and hydrogen storage properties of a $\mathrm{MgH}_{2}$ incorporated carbon aerogel scaffold. Nanotechnology, 2009, 20: 204027

72 Nielsen TK, Manickam K, Hirscher M, et al. Confinement of $\mathrm{MgH}_{2}$ nanoclusters within nanoporous aerogel scaffold materials. ACS Nano, 2009, 3: 3521-3528

73 Norberg NS, Arthur TS, Fredrick SJ, et al. Size-dependent hydrogen storage properties of $\mathrm{Mg}$ nanocrystals prepared from solution. J Am Chem Soc, 2011, 133: 10679-10681

74 Jeon KJ, Moon HR, Ruminski AM, et al. Air-stable magnesium nanocomposites provide rapid and high-capacity hydrogen storage without using heavy-metal catalysts. Nat Mater, 2011, 10: 286-290

75 Liu Y, Zou J, Zeng X, et al. Study on hydrogen storage properties of $\mathrm{Mg}-\mathrm{X}(\mathrm{X}=\mathrm{Fe}, \mathrm{Co}, \mathrm{V})$ nano-composites co-precipitated from solution. RSC Adv, 2015, 5: 7687-7696

76 de Jongh PE, Wagemans RWP, Eggenhuisen TM, et al. The preparation of carbon-supported magnesium nanoparticles using melt infiltration. Chem Mater, 2007, 19: 6052-6057

77 Gross AF, Ahn CC, Van Atta SL, et al. Fabrication and hydrogen sorption behaviour of nanoparticulate $\mathrm{MgH}_{2}$ incorporated in a porous carbon host. Nanotechnology, 2009, 20: 204005

78 Au YS, Obbink MK, Srinivasan S, et al. The size dependence of hydrogen mobility and sorption kinetics for carbon-supported $\mathrm{MgH}_{2}$ particles. Adv Funct Mater, 2014, 24: 3604-3611

79 Zhao-Karger Z, Hu J, Roth A, et al. Altered thermodynamic and kinetic properties of $\mathrm{MgH}_{2}$ infiltrated in microporous scaffold. Chem Commun, 2010, 46: 8353-8355

80 Konarova M, Tanksale A, Norberto Beltramini J, et al. Effects of nano-confinement on the hydrogen desorption properties of $\mathrm{MgH}_{2}$. Nano Energy, 2013, 2: 98-104

81 Jia Y, Yao X. Carbon scaffold modified by metal (Ni) or nonmetal $(\mathrm{N})$ to enhance hydrogen storage of $\mathrm{MgH}_{2}$ through nanoconfinement. Int J Hydrogen Energy, 2017, 42: 22933-22941

82 Wang $\mathrm{K}, \mathrm{Wu} \mathrm{G}, \mathrm{Cao} \mathrm{H}$, et al. Improved reversible dehydrogenation properties of $\mathrm{MgH}_{2}$ by the synergetic effects of graphene oxide-based porous carbon and $\mathrm{TiCl}_{3}$. Int J Hydrogen Energy, 2018, 43: 7440-7446

83 Shinde SS, Kim DH, Yu JY, et al. Self-assembled air-stable magnesium hydride embedded in 3-D activated carbon for reversible hydrogen storage. Nanoscale, 2017, 9: 7094-7103

84 Xia G, Tan Y, Chen X, et al. Monodisperse magnesium hydride nanoparticles uniformly self-assembled on graphene. Adv Mater, 2015, 27: 5981-5988 
Cho ES, Ruminski AM, Aloni S, et al. Graphene oxide/metal nanocrystal multilaminates as the atomic limit for safe and selective hydrogen storage. Nat Commun, 2016, 7: 10804

86 Huang Y, Xia G, Chen J, et al. One-step uniform growth of magnesium hydride nanoparticles on graphene. Prog Nat SciMater Int, 2017, 27: 81-87

87 Zhang J, Zhu Y, Lin $\mathrm{H}$, et al. Metal hydride nanoparticles with ultrahigh structural stability and hydrogen storage activity derived from microencapsulated nanoconfinement. Adv Mater, 2017, 29: 1700760

88 Shang CX, Guo ZX. Effect of carbon on hydrogen desorption and absorption of mechanically milled $\mathrm{MgH}_{2}$. J Power Sources, 2004, 129: $73-80$

89 Wu CZ, Wang P, Yao X, et al. Hydrogen storage properties of $\mathrm{MgH}_{2} / \mathrm{SWNT}$ composite prepared by ball milling. J Alloys Compd, 2006, 420: 278-282

90 Shao H, Felderhoff M, Schüth F. Hydrogen storage properties of nanostructured $\mathrm{MgH}_{2} / \mathrm{TiH}_{2}$ composite prepared by ball milling under high hydrogen pressure. Int J Hydrogen Energy, 2011, 36: 10828-10833

91 Korablov D, Besenbacher F, Jensen TR. Kinetics and thermodynamics of hydrogenation-dehydrogenation for $\mathrm{Mg}-25 \% \mathrm{TM}$ $(\mathrm{TM}=\mathrm{Ti}, \mathrm{Nb}$ or $\mathrm{V})$ composites synthesized by reactive ball milling in hydrogen. Int J Hydrogen Energy, 2018, 43: 1680416814

92 Cui J, Wang H, Liu J, et al. Remarkable enhancement in dehydrogenation of $\mathrm{MgH}_{2}$ by a nano-coating of multi-valence Tibased catalysts. J Mater Chem A, 2013, 1: 5603-5611

93 Ma LP, Kang XD, Dai HB, et al. Superior catalytic effect of $\mathrm{TiF}_{3}$ over $\mathrm{TiCl}_{3}$ in improving the hydrogen sorption kinetics of $\mathrm{MgH}_{2}$ : Catalytic role of fluorine anion. Acta Mater, 2009, 57: 2250-2258

94 Wang P, Wang AM, Zhang HF, et al. Hydrogenation characteristics of $\mathrm{Mg}-\mathrm{TiO}_{2}$ (rutile) composite. J Alloys Compd, 2000, 313: 218-223

95 Zhang L, Chen L, Fan X, et al. Enhanced hydrogen storage properties of $\mathrm{MgH}_{2}$ with numerous hydrogen diffusion channels provided by $\mathrm{Na}_{2} \mathrm{Ti}_{3} \mathrm{O}_{7}$ nanotubes. J Mater Chem A, 2017, 5: 61786185

96 Liu Y, Du H, Zhang X, et al. Superior catalytic activity derived from a two-dimensional $\mathrm{Ti}_{3} \mathrm{C}_{2}$ precursor towards the hydrogen storage reaction of magnesium hydride. Chem Commun, 2016, 52: 705-708

97 Dehouche Z, Klassen T, Oelerich W, et al. Cycling and thermal stability of nanostructured $\mathrm{MgH}_{2}-\mathrm{Cr}_{2} \mathrm{O}_{3}$ composite for hydrogen storage. J Alloys Compd, 2002, 347: 319-323

98 Zhang W, Xu G, Cheng Y, et al. Improved hydrogen storage properties of $\mathrm{MgH}_{2}$ by the addition of $\mathrm{FeS}_{2}$ micro-spheres. Dalton Trans, 2018, 47: 5217-5225

99 Mustafa NS, Ismail M. Hydrogen sorption improvement of $\mathrm{MgH}_{2}$ catalyzed by $\mathrm{CeO}_{2}$ nanopowder. J Alloys Compd, 2017, 695: 2532-2538

100 Zhang $\mathrm{M}$, Xiao X, Wang $\mathrm{X}$, et al. Excellent catalysis of $\mathrm{TiO}_{2}$ nanosheets with high-surface-energy $\{001\}$ facets on the hydrogen storage properties of $\mathrm{MgH}_{2}$. Nanoscale, 2019, 11: 7465-7473

101 Wang Y, Li L, An C, et al. Facile synthesis of TiN decorated graphene and its enhanced catalytic effects on dehydrogenation performance of magnesium hydride. Nanoscale, 2014, 6: 66846691

102 Wang Z, Ren Z, Jian N, et al. Vanadium oxide nanoparticles supported on cubic carbon nanoboxes as highly active catalyst precursors for hydrogen storage in $\mathrm{MgH}_{2}$. J Mater Chem A, 2018, 6: 16177-16185

103 Bhatnagar A, Pandey SK, Vishwakarma AK, et al. $\mathrm{Fe}_{3} \mathrm{O}_{4} @$ graphene as a superior catalyst for hydrogen de/absorption from/ in $\mathrm{MgH}_{2} / \mathrm{Mg}$. J Mater Chem A, 2016, 4: 14761-14772

104 Liu G, Wang Y, Qiu F, et al. Synthesis of porous Ni@rGO nanocomposite and its synergetic effect on hydrogen sorption properties of $\mathrm{MgH}_{2}$. J Mater Chem, 2012, 22: 22542-22549

105 Zhang Q, Wang Y, Zang L, et al. Core-shell $\mathrm{Ni}_{3} \mathrm{~N} @$ Nitrogendoped carbon: Synthesis and application in $\mathrm{MgH}_{2}$. J Alloys Compd, 2017, 703: 381-388

106 Kecik D, Aydinol MK. Density functional and dynamics study of the dissociative adsorption of hydrogen on $\mathrm{Mg}$ (0001) surface. Surf Sci, 2009, 603: 304-310

107 Liang G, Huot J, Boily S, et al. Catalytic effect of transition metals on hydrogen sorption in nanocrystalline ball milled $\mathrm{MgH}_{2}-\mathrm{Tm}$ ( Tm=Ti, V, Mn, Fe and Ni) systems. J Alloys Compd, 1999, 292: 247-252

108 Hanada N, Ichikawa T, Fujii H. Catalytic effect of nanoparticle $3 \mathrm{~d}$-transition metals on hydrogen storage properties in magnesium hydride $\mathrm{MgH}_{2}$ prepared by mechanical milling. J Phys Chem B, 2005, 109: 7188-7194

109 Oelerich W, Klassen T, Bormann R. Metal oxides as catalysts for improved hydrogen sorption in nanocrystalline Mg-based materials. J Alloys Compd, 2001, 315: 237-242

110 Aguey-Zinsou K, Ares Fernandez J, Klassen T, et al. Effect of $\mathrm{Nb}_{2} \mathrm{O}_{5}$ on $\mathrm{MgH}_{2}$ properties during mechanical milling. Int $\mathrm{J}$ Hydrogen Energy, 2007, 32: 2400-2407

111 Malka IE, Czujko T, Bystrzycki J. Catalytic effect of halide additives ball milled with magnesium hydride. Int J Hydrogen Energy, 2010, 35: 1706-1712

112 Jin SA, Shim JH, Cho YW, et al. Dehydrogenation and hydrogenation characteristics of $\mathrm{MgH}_{2}$ with transition metal fluorides. J Power Sources, 2007, 172: 859-862

113 Zhang J, Zhu Y, Zang X, et al. Nickel-decorated graphene nanoplates for enhanced $\mathrm{H}_{2}$ sorption properties of magnesium hydride at moderate temperatures. J Mater Chem A, 2016, 4: 25602570

114 Zhang J, Li S, Zhu Y, et al. Controllable fabrication of Ni-based catalysts and their enhancement on desorption properties of $\mathrm{MgH}_{2}$. J Alloys Compd, 2017, 715: 329-336

115 Wang Y, Liu G, An C, et al. Bimetallic NiCo functional graphene: An efficient catalyst for hydrogen-storage properties of $\mathrm{MgH}_{2}$. Chem Asian J, 2014, 9: 2576-2583

116 Soni PK, Bhatnagar A, Shaz MA, et al. Effect of graphene templated fluorides of $\mathrm{Ce}$ and $\mathrm{La}$ on the de/rehydrogenation behavior of $\mathrm{MgH}_{2}$. Int J Hydrogen Energy, 2017, 42: 20026-20035

117 Zhang $\mathrm{X}$, Leng $\mathrm{Z}$, Gao $\mathrm{M}$, et al. Enhanced hydrogen storage properties of $\mathrm{MgH}_{2}$ catalyzed with carbon-supported nanocrystalline $\mathrm{TiO}_{2}$. J Power Sources, 2018, 398: 183-192

118 Li HW, Yan Y, Orimo S, et al. Recent progress in metal borohydrides for hydrogen storage. Energies, 2011, 4: 185-214

119 Nakamori Y, Miwa K, Ninomiya A, et al. Correlation between thermodynamical stabilities of metal borohydrides and cation electronegativites: First-principles calculations and experiments. Phys Rev B, 2006, 74: 045126

120 Au M, Walters RT. Reversibility aspect of lithium borohydrides. Int J Hydrogen Energy, 2010, 35: 10311-10316

121 Varin RA, Chiu C. Structural stability of sodium borohydride $\left(\mathrm{NaBH}_{4}\right)$ during controlled mechanical milling. J Alloys Compd, 
2005, 397: 276-281

122 Wan X, Shaw LL. Novel dehydrogenation properties derived from nanoscale $\mathrm{LiBH}_{4}$. Acta Mater, 2011, 59: 4606-4615

123 Pang Y, Liu Y, Gao M, et al. A mechanical-force-driven physical vapour deposition approach to fabricating complex hydride nanostructures. Nat Commun, 2014, 5: 3519

124 Gross AF, Vajo JJ, Van Atta SL, et al. Enhanced hydrogen storage kinetics of $\mathrm{LiBH}_{4}$ in nanoporous carbon scaffolds. J Phys Chem C, 2008, 112: 5651-5657

125 Liu X, Peaslee D, Jost CZ, et al. Systematic pore-size effects of nanoconfinement of $\mathrm{LiBH}_{4}$ : Elimination of diborane release and tunable behavior for hydrogen storage applications. Chem Mater, 2011, 23: 1331-1336

126 Ngene P, van Zwienen MR, de Jongh PE. Reversibility of the hydrogen desorption from $\mathrm{LiBH}_{4}$ : a synergetic effect of nanoconfinement and $\mathrm{Ni}$ addition. Chem Commun, 2010, 46: 82018203

127 Ngene $\mathrm{P}$, Adelhelm $\mathrm{P}$, Beale $\mathrm{AM}$, et al. $\mathrm{LiBH}_{4} / \mathrm{SBA}-15$ nanocomposites prepared by melt infiltration under hydrogen pressure: Synthesis and hydrogen sorption properties. J Phys Chem C, 2010, 114: 6163-6168

128 Shao J, Xiao X, Fan X, et al. Enhanced hydrogen storage capacity and reversibility of $\mathrm{LiBH}_{4}$ nanoconfined in the densified zeolitetemplated carbon with high mechanical stability. Nano Energy, 2015, 15: 244-255

129 Ngene P, van den Berg R, Verkuijlen MHW, et al. Reversibility of the hydrogen desorption from $\mathrm{NaBH}_{4}$ by confinement in nanoporous carbon. Energy Environ Sci, 2011, 4: 4108-4115

130 Fang ZZ, Wang P, Rufford TE, et al. Kinetic- and thermodynamic-based improvements of lithium borohydride incorporated into activated carbon. Acta Mater, 2008, 56: 62576263

131 Sun W, Li S, Mao J, et al. Nanoconfinement of lithium borohydride in $\mathrm{Cu}-\mathrm{MOF}$ towards low temperature dehydrogenation. Dalton Trans, 2011, 40: 5673-5676

132 Liu H, Jiao L, Zhao Y, et al. Improved dehydrogenation performance of $\mathrm{LiBH}_{4}$ by confinement into porous $\mathrm{TiO}_{2}$ micro-tubes. J Mater Chem A, 2014, 2: 9244-9250

$133 \mathrm{Xu} \mathrm{X}$, Zang L, Zhao Y, et al. Hydrogen storage behavior of $\mathrm{LiBH}_{4}$ improved by the confinement of hierarchical porous $\mathrm{ZnO} /$ $\mathrm{ZnCo}_{2} \mathrm{O}_{4}$ nanoparticles. J Power Sources, 2017, 359: 134-141

134 Zang L, Sun W, Liu S, et al. Enhanced hydrogen storage properties and reversibility of $\mathrm{LiBH}_{4}$ confined in two-dimensional $\mathrm{Ti}_{3} \mathrm{C}_{2}$. ACS Appl Mater Interfaces, 2018, 10: 19598-19604

135 Ampoumogli A, Steriotis T, Trikalitis $\mathrm{P}$, et al. Nanostructured composites of mesoporous carbons and boranates as hydrogen storage materials. J Alloys Compd, 2011, 509: S705-S708

136 Peru F, Garroni S, Campesi R, et al. Ammonia-free infiltration of $\mathrm{NaBH}_{4}$ into highly-ordered mesoporous silica and carbon matrices for hydrogen storage. J Alloys Compd, 2013, 580: S309S 312

137 Chong L, Zeng X, Ding W, et al. $\mathrm{NaBH}_{4}$ in "Graphene Wrapper:" significantly enhanced hydrogen storage capacity and regenerability through nanoencapsulation. Adv Mater, 2015, 27: 50705074

138 Fichtner M, Zhao-Karger Z, Hu J, et al. The kinetic properties of $\mathrm{Mg}\left(\mathrm{BH}_{4}\right)_{2}$ infiltrated in activated carbon. Nanotechnology, 2009, 20: 204029

139 Yang Y, Liu Y, Li Y, et al. Towards the endothermic dehydrogenation of nanoconfined magnesium borohydride ammoni- ate. J Mater Chem A, 2015, 3: 11057-11065

140 Wahab MA, Jia YA, Yang D, et al. Enhanced hydrogen desorption from $\mathrm{Mg}\left(\mathrm{BH}_{4}\right)_{2}$ by combining nanoconfinement and a $\mathrm{Ni}$ catalyst. J Mater Chem A, 2013, 1: 3471-3478

141 Clémençon D, Davoisne C, Chotard JN, et al. Enhancement of the hydrogen release of $\mathrm{Mg}\left(\mathrm{BH}_{4}\right)_{2}$ by concomitant effects of nanoconfinement and catalysis. Int J Hydrogen Energy, 2019, 44: 4253-4262

142 Suwarno, Ngene P, Nale A, et al. Confinement effects for lithium borohydride: Comparing silica and carbon scaffolds. J Phys Chem C, 2017, 121: 4197-4205

143 Li Y, Ding X, Zhang Q. Self-printing on graphitic nanosheets with metal borohydride nanodots for hydrogen storage. Sci Rep, 2016, 6: 31144

144 Zhang H, Xia G, Zhang J, et al. Graphene-tailored thermodynamics and kinetics to fabricate metal borohydride nanoparticles with high purity and enhanced reversibility. Adv Energy Mater, 2018, 8: 1702975

$145 \mathrm{Yu} \mathrm{XB}, \mathrm{Wu} \mathrm{Z}$, Chen QR, et al. Improved hydrogen storage properties of $\mathrm{LiBH}_{4}$ destabilized by carbon. Appl Phys Lett, 2007, 90: 034106

146 Cai W, Chen J, Liu L, et al. Tuning the structural stability of $\mathrm{LiBH}_{4}$ through boron-based compounds towards superior dehydrogenation. J Mater Chem A, 2018, 6: 1171-1180

147 Dolotko O, Gupta S, Kobayashi T, et al. Mechanochemical reactions and hydrogen storage capacities in $\mathrm{MBH}_{4}-\mathrm{SiS}_{2}$ systems ( $\mathrm{M}=\mathrm{Li}$ or $\mathrm{Na}$ ). Int J Hydrogen Energy, 2019, 44: 7381-7391

148 Fu H, Wu Y, Chen J, et al. Promoted hydrogen release from alkali metal borohydrides in ionic liquids. Inorg Chem Front, 2016, 3: 1137-1145

149 Zhang W, Xu G, Chen L, et al. Enhanced hydrogen storage performances of $\mathrm{LiBH}_{4}$ modified with three-dimensional porous fluorinated graphene. Int J Hydrogen Energy, 2017, 42: 1526215270

150 Pinkerton FE, Meisner GP, Meyer MS, et al. Hydrogen desorption exceeding ten weight percent from the new quaternary hydride $\mathrm{Li}_{3} \mathrm{BN}_{2} \mathrm{H}_{8}$. J Phys Chem B, 2005, 109: 6-8

151 Vajo JJ, Skeith SL, Mertens F. Reversible storage of hydrogen in destabilized $\mathrm{LiBH}_{4}$. J Phys Chem B, 2005, 109: 3719-3722

152 Xia G, Tan Y, Wu F, et al. Graphene-wrapped reversible reaction for advanced hydrogen storage. Nano Energy, 2016, 26: 488-495

153 Huang X, Xiao X, Shao J, et al. Building robust architectures of carbon-wrapped transition metal nanoparticles for high catalytic enhancement of the $2 \mathrm{LiBH}_{4}-\mathrm{MgH}_{2}$ system for hydrogen storage cycling performance. Nanoscale, 2016, 8: 14898-14908

154 Yang J, Sudik A, Wolverton C. Destabilizing $\mathrm{LiBH}_{4}$ with a metal $\left(\mathrm{M}=\mathrm{Mg}, \mathrm{Al}, \mathrm{Ti}, \mathrm{V}, \mathrm{Cr}\right.$, or Sc) or metal hydride $\left(\mathrm{MH}_{2}=\mathrm{MgH}_{2}\right.$, $\mathrm{TiH}_{2}$, or $\mathrm{CaH}_{2}$ ). J Phys Chem C, 2007, 111: 19134-19140

$155 \mathrm{Li} \mathrm{Y,} \mathrm{Li} \mathrm{P,} \mathrm{Qu} \mathrm{X.} \mathrm{Investigation} \mathrm{on} \mathrm{LiBH}_{4}-\mathrm{CaH}_{2}$ composite and its potential for thermal energy storage. Sci Rep, 2017, 7: 41754

156 Jin SA, Lee YS, Shim JH, et al. Reversible hydrogen storage in $\mathrm{LiBH}_{4}-\mathrm{MH}_{2}(\mathrm{M}=\mathrm{Ce}, \mathrm{Ca})$ composites. J Phys Chem C, 2008, 112: 9520-9524

157 Yu XB, Grant DM, Walker GS. Dehydrogenation of $\mathrm{LiBH}_{4}$ destabilized with various oxides. J Phys Chem C, 2009, 113: 1794517949

158 Zang L, Zhang Q, Li L, et al. Improved dehydrogenation properties of $\mathrm{LiBH}_{4}$ using catalytic nickel- and cobalt-based mesoporous oxide nanorods. Chem Asian J, 2018, 13: 99-105

159 Guo YH, Yu XB, Gao L, et al. Significantly improved dehy- 
drogenation of $\mathrm{LiBH}_{4}$ destabilized by $\mathrm{TiF}_{3}$. Energy Environ Sci, 2010, 3: 465-470

160 Au M, Jurgensen AR, Spencer WA, et al. Stability and reversibility of lithium borohydrides doped by metal halides and hydrides. J Phys Chem C, 2008, 112: 18661-18671

161 Chong L, Zou J, Zeng X, et al. Effects of $\mathrm{LnF}_{3}$ on reversible and cyclic hydrogen sorption behaviors in $\mathrm{NaBH}_{4}$ : electronic nature of Ln versus crystallographic factors. J Mater Chem A, 2015, 3: 4493-4500

162 Zhao Y, Liu Y, Liu H, et al. Improved dehydrogenation performance of $\mathrm{LiBH}_{4}$ by 3D hierarchical flower-like $\mathrm{MoS}_{2}$ spheres additives. J Power Sources, 2015, 300: 358-364

163 Somer M, Acar S, Koz C, et al. $\alpha$ - and $\beta-\mathrm{Na}_{2}\left[\mathrm{BH}_{4}\right]\left[\mathrm{NH}_{2}\right]$ : Two modifications of a complex hydride in the system $\mathrm{NaNH}_{2}-$ $\mathrm{NaBH}_{4}$; syntheses, crystal structures, thermal analyses, mass and vibrational spectra. J Alloys Compd, 2010, 491: 98-105

164 Garroni S, Pistidda C, Brunelli M, et al. Hydrogen desorption mechanism of $2 \mathrm{NaBH}_{4}+\mathrm{MgH}_{2}$ composite prepared by high-energy ball milling. Scripta Mater, 2009, 60: 1129-1132

165 Christian ML, Aguey-Zinsou KF. Core-shell strategy leading to high reversible hydrogen storage capacity for $\mathrm{NaBH}_{4}$. ACS Nano, 2012, 6: 7739-7751

166 Mao J, Guo Z, Nevirkovets IP, et al. Hydrogen de-/absorption improvement of $\mathrm{NaBH}_{4}$ catalyzed by titanium-based additives. J Phys Chem C, 2012, 116: 1596-1604

167 Chong L, Zou J, Zeng X, et al. Mechanisms of reversible hydrogen storage in $\mathrm{NaBH}_{4}$ through $\mathrm{NdF}_{3}$ addition. J Mater Chem A, 2013, 1: 3983-3991

$168 \mathrm{Yu} \mathrm{XB}$, Guo YH, Sun DL, et al. A combined hydrogen storage system of $\mathrm{Mg}\left(\mathrm{BH}_{4}\right)_{2}-\mathrm{LiNH}_{2}$ with favorable dehydrogenation. J Phys Chem C, 2010, 114: 4733-4737

169 Li HW, Kikuchi K, Nakamori Y, et al. Effects of ball milling and additives on dehydriding behaviors of well-crystallized $\mathrm{Mg}\left(\mathrm{BH}_{4}\right)_{2}$. Scripta Mater, 2007, 57: 679-682

170 Newhouse RJ, Stavila V, Hwang SJ, et al. Reversibility and improved hydrogen release of magnesium borohydride. J Phys Chem C, 2010, 114: 5224-5232

171 Zavorotynska O, Saldan I, Hino S, et al. Hydrogen cycling in $\gamma$ $\mathrm{Mg}\left(\mathrm{BH}_{4}\right)_{2}$ with cobalt-based additives. J Mater Chem A, 2015, 3: 6592-6602

172 Yang Y, Liu Y, Li Y, et al. Fluorine-substituted $\mathrm{Mg}\left(\mathrm{BH}_{4}\right)_{2} \cdot 2 \mathrm{NH}_{3}$ with improved dehydrogenation properties for hydrogen storage. J Mater Chem A, 2015, 3: 570-578

173 Liu C, Huang S. A first-principles study of the tuning effect of a $\mathrm{Fe}_{2} \mathrm{O}_{3}$ cluster on the dehydrogenation properties of a $\mathrm{LiBH}_{4}(001)$ surface. Dalton Trans, 2016, 45: 10954-10959

174 Zhang J, Li P, Wan Q, et al. Superior destabilization effects of $\mathrm{LiBH}_{4}$ with the addition of nano-sized nickel ferrite $\mathrm{NiFe}_{2} \mathrm{O}_{4}$. RSC Adv, 2015, 5: 81212-81219

175 Ali NA, Yahya MS, Mustafa NS, et al. Modifying the hydrogen storage performances of $\mathrm{NaBH}_{4}$ by catalyzing with $\mathrm{MgFe}_{2} \mathrm{O}_{4}$ synthesized via hydrothermal method. Int J Hydrogen Energy, 2019, 44: 6720-6727

176 Yin L, Wang $\mathrm{P}$, Fang $\mathrm{Z}$, et al. Thermodynamically tuning $\mathrm{LiBH}_{4}$ by fluorine anion doping for hydrogen storage: A density functional study. Chem Phys Lett, 2008, 450: 318-321 Richter B, Ravnsbæk DB, Sharma M, et al. Fluoride substitution in $\mathrm{LiBH}_{4}$; destabilization and decomposition. Phys Chem Chem Phys, 2017, 19: 30157-30165
$\mathrm{Mg}\left(\mathrm{BH}_{4}\right)_{2}-\mathrm{NaBH}_{4}$-fluorographene composite with unexpected superior dehydrogenation performances. J Mater Chem A, 2017, 5: 9723-9732

179 Bogdanović B, Schwickardi M. Ti-doped alkali metal aluminium hydrides as potential novel reversible hydrogen storage materials. J Alloys Compd, 1997, 253-254: 1-9

180 Nielsen TK, Javadian P, Polanski M, et al. Nanoconfined $\mathrm{NaAlH}_{4}$ : Determination of distinct prolific effects from pore size, crystallite size, and surface interactions. J Phys Chem C, 2012, 116: 2104621051

181 Li L, Xu C, Chen C, et al. Sodium alanate system for efficient hydrogen storage. Int J Hydrogen Energy, 2013, 38: 8798-8812

182 Wahab MA, Beltramini JN. Catalytic nanoconfinement effect of in-situ synthesized Ni-containing mesoporous carbon scaffold (Ni-MCS) on the hydrogen storage properties of $\mathrm{LiAlH}_{4}$. Int J Hydrogen Energy, 2014, 39: 18280-18290

183 Wang H, Lin HJ, Cai WT, et al. Tuning kinetics and thermodynamics of hydrogen storage in light metal element based systems-A review of recent progress. J Alloys Compd, 2016, 658: 280-300

184 Adimi S, Arabi H, Ghorbani SR, et al. AB-initio study of pressureinduced aluminum hydrides $\mathrm{AAlH}_{4}(\mathrm{~A}=\mathrm{Li}, \mathrm{Na}, \mathrm{K}, \mathrm{Rb}, \mathrm{Cs})$. Int J Hydrogen Energy, 2017, 42: 25303-25309

185 Pang Y, Li Q. Insight into the kinetic mechanism of the first-step dehydrogenation of $\mathrm{Mg}\left(\mathrm{AlH}_{4}\right)_{2}$. Scripta Mater, 2017, 130: 223228

186 Lohstroh W, Roth A, Hahn H, et al. Thermodynamic effects in nanoscale $\mathrm{NaAlH}_{4}$. ChemPhysChem, 2010, 11: 789-792

187 Stavila V, Bhakta RK, Alam TM, et al. Reversible hydrogen storage by $\mathrm{NaAlH}_{4}$ confined within a titanium-functionalized MOF74(Mg) nanoreactor. ACS Nano, 2012, 6: 9807-9817

188 Klose M, Lindemann I, Minella CB, et al. Unusual oxidation behavior of light metal hydride by tetrahydrofuran solvent molecules confined in ordered mesoporous carbon. J Mater Res, 2013, 29: 55-63

189 Javadian P, Sheppard D, Buckley C, et al. Hydrogen desorption properties of bulk and nanoconfined $\mathrm{LiBH}_{4}-\mathrm{NaAlH}_{4}$. Crystals, 2016, 6: 70

190 Gao Q, Xia G, Yu X. Confined $\mathrm{NaAlH}_{4}$ nanoparticles inside $\mathrm{CeO}_{2}$ hollow nanotubes towards enhanced hydrogen storage. Nanoscale, 2017, 9: 14612-14619

191 Kim JW, Shim JH, Kim SC, et al. Catalytic effect of titanium nitride nanopowder on hydrogen desorption properties of $\mathrm{NaAlH}_{4}$ and its stability in $\mathrm{NaAlH}_{4}$. J Power Sources, 2009, 192: 582-587

192 Li L, Qiu F, Wang Y, et al. Crystalline $\mathrm{TiB}_{2}$ : An efficient catalyst for synthesis and hydrogen desorption/absorption performances of $\mathrm{NaAlH}_{4}$ system. J Mater Chem, 2012, 22: 3127

193 Li L, An C, Wang Y, et al. Enhancement of the $\mathrm{H}_{2}$ desorption properties of $\mathrm{LiAlH}_{4}$ doping with $\mathrm{NiCO}_{2} \mathrm{O}_{4}$ nanorods. Int J Hydrogen Energy, 2014, 39: 4414-4420

194 Zhao X, Ma Z, Wu D, et al. Computational study of catalytic effect of $\mathrm{C}_{3} \mathrm{~N}_{4}$ on $\mathrm{H}_{2}$ release from complex hydrides. Int J Hydrogen Energy, 2015, 40: 8897-8902

195 Filippi M, Rector JH, Gremaud R, et al. Lightweight sodium alanate thin films grown by reactive sputtering. Appl Phys Lett, 2009, 95: 121904

196 Beattie SD, McGrady GS. Hydrogen desorption studies of $\mathrm{NaAlH}_{4}$ and $\mathrm{LiAlH}_{4}$ by in situ heating in an ESEM. Int J Hydrogen Energy, 2009, 34: 9151-9156 
197 Pang Y, Liu Y, Zhang X, et al. Composition-dependent reaction pathways and hydrogen storage properties of $\mathrm{LiBH}_{4} / \mathrm{Mg}\left(\mathrm{AlH}_{4}\right)_{2}$ composites. Chem Asian J, 2015, 10: 2452-2459

198 Halim Yap FA, Ali NA, Idris NH, et al. Catalytic effect of $\mathrm{MgFe}_{2} \mathrm{O}_{4}$ on the hydrogen storage properties of $\mathrm{Na}_{3} \mathrm{AlH}_{6}-\mathrm{LiBH}_{4}$ composite system. Int J Hydrogen Energy, 2018, 43: 20882-20891

199 Gao J, Adelhelm P, Verkuijlen MHW, et al. Confinement of $\mathrm{NaAlH}_{4}$ in nanoporous carbon: Impact on $\mathrm{H}_{2}$ release, reversibility, and thermodynamics. J Phys Chem C, 2010, 114: 46754682

200 Wang L, Rawal A, Quadir MZ, et al. Nanoconfined lithium aluminium hydride $\left(\mathrm{LiAlH}_{4}\right)$ and hydrogen reversibility. Int J Hydrogen Energy, 2017, 42: 14144-14153

201 Pinkerton FE. Comparison of hydrogen cycling kinetics in $\mathrm{NaAlH}_{4}$-carbon aerogel composites synthesized by melt infusion or ball milling. J Alloys Compd, 2011, 509: 8958-8964

202 Gutowska A, Li L, Shin Y, et al. Nanoscaffold mediates hydrogen release and the reactivity of ammonia borane. Angew Chem Int Ed, 2005, 44: 3578-3582

203 Mueller T, Ceder G. Effect of particle size on hydrogen release from sodium alanate nanoparticles. ACS Nano, 2010, 4: 56475656

204 Varin RA, Zbroniec L. Decomposition behavior of unmilled and ball milled lithium alanate $\left(\mathrm{LiAlH}_{4}\right)$ including long-term storage and moisture effects. J Alloys Compd, 2010, 504: 89-101

205 Prasad Yadav T, Manohar Yadav R, Pratap Singh D. Mechanical milling: A top down approach for the synthesis of nanomaterials and nanocomposites. NN, 2012, 2: 22-48

206 Xiong R, Sang G, Yan X, et al. Improvement of the hydrogen storage kinetics of $\mathrm{NaAlH}_{4}$ with Ti-loaded high-ordered mesoporous carbons (Ti-OMCs) by melt infiltration. J Mater Chem, 2012, 22: 17183

207 Fan X, Xiao X, Shao J, et al. Size effect on hydrogen storage properties of $\mathrm{NaAlH}_{4}$ confined in uniform porous carbons. Nano Energy, 2013, 2: 995-1003

208 Zheng S, Fang F, Zhou G, et al. Hydrogen storage properties of space-confined $\mathrm{NaAlH}_{4}$ nanoparticles in ordered mesoporous silica. Chem Mater, 2008, 20: 3954-3958

209 Li Y, Zhou G, Fang F, et al. De-/re-hydrogenation features of $\mathrm{NaAlH}_{4}$ confined exclusively in nanopores. Acta Mater, 2011, 59: 1829-1838

210 Balde CP, Hereijgers BPC, Bitter JH, et al. Sodium alanate nanoparticles-linking size to hydrogen storage properties. J Am Chem Soc, 2008, 130: 6761-6765

211 Stephens RD, Gross AF, Van Atta SL, et al. The kinetic enhancement of hydrogen cycling in $\mathrm{NaAlH}_{4}$ by melt infusion into nanoporous carbon aerogel. Nanotechnology, 2009, 20: 204018

212 Carr $\mathrm{CL}$, Jayawardana W, Zou $\mathrm{H}$, et al. Anomalous $\mathrm{H}_{2}$ desorption rate of $\mathrm{NaAlH}_{4}$ confined in nitrogen-doped nanoporous carbon frameworks. Chem Mater, 2018, 30: 2930-2938

213 Bhakta RK, Herberg JL, Jacobs B, et al. Metal-organic frameworks as templates for nanoscale $\mathrm{NaAlH}_{4}$. J Am Chem Soc, 2009, 131: 13198-13199

214 Christian M, Aguey-Zinsou KF. Destabilisation of complex hydrides through size effects. Nanoscale, 2010, 2: 2587-2590

215 Liu Y, Ren Z, Zhang X, et al. Development of catalyst-enhanced sodium alanate as an advanced hydrogen-storage material for mobile applications. Energy Technol, 2018, 6: 487-500

216 Abd.Khalim Khafidz NZ, Yaakob Z, Lim KL, et al. The kinetics of lightweight solid-state hydrogen storage materials: A review. Int J
Hydrogen Energy, 2016, 41: 13131-13151

217 Wang Q, Chen YG, Wu CL, et al. Catalytic effect and reaction mechanism of Ti doped in $\mathrm{NaAlH}_{4}$ : A review. Sci Bull, 2008, 53: 1784-1788

218 Jensen C. Advanced titanium doping of sodium aluminum hydride: segue to a practical hydrogen storage material? Int J Hydrogen Energy, 1999, 24: 461-465

219 Sandrock G, Gross K, Thomas G, et al. Engineering considerations in the use of catalyzed sodium alanates for hydrogen storage. J Alloys Compd, 2002, 330-332: 696-701

220 Wang $\mathrm{P}$, Kang $\mathrm{XD}$, Cheng HM. Improved hydrogen storage of $\mathrm{TiF}_{3}$-doped $\mathrm{NaAlH}_{4}$. ChemPhysChem, 2005, 6: 2488-2491

221 Langmi HW, McGrady GS, Liu X, et al. Modification of the $\mathrm{H}_{2}$ desorption properties of $\mathrm{LiAlH}_{4}$ through doping with Ti. J Phys Chem C, 2010, 114: 10666-10669

222 Liu SS, Zhang Y, Sun LX, et al. The dehydrogenation performance and reaction mechanisms of $\mathrm{Li}_{3} \mathrm{AlH}_{6}$ with $\mathrm{TiF}_{3}$ additive. Int $\mathrm{J}$ Hydrogen Energy, 2010, 35: 4554-4561

223 Tan CY, Tsai WT. Effects of $\mathrm{TiCl}_{3}$-decorated MWCNTs addition on the dehydrogenation behavior and stability of $\mathrm{LiAlH}_{4}$. Int $\mathrm{J}$ Hydrogen Energy, 2014, 39: 20038-20044

224 Liu X, Langmi HW, Beattie SD, et al. Ti-doped $\mathrm{LiAlH}_{4}$ for hydrogen storage: synthesis, catalyst loading and cycling performance. J Am Chem Soc, 2011, 133: 15593-15597

225 Resan M, Hampton M, Lomness J, et al. Effects of various catalysts on hydrogen release and uptake characteristics of LiAlH. Int J Hydrogen Energy, 2005, 30: 1413-1416

226 Pukazhselvan D, Fagg DP, Srivastava ON. One step high pressure mechanochemical synthesis of reversible alanates $\mathrm{NaAlH}_{4}$ and $\mathrm{KAlH}_{4}$. Int J Hydrogen Energy, 2015, 40: 4916-4924

227 Ismail M, Zhao Y, Yu XB, et al. Significantly improved dehydrogenation of $\mathrm{LiAlH}_{4}$ catalysed with $\mathrm{TiO}_{2}$ nanopowder. Int J Hydrogen Energy, 2011, 36: 8327-8334

228 Zhang X, Liu Y, Wang K, et al. Remarkably improved hydrogen storage properties of nanocrystalline $\mathrm{TiO}_{2}$-modified $\mathrm{NaAlH}_{4}$ and evolution of Ti-containing species during dehydrogenation/hydrogenation. Nano Res, 2015, 8: 533-545

229 Fan Y, Yuan Z, Zou G, et al. Two-dimensional MXene/A- $\mathrm{TiO}_{2}$ composite with unprecedented catalytic activation for sodium alanate. Catal Today, 2018, 318: 167-174

230 Xiao X, Fan X, Yu K, et al. Catalytic mechanism of new TiCdoped sodium alanate for hydrogen storage. J Phys Chem C, 2009, 113: 20745-20751

231 Li L, Qiu F, Wang Y, et al. TiN catalyst for the reversible hydrogen storage performance of sodium alanate system. J Mater Chem, 2012, 22: 13782

232 Bogdanović B, Felderhoff M, Kaskel S, et al. Improved hydrogen storage properties of $\mathrm{Ti}$-doped sodium alanate using titanium nanoparticles as doping agents. Adv Mater, 2003, 15: 1012-1015

233 Li L, Qiu F, Wang Y, et al. Improved dehydrogenation performances of $\mathrm{TiB}_{2}$-doped sodium alanate. Mater Chem Phys, 2012, 134: 1197-1202

234 Li L, Qiu F, Wang Y, et al. Enhanced hydrogen storage properties of $\mathrm{TiN}^{-\mathrm{LiAlH}_{4}}$ composite. Int J Hydrogen Energy, 2013, 38: 3695-3701

235 Bogdanović B, Felderhoff M, Pommerin A, et al. Advanced hydrogen-storage materials based on Sc-, Ce-, and Pr-doped $\mathrm{NaAlH}_{4}$. Adv Mater, 2006, 18: 1198-1201

236 Bogdanović B, Felderhoff M, Pommerin A, et al. Cycling properties of Sc- and Ce-doped $\mathrm{NaAlH}_{4}$ hydrogen storage materials 
prepared by the one-step direct synthesis method. J Alloys Compd, 2009, 471: 383-386

237 Cao Z, Ma X, Wang $\mathrm{H}$, et al. Catalytic effect of $\mathrm{ScCl}_{3}$ on the dehydrogenation properties of $\mathrm{LiAlH}_{4}$. J Alloys Compd, 2018, 762: 73-79

238 Fan X, Xiao X, Chen L, et al. Thermodynamics, kinetics, and modeling investigation on the dehydrogenation of $\mathrm{CeAl}_{4}$-doped $\mathrm{NaAlH}_{4}$ hydrogen storage material. J Phys Chem C, 2011, 115: 22680-22687

239 Fan X, Xiao X, Chen L, et al. Enhanced hydriding-dehydriding performance of $\mathrm{CeAl}_{2}$-doped $\mathrm{NaAlH}_{4}$ and the evolvement of Cecontaining species in the cycling. J Phys Chem C, 2011, 115: 2537-2543

240 Rossin A, Tuci G, Luconi L, et al. Metal-organic frameworks as heterogeneous catalysts in hydrogen production from lightweight inorganic hydrides. ACS Catal, 2017, 7: 5035-5045

241 Mustafa NS, Yahya MS, Sazelee N, et al. Dehydrogenation properties and catalytic mechanism of the $\mathrm{K}_{2} \mathrm{NiF}_{6}$-doped $\mathrm{NaAlH}_{4}$ system. ACS Omega, 2018, 3: 17100-17107

242 Varin RA, Zbroniec L, Czujko T, et al. The effects of nanonickel additive on the decomposition of complex metal hydride $\mathrm{LiAlH}_{4}$ (lithium alanate). Int J Hydrogen Energy, 2011, 36: 1167-1176

243 Suttisawat $\mathrm{Y}$, Rangsunvigit $\mathrm{P}$, Kitiyanan B, et al. Catalytic effect of $\mathrm{Zr}$ and $\mathrm{Hf}$ on hydrogen desorption/absorption of $\mathrm{NaAlH}_{4}$ and $\mathrm{LiAlH}_{4}$. Int J Hydrogen Energy, 2007, 32: 1277-1285

244 Sun $\mathrm{T}$, Zhou B, Wang $\mathrm{H}$, et al. The effect of doping rare-earth chloride dopant on the dehydrogenation properties of $\mathrm{NaAlH}_{4}$ and its catalytic mechanism. Int J Hydrogen Energy, 2008, 33: 2260-2267

245 Zhai F, Li P, Sun A, et al. Significantly improved dehydrogenation of $\mathrm{LiAlH}_{4}$ destabilized by $\mathrm{MnFe}_{2} \mathrm{O}_{4}$ nanoparticles. J Phys Chem C, 2012, 116: 11939-11945

246 Li Z, Zhai F, Wan Q, et al. Enhanced hydrogen storage properties of $\mathrm{LiAlH}_{4}$ catalyzed by $\mathrm{CoFe}_{2} \mathrm{O}_{4}$ nanoparticles. RSC Adv, 2014, 4: 18989-18997

247 Zhang $\mathrm{X}, \mathrm{Wu} \mathrm{R}$, Wang $\mathrm{Z}$, et al. Preparation and catalytic activity of a novel nanocrystalline $\mathrm{ZrO}_{2} @ \mathrm{C}$ composite for hydrogen storage in $\mathrm{NaAlH}_{4}$. Chem Asian J, 2016, 11: 3541-3549

248 Huang $\mathrm{Y}$, Li $\mathrm{P}$, Wan $\mathrm{Q}$, et al. Improved dehydrogenation performance of $\mathrm{NaAlH}_{4}$ using $\mathrm{NiFe}_{2} \mathrm{O}_{4}$ nanoparticles. J Alloys Compd, 2017, 709: 850-856

249 Sulaiman NN, Ismail M. Catalytic effect of $\mathrm{SrFe}_{12} \mathrm{O}_{19}$ on the hydrogen storage properties of $\mathrm{LiAlH}_{4}$. Int J Hydrogen Energy, 2017, 42: 19126-19134

250 Pitt MP, Vullum PE, Sørby MH, et al. Hydrogen absorption kinetics of the transition-metal-chloride-enhanced $\mathrm{NaAlH}_{4}$ system. J Phys Chem C, 2012, 116: 14205-14217

251 Zaluska A, Zaluski L, Ström-Olsen JO. Sodium alanates for reversible hydrogen storage. J Alloys Compd, 2000, 298: 125-134

252 Chen TT, Yang CH, Tsai WT. In-situ synchrotron X-ray diffraction study on the dehydrogenation behavior of $\mathrm{NaAlH}_{4}$ modified by multi-walled carbon nanotubes. Int $\mathrm{J}$ Hydrogen Energy, 2012, 37: 14285-14291

253 Kumar LH, Rao CV, Viswanathan B. Catalytic effects of nitrogendoped graphene and carbon nanotube additives on hydrogen storage properties of sodium alanate. J Mater Chem A, 2013, 1: 3355

254 Hsu WC, Yang CH, Tsai WT. Catalytic effect of MWCNTs on the dehydrogenation behavior of $\mathrm{LiAlH}_{4}$. Int J Hydrogen Energy, 2014, 39: 927-933
255 Suttisawat $\mathrm{Y}$, Rangsunvigit $\mathrm{P}$, Kitiyanan B, et al. Effect of codopants on hydrogen desorption/absorption of $\mathrm{HfCl}_{4}{ }^{-}$and $\mathrm{TiO}_{2}-$ doped $\mathrm{NaAlH}_{4}$. Int J Hydrogen Energy, 2008, 33: 6195-6200

256 Wang T, Wang J, Ebner AD, et al. Synergistic effects of bimetallic catalysis on the cycling behavior of $\mathrm{NaAlH}_{4}$ Co-doped with $\mathrm{Zr}$ and Fe. J Alloys Compd, 2012, 539: 242-248

257 Schmidt T, Röntzsch L. Reversible hydrogen storage in Ti-Zrcodoped $\mathrm{NaAlH}_{4}$ under realistic operation conditions. J Alloys Compd, 2010, 496: L38-L40

258 Wang P, Kang XD, Cheng HM. KH+Ti co-doped $\mathrm{NaAlH}_{4}$ for high-capacity hydrogen storage. J Appl Phys, 2005, 98: 074905

259 Zhang X, Liu Y, Wang $\mathrm{K}$, et al. Ultrafine nanocrystalline $\mathrm{CeO}_{2} @ \mathrm{C}$-containing $\mathrm{NaAlH}_{4}$ with fast kinetics and good reversibility for hydrogen storage. ChemSusChem, 2015, 8: 4180-4188

260 Tan CY, Tsai WT. Catalytic and inhibitive effects of Pd and Pt decorated MWCNTs on the dehydrogenation behavior of $\mathrm{LiAlH}_{4}$. Int J Hydrogen Energy, 2015, 40: 10185-10193

261 Zhang X, Ren Z, Lu Y, et al. Facile synthesis and superior catalytic activity of nano-TiN@N-C for hydrogen storage in $\mathrm{NaAlH}_{4}$. ACS Appl Mater Interfaces, 2018, 10: 15767-15777

262 Choi J, Ha T, Park J, et al. Mechanochemical synthesis of $\mathrm{Ce}_{3} \mathrm{Al}_{11}$ powder and its catalytic effect on the hydrogen sorption properties of $\mathrm{NaAlH}_{4}$. J Alloys Compd, 2019, 784: 313-318

263 Zhang X, Ren Z, Zhang X, et al. Triggering highly stable catalytic activity of metallic titanium for hydrogen storage in $\mathrm{NaAlH}_{4}$ by preparing ultrafine nanoparticles. J Mater Chem A, 2019, 7: 4651-4659

264 Xiong R, Sang G, Yan X, et al. Separation and characterization of the active species in Ti-doped $\mathrm{NaAlH}_{4}$. Chem Commun, 2013, 49: 2046-2048

265 Gabis I, Evard E, Voyt A, et al. Kinetics of decomposition of erbium hydride. J Alloys Compd, 2003, 356-357: 353-357

266 Xiong R, Sang G, Zhang G, et al. Evolution of the active species and catalytic mechanism of Ti doped $\mathrm{NaAlH}_{4}$ for hydrogen storage. Int J Hydrogen Energy, 2017, 42: 6088-6095

$267 \mathrm{Hu}$ J, Ren S, Witter R, et al. Catalytic influence of various cerium precursors on the hydrogen sorption properties of $\mathrm{NaAlH}_{4}$. Adv Energy Mater, 2012, 2: 560-568

268 Gross KJ, Guthrie S, Takara S, et al. In-situ X-ray diffraction study of the decomposition of $\mathrm{NaAlH}_{4}$. J Alloys Compd, 2000, 297: 270-281

269 Walters RT, Scogin JH. A reversible hydrogen storage mechanism for sodium alanate: The role of alanes and the catalytic effect of the dopant. J Alloys Compd, 2004, 379: 135-142

270 Dathara GKP, Mainardi DS. Structure and dynamics of Ti-Al-H compounds in Ti-doped $\mathrm{NaAlH}_{4}$. Mol Simul, 2008, 34: 201-210

271 Michel KJ, Ozoliņ̌ V. Theory of mass transport in sodium alanate. J Mater Chem A, 2014, 2: 4438-4448

272 Huang CK, Zhao YJ, Wang $\mathrm{H}$, et al. $\mathrm{AlH}_{3}$-mediated mechanism in hydriding/dehydriding of $\mathrm{NaAlH}_{4}$. Int J Hydrogen Energy, 2011, 36: 9767-9771

Acknowledgements This work was supported by the National Key R\&D Program of China (2018YFB1502102), the National Natural Science Foundation of China (51571124, 51571125, 51871123 and 51501072), 111 Project (B12015) and MOE (IRT13R30).

Author contributions $\quad \mathrm{Li} \mathrm{L}$ and Huang Y wrote the manuscript; An C and Wang Y developed the concept and revised the manuscript. All authors participated in the general discussion. 
Conflict of interest The authors declare that they have no conflict of interest.

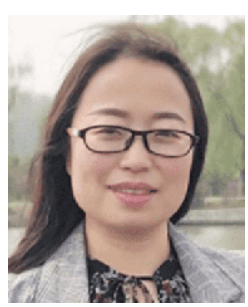

$\mathbf{L i ~} \mathbf{L i}$ is currently a research scientist at University of Jinan (UJN). She received her $\mathrm{PhD}$ degree from Nankai University (NKU) in 2014. Her research interests include hydrogen storage of lightweight hydrides materials and the development of novel electrode materials for $\mathrm{Li}$ ion batteries and supercapacitors.

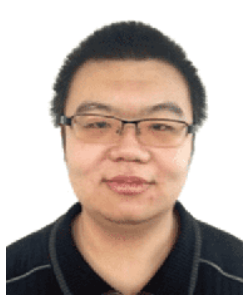

Yike Huang received his BSc degree in chemistry from NKU in 2017 and continued his Master degree study under the supervision of Professor Yijing Wang at the College of Chemistry, NKU. His current research focuses on hydrogen storage of Mg-based materials

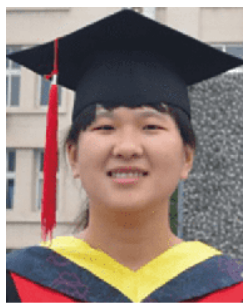

Cuihua An is currently a research scientist at Tianjin University of Technology (TUT). She received her $\mathrm{PhD}$ degree from NKU in 2015, and then joined the Institute for New Energy Materials \& Low-Carbon Technologies at TUT as a postdoctor. Her research focuses on the design and synthesis of nano/micromaterials and their applications in $\mathrm{Li}$ ion batteries and supercapacitors.

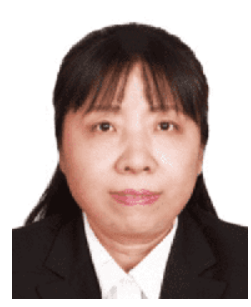

Yijing Wang obtained BSc (1989), and $\mathrm{PhD}$ (2000) degrees from NKU and worked as a postdoctoral fellow at Tokyo University, Japan during 2000-2004. Since 2008, she has been a full professor in the College of Chemistry, NKU. Her research interests include hydrogen storage and high performance electrode materials.

\section{轻质氢化物储氢材料: 挑战, 进展和展望}

李丽 $^{1,2 \dagger^{*}}$, 黄一可 ${ }^{2 \dagger}$, 安翠华 ${ }^{3}$, 王一菁 ${ }^{2 *}$

摘要 在众多的储氢材料中, 轻质储氢材料由于具有极高的质量比 容量和体积比容量而受到广泛的关注. 然而, 热力学稳定性高、动 力学性能差等因素, 使得轻质储氢材料存在放氢温度高、可逆性 差等缺点, 限制了其实际应用. 本文总结了几种调控轻质储氢材料 热力学、动力学性能的方法, 着重介绍了镁基储氢材料、硼氢配 位氢化物和铝氢配位氢化物的研究进展. 首先总结了轻质储氢材 料的研究现状、优势与挑战, 接着举例分析了合金、纳米化与添 加掺杂剂策略的优缺点, 对放氢温度与材料吸放氢可逆性的影响, 系统归纳了不同的基体、添加剂、制备方法和对应的吸放氢性能 数据. 最后, 详细讨论了掺杂剂、合成方法和调控策略的演变及发 展趋势, 以及改善热力学、动力学行为的机理, 并对未来的研究方 向进行了展望. 